\title{
Elevated O-GlcNAcylation Enhances Pro-Inflammatory Th17 Function by Altering the Lipid Microenvironment
}

\author{
By \\ (C) 2018 \\ Miranda Machacek \\ B.A., Boston University, 2009 \\ Submitted to the graduate degree program in Pathology and Laboratory Medicine and the \\ Graduate Faculty of the University of Kansas in partial fulfillment of the requirements for the \\ degree of Doctor of Philosophy.
}

Co-Chair: Patrick Fields, PhD

Co-Chair: Chad Slawson, PhD

Timothy Fields, MD, PhD

Fariba Behbod, PharmD, PhD

Mary Markiewicz, $\mathrm{PhD}$

Date Defended: 16 April 2018 
The dissertation committee for Miranda Machacek certifies that this is the approved version of the following dissertation:

\section{Elevated O-GlcNAcylation Enhances Pro-Inflammatory Th17 Function by Altering the Lipid Microenvironment}

Co-Chair: Patrick Fields, PhD

Co-Chair: Chad Slawson, PhD

Date Approved: 16 April 2018 


\begin{abstract}
Chronic inflammation is a feature of obesity and enhances the risk of atherosclerosis, cancer, diabetes, and autoimmunity. Specifically, pro-inflammatory Th17 and Th1 CD4 ${ }^{+}$effector T cells are increased in metabolic diseases. However, a clear molecular mechanism linking metabolic changes with pro-inflammatory $\mathrm{T}$ cells is lacking. We hypothesize that elevated levels of $\mathrm{O}$ linked $\beta$-N-acetylglucosamine (O-GlcNAc), a post-translational modification of nuclear and cytoplasmic proteins, promotes pro-inflammatory CD4+ T cell function. Since production of OGlcNAc involves input from carbohydrate, amino acid, fatty acid, and nucleic acid metabolism, the modification acts as a general sensor of a cell's nutritional status. To investigate the role of O-GlcNAc in CD4+ $\mathrm{T}$ cell function, we treated CD4+ $\mathrm{T}$ cells with Thiamet-G (TMG, an inhibitor of the enzyme that removes O-GlcNAc (O-GlcNAcase, OGA)) before activation of the cells without addition of polarizing cytokines. After culturing for four days and then restimulating the cells for 24 hours, we found that these non-polarized CD4+ T cells produced significantly more pro-inflammatory IL-17A by both protein and transcript levels. Since IL17A is critically involved in exacerbating obesity-related pathology, such as atherosclerosis and insulin resistance, we next looked for an effect of O-GlcNAcylation in metabolic disease. To investigate the role of $\mathrm{O}-\mathrm{GlcNAc}$ in a setting of metabolic disease, we analyzed O-GlcNAc levels in $\mathrm{CD}^{+} \mathrm{T}$ cells from mice fed a high fat and cholesterol "Western" diet. Naïve CD4+ T cells from obese mice have elevated O-GlcNAc levels compared to cells from mice fed standard chow. When polarized to a Th17 lineage, cells from obese mice secrete more IL-17A, the eponymous Th17 cytokine. Importantly, when naïve CD4+ T cells from lean and obese mice are polarized to a Th17 lineage in the presence of TMG, the cells from lean mice secrete levels of IL-17 comparable to those from obese mice. Moreover, IL-17A secretion was exacerbated in
\end{abstract}


cells from obese mice. Transcript levels of IL-17 are similarly elevated in both lean and obese mice Th17 cells treated with TMG. Importantly, these results are recapitulated in human CD4+ T cells treated with TMG, suggesting a similar mechanism may operate in both mice and humans. ROR $\gamma t$ (retinoic acid-related orphan receptor gamma) acts as the Th17 master transcription factor, orchestrating the Th17 differentiation program. While protein and transcript levels of ROR $\gamma \mathrm{t}$ did not change in the presence of TMG, chromatin immunoprecipitation demonstrated enhanced ROR $\gamma \mathrm{t}$ association with the IL-17 promoter and an enhancer, CNS2 (conserved noncoding sequence 2 ) with TMG treatment. Uniquely among the CD4 ${ }^{+}$effector T cell master transcription factors, ROR $\gamma \mathrm{t}$ is regulated by lipid ligands that promote or repress its activity. We performed a broad lipidomics analysis on $\mathrm{T}$ cells and discovered that sterols and saturated fatty acids, known activating ligands of ROR $\gamma \mathrm{t}$, were increased with TMG treatment. An investigation of potential mechanisms underlying these changes in lipid content in $\mathrm{T}$ cells revealed that the rate-limiting enzyme in fatty acid synthesis, ACC1, is O-GlcNAcylated in the carboxyltransferase and central region domains, which are important for catalytic conversion of acetyl CoA to malonyl CoA. Collectively, our data suggest that elevated O-GlcNAc levels increase pro-inflammatory IL-17 secretion from Th17 cells through alteration of the lipidome and retention of ROR $\gamma \mathrm{t}$ at the IL-17 promoter complex. These studies provide a potential molecular link between nutritional excess and Th17 differentiation and function. Further study of these molecular mechanisms will provide insight into the link between O-GlcNAcylation and inflammatory disease associated with obesity and other metabolic disorders. 


\section{ACKNOWLEDGEMENTS}

My thesis work would not have been possible without the invaluable support and assistance of many people. First, I need to thank my mentors, Pat Fields and Chad Slawson. I always found it difficult to fully describe the role of a mentor to family and friends from a non-science background. They are not simply your boss... although they do supervise you, labor for funding, and "volunteer" you for certain tasks you would otherwise prefer not to perform. They're not just a colleague or friend...although they are at times the only voice you hear through your own noisy, disorienting self-doubt, reminding you that you are capable and smart enough, to stay the course and "try again." The fact is it's a delightfully dysfunctional and symbiotic relationshiplike most families really. And in a way, the process forges you together as family. So I gladly tip my hat to my scientific "fathers," who put in the time and effort to train me and gave me the freedom to pursue my ideas. Many thanks also to my committee members, Tim Fields, Fariba Behbod, Mary Markiewicz, and Tom Yankee (your untimely passing was a great loss for your students and the immunology community) for giving their time and guidance on this project. Second, I need to thank my parents, Mark and Marilyn, who gave me a love of learning and reading. I would not be in this position were it not for the value they placed on education and demonstration of that through their own lives. I also need to thank my sisters, Melissa and Michelle, for their constant assurance that I would in fact make it to this point, and also the abundance of niece dog pictures, funny things from the internet, and song recommendations which buoyed me when I was down. Third, many dear friends (special shout-out to Marie Adams, Kaitlin Ho Givens, Dr. Lauren Dollar, and Dr. Ee Phie Tan!) over the years have made me laugh, wisely told me to quit for the day and sleep on it, fed me, and escaped with me to the mountains for mental, physical, and spiritual refreshment. Thanks for giving me a hand up when 
grad school life knocked me down. Next, I would like to acknowledge the MD/PhD program and Pathology Department, specifically Tim Fields, Brenda Rongish, Janice Fletcher, and Zoe Baldwin, for allowing me to have this opportunity and coordinating all the behind the scenes details so that I could focus on my training. And last-but certainly not least- thanks to my fellow MD/PhDers, medical school buddies, and former lab-mates (Dr. Ee Phie Tan, Dr. Zhen Zhang, Dr. Carrie Malcom, Dr. Nehemiah Alvarez, and Dr. Joanna (Asia) Piasecka-Srader) who besides being geniuses are also thoroughly decent and kind human beings. It has been and continues to be a privilege to be your colleague. 


\section{TABLE OF CONTENTS}

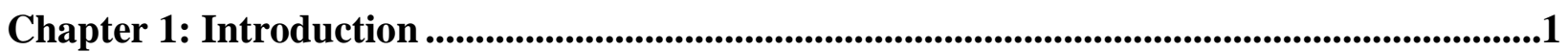

Distinct metabolic programs are critical during $\mathrm{T}$ cell activation ............................................

Intrinsic and external metabolic factors are required for specific CD4+ T cell differentiation

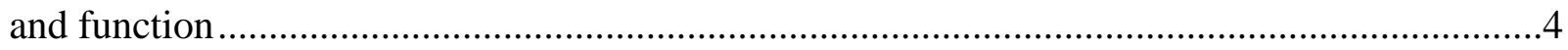

O-GlcNAcylation is required for T cell activation...............................................................

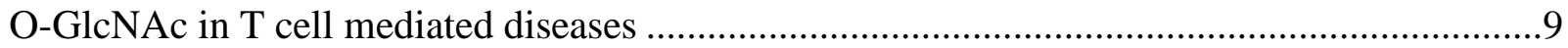

Chapter 2: Methodology...............................................................................................................................11

Mouse $\mathrm{T}$ cell isolation, activation, and differentiation..........................................................11

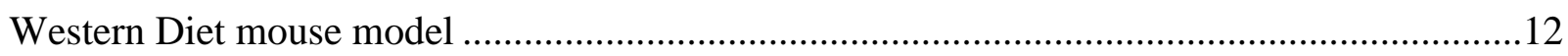

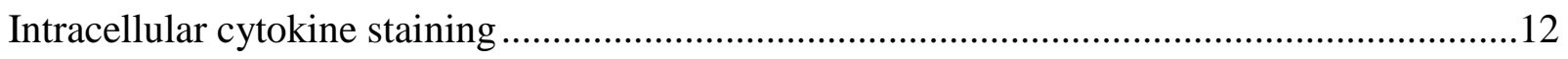

Quantitative Real Time Polymerase Chain Reaction (qPCR)...................................................13

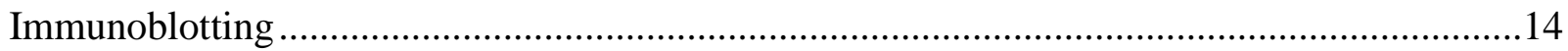

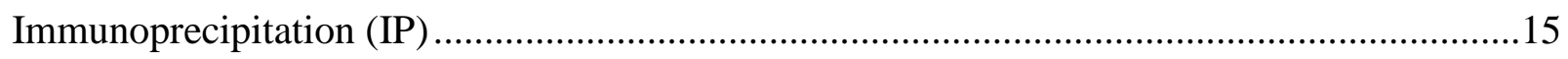

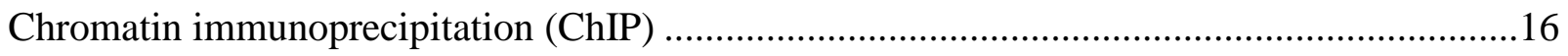

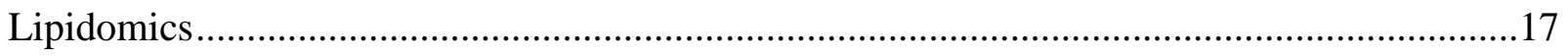

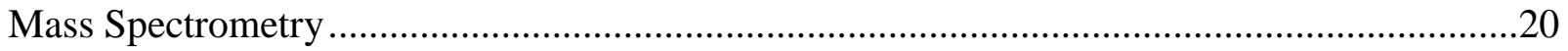

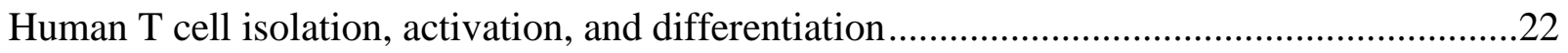

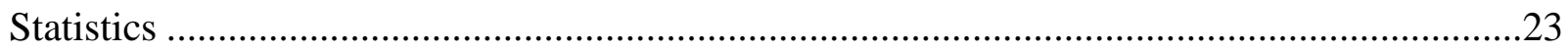

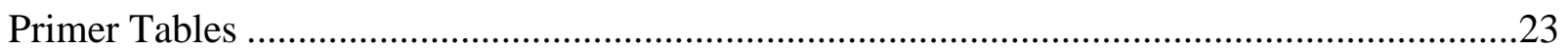


Chapter 3: Results.

In murine CD4+ T cells, elevated O-GlcNAc increases pro-inflammatory IL-17A and IFN $\gamma$ cytokines, while having no effect on anti-inflammatory IL-10 and IL-4 cytokines. .25

In human CD4+ T cells, elevated O-GlcNAc increases pro-inflammatory IL-17A cytokine. ..29

Naïve CD4+ T cells isolated from mice fed a Western diet have higher O-GlcNAc levels and when polarized to a Th17 lineage secrete more IL-17 which is exacerbated by TMG. 32

Elevated O-GlcNAcylation has no effect on ROR $\gamma \mathrm{t}$ protein or transcript levels. .35

Elevated O-GlcNAcylation has no effect on pSTAT3:STAT3 protein levels. .36

Elevated O-GlcNAcylation promotes retention of ROR $\gamma \mathrm{t}$ at the IL-17 locus.

Elevated O-GlcNAcylation increases lipid ligands capable of increasing ROR $\gamma \mathrm{t}$ transcriptional activity at the IL-17 locus

Elevated O-GlcNAcylation alters flux through the interrelated ceramide, sphingomyelin, and choline metabolic pathways. .44

Acetyl CoA Carboxylase 1 (ACC1), the rate-limiting enzyme in lipid biosynthesis, is OGlcNAcylated. .46

Summary: Over-nutrition elevates CD4+ T cell O-GlcNAc levels, leading to increased proinflammatory IL-17 cytokine production and enhanced risk for obesity-related pathology......51

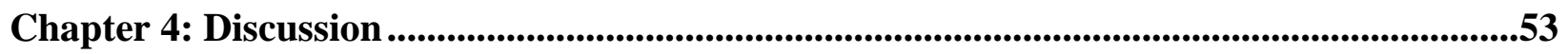

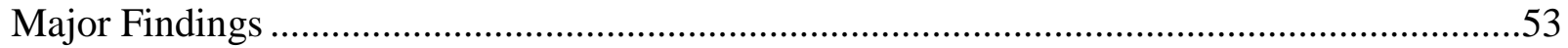

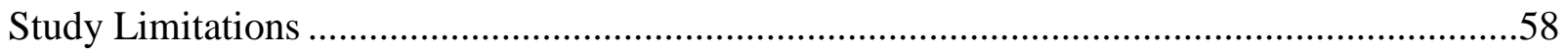

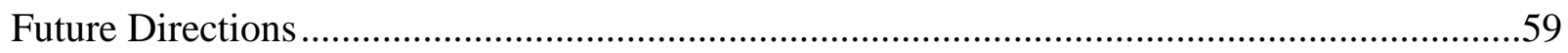




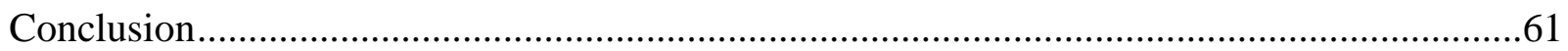

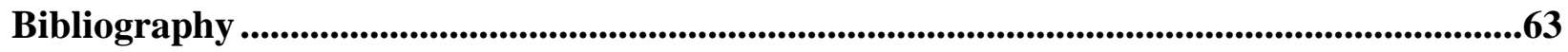




\section{CHAPTER 1: INTRODUCTION}

Reprinted with permission from Machacek, M., Slawson, C., and Fields, P. E. (2018) O-GlcNAc: a novel regulator of immunometabolism. Journal of Bioenergetics and Biomembranes.

The immune system is composed of a host of widely distributed and extremely dynamic cells capable of expanding and contracting rapidly in response to a myriad of microbial and environmental threats. Within this complex network of cells, $\mathrm{CD} 4^{+} \mathrm{T}$ cells orchestrate the adaptive immune response's elimination of a pathogen in a highly specific manner. Among their many functions, $\mathrm{CD}^{+} \mathrm{T}$ cells dictate which class of immunoglobulin is expressed by $\mathrm{B}$ cells, enhance phagocytic function of innate immune cells like macrophages, and themselves differentiate into various effector cells specialized to eliminate specific classes of pathogens (1). Due to the dynamic and highly proliferative nature of $\mathrm{CD}^{+} \mathrm{T}$ cells, a fascinating question about their biology has emerged: How can metabolism — another highly dynamic cellular processinfluence their function? The burgeoning field of immunometabolism seeks to understand how the metabolic state of immune cells alters function and may be targeted or manipulated for therapeutic purposes. An intriguing target in elucidating how metabolism alters immune cell function is the dynamic post-translational protein modification O-GlcNAc (O-linked Nacetylglucosamine). Since O-GlcNAc levels fluctuate as the metabolic state of the cell changes, O-GlcNAc is an appealing explanation for how a cell integrates extra- and intra-cellular metabolic signals to modify cytoplasmic, nuclear, and mitochondrial enzymes and subsequently alter cellular function. Indeed, O-GlcNAcylation is critical for T cell activation (2,3), and when aberrant, contributes to inflammatory diseases (4-6). 


\section{Distinct metabolic programs are critical during $\mathbf{T}$ cell activation}

In lymph nodes, naïve $\mathrm{CD}^{+} \mathrm{T}$ cells are activated by antigen presenting cells (APC), such as dendritic cells, expressing major histocompatibility complex II (MHC II) loaded with an antigenic peptide on their cell surface. Activation requires recognition of this peptide-MHC II complex by the clonally unique $\mathrm{T}$ cell receptor (TCR). In addition to this first signal, a second signal is required to stimulate optimal proliferation of that particular $\mathrm{T}$ cell receptor-bearing clone. This second signal is provided by a co-stimulatory molecule, such as CD28. With these two signals, a $\mathrm{T}$ cell is now activated to respond specifically to the pathogen loaded onto the

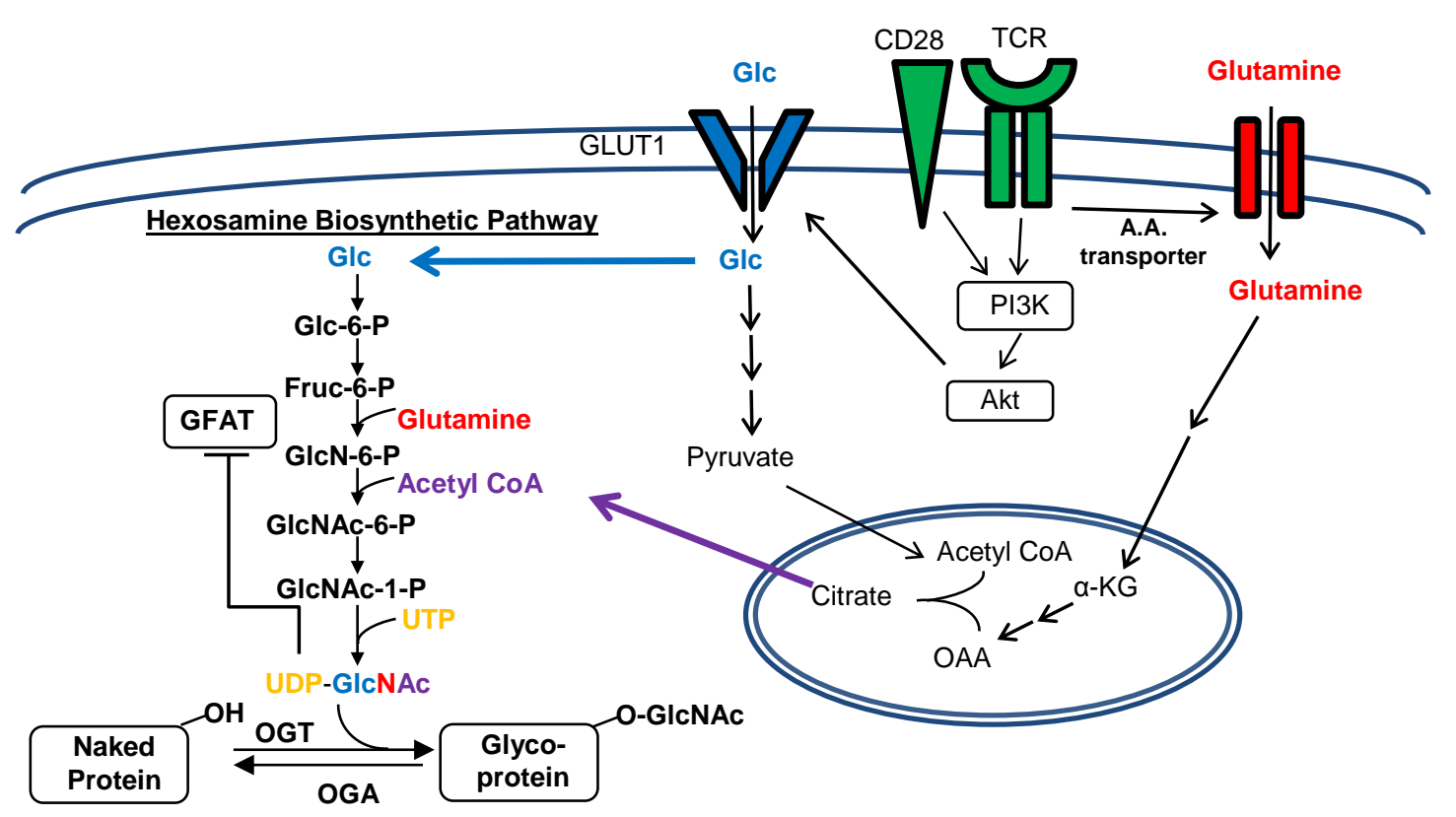

Figure 1. T cell activation induces cell surface expression of GLUT1 and amino acid transporters, facilitating uptake of glucose and glutamine. This enhanced nutrient state provides substrates that directly feed into the hexosamine biosynthetic pathway (HBP), driving increased UDP-GlcNAc synthesis and protein O-GlcNAcylation by O-GlcNAc transferase (OGT).

MHC II complex. Activation triggers massive proliferation of the $\mathrm{T}$ cell and thus requires a tremendous influx of metabolites to sustain initial cell growth and subsequent multiple cell divisions. Not surprisingly, $\mathrm{T}$ cell activation triggers a complete switch in metabolic programs. 
Upon activation, naïve $\mathrm{CD} 4^{+} \mathrm{T}$ cells switch from relying primarily on oxidative phosphorylation for their metabolic needs to aerobic glycolysis and glutaminolytic programs. With this switch comes an influx of metabolites capable of fueling cell growth and proliferation. For example, early studies identified a sudden influx of glucose into activated $\mathrm{T}$ cells (7). This initial observation has been further expanded upon by studies showing that activation triggers the upregulation of GLUT1 on the T cell surface. This upregulation is mediated through the CD28 co-stimulatory signaling pathway that engages the PI3K-AKT signaling cascade as well as MYC-mediated transcriptional activation of glycolytic genes (8-10). In addition to increased glucose, activated T cells also require more amino acids. TCR and CD28 engagement increases expression of amino acid transporters, particularly those needed for the import of leucine and glutamine $(11,12)$. Activated $\mathrm{T}$ cells have a nearly essential requirement for glutamine as an energy source (13) - increasing uptake of this particular amino acid ten times more than any other amino acid (14). Besides being necessary for increased protein translation, glutamine is a versatile building block for many other cellular metabolites, including nucleotides via the de novo synthetic pathway and serving as an anaplerotic source of oxaloacetate (OAA) in the TCA cycle (15). By replenishing OAA, citrate can be continuously generated and transported out of the mitochondria, where it is converted to acetyl CoA, the foundational building block for fatty acid and cholesterol synthesis. Essentially, conversion of glutamine to acetyl CoA provides the building block required for increased fatty acid synthesis during $\mathrm{T}$ cell activation. This step is critical since activated effector $\mathrm{T}$ cells favor de novo synthesis rather than exogenous uptake of fatty acids (10). Overall, $\mathrm{T}$ cell activation induces major metabolic shifts, resulting in the cell switching from oxidative phosphorylation and fatty acid oxidation for its energetic needs to aerobic glycolysis, glutaminolysis, increased pentose phosphate pathway flux, and de novo lipid 
generation. This substantial change in metabolism is thought to be required to meet the cell's new, increased metabolic demands. Importantly, these metabolic pathways all produce substrates required in the hexosamine biosynthetic pathway for UDP-GlcNAc synthesis and thus protein O-GlcNAcylation (Figure 1).

\section{Intrinsic and external metabolic factors are required for specific CD4+ $\mathrm{T}$ cell differentiation and function}

In addition to providing the stimuli needed for $\mathrm{T}$ cell activation, cytokines secreted by the antigen-presenting cell during activation will direct $\mathrm{CD}^{+} \mathrm{T}$ cell differentiation into one of at

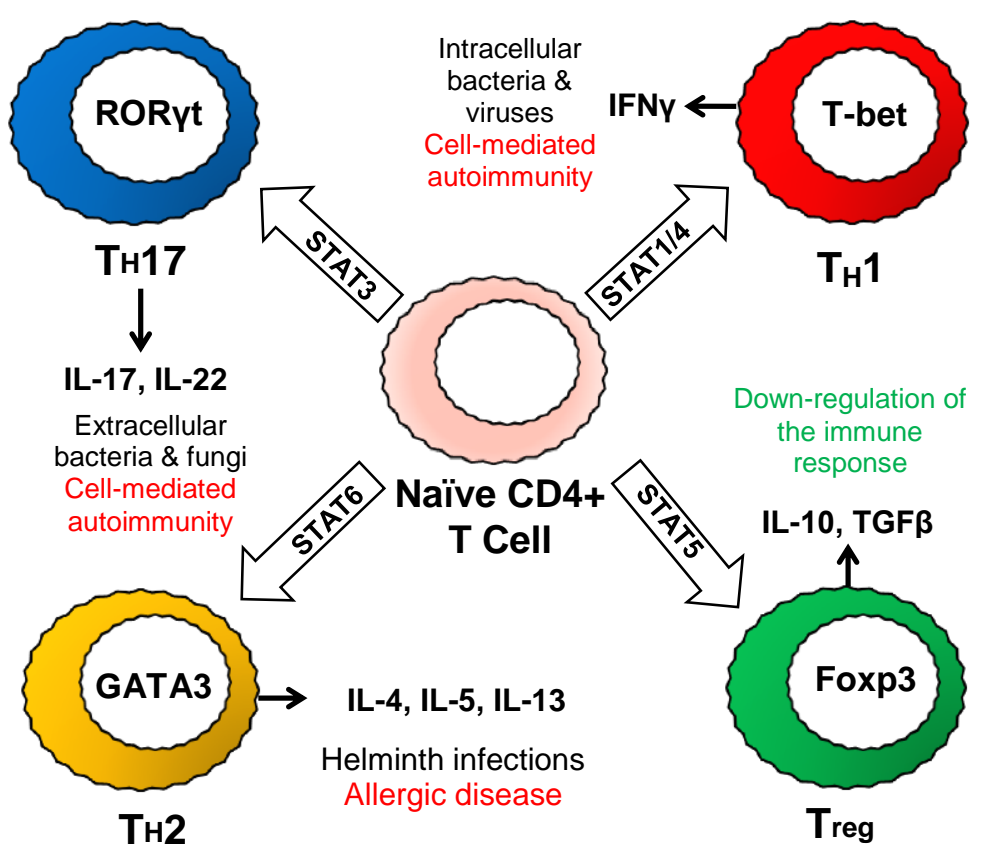

Figure 2. Cytokines secreted by antigen presenting cells (APC) induce signaling through STAT proteins, which upregulate a lineage-defining transcription factor. This "master" transcription factor then induces transcription of cytokines that carry out the specialized function of the $\mathrm{T}$ cell. Th1, Th2, and Th17 have effector functions in eliminating specific classes of pathogens, but over-activity can lead to disease. Inducible Tregs serve an opposing function in diminishing effector $\mathrm{T}$ cell responses.

least six classes of specialized effectors. The four "main" classes of effectors are 1) T helper 1

(Th1), which target intracellular and viral pathogens; 2) Th2, which target helminths; 3) Th17, 
which target fungal and extracellular bacteria; and 4) inducible regulatory T cells (iTregs), which have an opposing function in decreasing the inflammatory immune response (Figure 2). Th1, Th2, and Th17 are often categorized as "effectors" due to their vital function in eliminating specific classes of pathogens, while regulatory T cells serve to "soothe" inflammation and thus can be considered a special class of effector T cell. Additionally, effectors are inappropriately increased in situations of autoimmunity (Th1 and Th17) and allergies (Th2). Based on their varied functions, it is not surprising that distinct metabolic pathways are also critical for the differentiation of specific $\mathrm{T}$ cell subsets. Th1, Th2, Th17 primarily utilize glycolysis and glutaminolysis for their energy needs and absolutely require GLUT1, while iTregs continue to utilize oxidative phosphorylation to meet their energetic needs and are unaffected by GLUT1 deficiency $(16,17)$. Instead, inhibition of fatty acid catabolism blunts iTreg differentiation, and increased AMPK signaling (such as that induced by metformin) serves to increase iTreg differentiation (16). A glycolytic enzyme recently found to be integral to $\mathrm{CD}^{+} \mathrm{T}$ cell differentiation is pyruvate dehydrogenase $(\mathrm{PDH})$, which converts pyruvate to acetyl CoA, the major building block for fatty acid biosynthesis. Pyruvate dehydrogenase kinase 1 (PDHK1) inhibits PDH activity and enhances glycolytic flux. PDHK1 is selectively upregulated in Th17, but not in Th1 or iTregs. Inhibition of PDHK1 decreases Th17 differentiation, demonstrating a glycolytic dependence for Th17 cells (18). Besides metabolizing glucose differently, differential components of the amino-acid sensing mTOR signaling pathway are specifically required by different $\mathrm{T}$ cell subsets. Loss of the entire mTOR complex leads to loss of differentiation into all effector lineages except for iTreg, whose differentiation remains unaffected. This underscores the iTreg reliance on AMPK signaling, which normally serves to inhibit mTOR activity (19). mTOR is composed of two different complexes (mTORC1 and mTORC2), each with its own 
distinct regulation and function (20). Interestingly, mTORC1 and Rheb, the GTP-binding protein that activates mTORC1, are required for Th1 and Th17 differentiation, while mTORC2 is needed for Th2 differentiation (21). T cell effectors also have a differential requirement for fatty acid metabolic pathways. Specifically, Th17 cells require acetyl CoA carboxylase (ACC1), the rate-limiting enzyme in fatty acid synthesis, while iTreg differentiation is unaffected by ACC1 knockout (22). Further demonstrating a necessity for fatty acid anabolism versus catabolism in iTregs, ACC1 is upregulated in obese mice and human memory $\mathrm{CD} 4^{+} \mathrm{T}$ cells. The enzyme also provides fatty acid ligands that enhance retinoic acid receptor-related orphan receptor $\mathrm{t}$ isoform (ROR $\gamma \mathrm{t}$ ), the lineage-defining, "master" transcription factor for Th17 cells, critical for their activity and IL-17 production (23). Increased ACC1 activity also increases substrates for cholesterol metabolism. Specific oxysterols derived from cholesterol metabolism are potent activating ligands for $\mathrm{ROR} \gamma \mathrm{t}$, increasing ROR $\gamma \mathrm{t}$ transcriptional activity, and thus Th17 differentiation $(24,25)$.

In addition to intrinsic metabolic pathways, various extrinsic metabolic and environmental signals heavily influence $\mathrm{CD} 4^{+} \mathrm{T}$ cell differentiation, particularly along the Th17 and iTreg axis. As an example, sites of inflammation are frequently hypoxic. Accordingly, hypoxia inducible factor-1 $\alpha$ (HIF-1 $\alpha)$ has been demonstrated to be essential in upregulating glycolytic genes in Th17 cells (26). HIF-1 $\alpha$ also directly enhances transcription of ROR $\gamma$ t, while actively targeting forkhead box P3 (Foxp3), the iTreg master transcription factor, for ubiquitin-mediated degradation (27). Hormones also exogenously regulate $\mathrm{CD}^{+} \mathrm{T}$ cell differentiation. Many autoimmune diseases exhibit sexual dimorphism with increased incidence in females. Androgens act as ligands for different peroxisome proliferator activated receptor (PPAR) types. In human $\mathrm{CD}^{+} \mathrm{T}$ cells, androgens upregulate PPAR $\alpha$ which suppresses Th1 and interferon- $\gamma$ 
(IFN $\gamma$ ) production, while selectively enhancing IL-17 secretion (28). Human male CD4 ${ }^{+} \mathrm{T}$ cells with PPAR $\alpha$ knockout secreted IFN $\gamma$ similarly to female $\mathrm{CD}^{+} \mathrm{T}$ cells (28). Other hormonal influences on $\mathrm{T}$ cell differentiation include leptin, a hormone released to indicate satiety. Leptin signals through signal transducer and activator of transcription 3 (STAT3), which is the major STAT required for enhancing ROR $\gamma \mathrm{t}$ and IL-17 transcription in Th17 cells. Fittingly, leptin receptor expression is required for Th17 differentiation (29) and is yet another signaling pathway found to upregulate glycolytic metabolism via HIF-1 $\alpha$ (30).

On the stranger, yet fascinating side, disrupted circadian rhythms have been shown to increase Th17 differentiation (31). Clock proteins rhythmically inhibit NFIL3 (nuclear factor, IL-3 regulated) expression, which ordinarily represses ROR $\gamma \mathrm{t}$ transcription. However, when mice are subjected to altered light/dark cycles to mimic jet lag, increased inhibition of NFIL3 by the Reverb $\alpha$ clock protein results in increased Th17 differentiation (31). Finally, modestly elevated $\mathrm{NaCl}$ concentrations induce activity of serum glucocorticoid kinase 1 (SGK1), which stabilizes IL-23 receptor expression, important for locking in a pathogenic Th17 phenotype $(32,33)$. Knockout of SGK1 results in decreased Th1- and Th17-driven autoimmune inflammation in a mouse model of multiple sclerosis (EAE, experimental autoimmune encephalomyelitis) due to a loss of Th17 stability. This effect was completely reversed by feeding the mice a high-salt diet (32,33). Recently, SGK1 regulation of the Th1 vs Th2 axis was clarified (34). Activation of SGK1 occurs downstream of mTORC2, which is required for Th2 differentiation (21). Accordingly, knockout of SGK1 ameliorated Th2-mediated allergic lung inflammation, suggesting importance of Th2 rather than Th1 differentiation (34).

Finally, bacterial metabolic by-products unique to the gut can regulate $\mathrm{CD}^{+} \mathrm{T}$ cell differentiation. The gut is considered a distinct immunological site due to the constant presence 
of commensal and potentially pathogenic bacteria, which the immune system must carefully discriminate between to appropriately balance inflammation and tolerance. Proper balance of the Th17 versus iTreg axis is of particular importance in the gut, and thus much research has gone into exploring mechanisms regulating this balance. Specific strains of bacteria, the segmented filamentous bacteria, are required to induce gut resident Th17 cells (35). Fatty acids derived from the microbiota critically regulate the balance of iTreg and Th17 in the gut. Short chain fatty acids, such as butyrate, induce iTregs, while long chain fatty acids induce Th1 and/or Th17 differentiation sufficient to enhance autoimmune EAE (36). Additionally, tryptophan derivatives derived from gut bacteria promote iTreg differentiation and quell EAE autoimmune inflammation (37).

\section{O-GIcNAcylation is required for $\mathbf{T}$ cell activation}

A less well known, yet critical metabolic pathway is the hexosamine biosynthetic pathway (HBP). Incorporating metabolites from carbohydrate, amino acid, fatty acid, and nucleic acid pathways, the HBP results in the synthesis of UDP-GlcNAc, the substrate used by O-GlcNAc transferase (OGT) to O-GlcNAcylate proteins. As the concentration of UDP-GlcNAc rises, more substrate is available and O-GlcNAcylation increases (38). Glutamine is a substrate required by GFAT (glucose:fructose-6-phosphate amidotransferase), the rate-limiting enzyme in the HBP. Thus, when glucose and glutamine influx rapidly increase during $\mathrm{T}$ cell activation, UDP-GlcNAc levels and subsequent O-GlcNAcylation can also increase (39). This effect was first observed during the initial identification of intracellular glycosylation with O-GlcNAc in activated Jurkat $\mathrm{T}$ cells (40). T cell activation rapidly induced distinct changes in the population of O-GlcNAcylated nuclear and cytoplasmic proteins. O-GlcNAcylation is essential during $\mathrm{T}$ cell activation, since siRNA knock-down of OGT significantly hinders T cell activation (2). 
This effect is due in part because O-GlcNAcylation of NF- $\mathrm{B}$ and NFAT, transcription factors essential for IL-2 gene transcription that drive the proliferative response, is required for their translocation from the cytoplasm to the nucleus $(2,41)$. Interestingly, O-GlcNAcylation of NF$\kappa \mathrm{B}$ was induced under specific conditions such as hyperglycemia, suggesting a link between increased O-GlcNAcylation and exaggerated production of inflammatory cytokines such as IFN $\gamma$ under its transcriptional control (41). O-GlcNAcylation is required during activation in primary human T cells as well (3). A specific requirement for OGT but not OGA function was identified, which was linked to OGT localization to a cluster of kinases immediately downstream of TCR signaling (3). This study also identified several new O-GlcNAcylated proteins among these proximal kinases, such as LCK and ZAP-70, which are key players in transmitting the TCR signal (3). Identification of OGT-mediated modification of proteins at the beginning of the TCR signaling pathway provides a possible explanation for why O-GlcNAcylation levels rise so rapidly after activation before nutrient transporters have had a chance to demonstrably increase nutrient flux. Taken together, the data strongly support O-GlcNAc as a critical regulator of activation signals needed for $\mathrm{T}$ cell proliferation.

\section{O-GlcNAc in $\mathbf{T}$ cell mediated diseases}

The role of O-GlcNAc in $\mathrm{CD}^{+} \mathrm{T}$ cell differentiation is poorly understood, but several studies hint at a role for this modification in regulating $\mathrm{T}$ cell effectors in autoimmune diseases. The $\mathrm{X}$ linked OGT gene is hypomethylated in $\mathrm{T}$ cells from female patients with systemic lupus erythematosus, an autoimmune disease with a high prevalence especially in females, mediated in part by Th1 and Th17 cells (4). Additionally, miRNA15-b targeting of OGT transcripts was recently found to be down-regulated in $\mathrm{T}$ cells from multiple sclerosis patients, resulting in increased Th17 differentiation (5). ELF-1, a transcription factor for the TCR $\zeta$ chain gene, 
requires O-GlcNAcylation and phosphorylation to translocate from the cytoplasm to the nucleus. Decreased O-GlcNAcylation was found on ELF-1 in SLE patients and led to a decrease in TCR $\zeta$ chain levels on their T cells $(42,43)$. Interestingly, restoring appropriate levels of TCR $\zeta$ chain was sufficient to ameliorate $\mathrm{T}$ effector cell dysfunction (44). These observations suggest dysregulated O-GlcNAcylation results in aberrant $\mathrm{CD}^{+} \mathrm{T}$ cell effector function. In particular, dysregulated cycling of O-GlcNAc due to changes in OGT levels may have a role in enhancing pro-inflammatory $\mathrm{T}$ effector function in the context of autoimmunity. Finally, O-GlcNAcylation is essential for $\mathrm{T}$ cell malignancy, since $\mathrm{T}$ cell-specific OGT knockout prevented malignant transformation of PTEN-knockout thymocytes (39). However, this is likely due more to OGlcNAc's essential role in organizing the mitotic spindle and regulating cellular division than in regulating $\mathrm{T}$ cell cancers specifically (45-47). Many unanswered questions remain in our understanding of how O-GlcNAc regulates $\mathrm{CD}^{+} \mathrm{T}$ cell differentiation and how aberrant $\mathrm{O}$ GlcNAcylation may promote inflammatory diseases. 


\section{CHAPTER 2: METHODOLOGY}

\section{Mouse $\mathbf{T}$ cell isolation, activation, and differentiation}

C57BL/6 male (Western diet experiments) and female mice (Jackson Laboratories) between 6-24 weeks of age were used in these studies. Mice were humanely euthanized using $\mathrm{CO}_{2}$ asphyxiation according to an Institutional Animal Care and Use Committee (IACUC) approved protocol. CD4+ T cells were isolated from spleen using the CD4+ T cell isolation kit (Stem Cell Technologies). CD4+ T cells alone or naïve cells obtained by staining with APC-CD62L and FITC-CD44 (BD Biosciences) were sorted and treated with $10 \mu \mathrm{M}$ Thiamet-G (SD Chemmolecules, LLC) or vehicle control for 6 hours. Cells $\left(2.5 \times 10^{5}\right.$ cells/well $)$ were then activated on anti-CD3 and anti-CD28 (Bio X Cell) antibody coated plates. Plates were prepared by addition of $2 \mu \mathrm{g}$ anti-CD3 and $1 \mu \mathrm{g}$ anti-CD28 per well of a 48 -well plate in PBS containing calcium and magnesium incubated overnight at $4^{\circ} \mathrm{C}$. At the time of activation, polarizing cytokines were added to cells to promote differentiation towards specific lineages as follows: Th0 - no cytokines added; Th17- mouse IL-6 (20 ng/mL, Miltenyi), human TGF $\beta 1$ ( 2 ng/mL, Miltenyi), anti-IL-4 $(10 \mu \mathrm{g} / \mathrm{mL})$, anti-IFN $\gamma(10 \mu \mathrm{g} / \mathrm{mL})$. All cells were incubated at $37{ }^{\circ} \mathrm{C}$ in $5 \%$ $\mathrm{CO}_{2}$ in a $95 \%$ humidified incubator. On the second day of culture, mouse IL-2 (eBioscience) at $20 \mathrm{ng} / \mathrm{mL}$ was added to cultures and the cells were re-suspended. On the fourth day of culture, cells were re-suspended, any dead cells were removed by gradient centrifugation with Lymphocyte Separation Medium (Corning), and counted with a hemocytometer. 2.5 x $10^{5}$ cells per well were then re-stimulated on plates containing $3 \mu \mathrm{g}$ anti-CD3 and $1 \mu \mathrm{g}$ anti-CD28 per well, which were prepared as previously described. 24 hours after re-stimulation supernatants and cells were harvested. Mouse IL-17A, IFN $\gamma$, IL-4, or IL-10 levels in the supernatants were quantified using the cytokine's corresponding ELISA kit (eBioscience). 


\section{Western Diet Mouse Model}

For Western diet studies, 6-8 week old male C57BL/6 mice (Jackson Laboratories) were fed a $42 \%$ kcal from fat $(>60 \%$ saturated fat), $0.2 \%$ cholesterol, and high sucrose "Western diet" (Teklad TD.88137) for 16 weeks. Control 6-8 week old male C57BL/6 mice were fed standard chow, containing $14 \% \mathrm{kcal}$ from fat (Teklad 8604). Mice were weighed at $0,2,4,6,8,10,12$, 14, and 16 weeks. At 15 weeks, control and Western diet fed mice were fasted overnight for 15 hours. At the end of the fast, tail vein blood was used to determine the blood glucose level (mg/dL) using One Touch Ultra Blue test strips and the One Touch UltraMini blood glucose monitoring system (LifeScan). At 16 weeks mice were sacrificed following a 15 hour overnight fast, and splenic CD4+ T cells were used for subsequent studies as described.

\section{Intracellular Cytokine Staining}

CD4+ T cells were isolated and cultured as previously described. After four days of culture, cells were re-suspended, any dead cells were removed by gradient centrifugation with Lymphocyte Separation Medium (Corning), and viable cells were re-suspended at a concentration of 1-10 million cells per mL. Cells were stimulated with $50 \mathrm{ng} / \mathrm{mL}$ PMA (phorbol 12-myristate 13-acetate) and $1 \mu \mathrm{g} / \mathrm{mL}$ ionomycin (both Sigma) for 5 hours. Protein secretion was inhibited by addition of $4 \mu \mathrm{L}$ of BD GolgiStop ${ }^{\mathrm{TM}}$ Protein Transport Inhibitor (containing monensin) per $6 \mathrm{~mL}$ of culture. After stimulation, cells were washed twice with PBS $+2 \%$ FBS and counted. One million cells per condition were added to an Eppendorf tube, spun, and resuspended in cold BD Cytofix ${ }^{\mathrm{TM}}$ buffer from the Mouse Th1/Th17 Phenotyping Kit (BD Biosciences) and incubated for 20 minutes at room temperature. Cells were then washed twice with $\mathrm{PBS}+2 \%$ FBS and diluted in $\mathrm{BD}$ Perm/Wash Buffer $^{\mathrm{TM}}$ for 15 minutes at room 
temperature. Cells were centrifuged and then re-suspended in $50 \mu \mathrm{L}$ BD Perm/Wash Buffer ${ }^{\mathrm{TM}}$ plus $20 \mu \mathrm{L} /$ tube of staining cocktail (mouse PerCP-Cy5.5-CD4, PE-IL-17A, FITC-IFN $\gamma$ ) or BD Perm/Wash Buffer ${ }^{\mathrm{TM}}$ as a negative control for 30 minutes at room temperature. Cells were washed twice with PBS $+2 \%$ FBS and data was acquired on an LSR II (BD Biosciences) and analyzed with FlowJo (Tree Star).

\section{Quantitative Real Time Polymerase Chain Reaction (qPCR)}

Mouse or human RNA was extracted by dissolving $2 \times 10^{6}$ cells in TRI reagent (Sigma) followed by the addition of chloroform. The mixture was mixed by inversion, centrifuged, and the aqueous layer was taken. Isopropanol was added to the aqueous layer to precipitate the RNA. The RNA was pelleted by centrifugation, washed with $75 \%$ ethanol, and allowed to air-dry before adding DEPC-treated, RNase free water (Ambion). RNA of high purity (260/280 and 260/230 greater than 1.7) was used for further analysis. $0.5-0.75 \mu$ g RA was converted to cDNA using iScript reverse transcriptase reaction mix (Biorad) in a thermal cycler (Model 2720, Applied Biosystems) using the following protocol: priming, $5 \mathrm{~min}$ at $25^{\circ} \mathrm{C}$; RT, $30 \mathrm{~min}$ at $42{ }^{\circ} \mathrm{C}$; and RT inactivation, 5 min at $85{ }^{\circ} \mathrm{C}$. For qPCR reactions, $10 \mu \mathrm{L}$ SsoAdvanced Universal SYBR Green Supermix (Biorad), 10-100 ng of cDNA, $0.2 \mu \mathrm{L}$ each of forward and reverse primers (100 $\mu \mathrm{M}$ stock concentration), and water to a final reaction volume of $20 \mu \mathrm{L}$ were added per well to 96 well-plates (Midsci). The reactions were run on a CFX96 Real Time PCR Detection System (Biorad), using the following conditions: polymerase activation and DNA denaturation, $30 \mathrm{~s}$ at $95^{\circ} \mathrm{C}$; amplification denaturation, $5 \mathrm{~s}$ at $95{ }^{\circ} \mathrm{C}$; and amplification annealing and extension, $30 \mathrm{~s}$ at $60{ }^{\circ} \mathrm{C}$ or $62{ }^{\circ} \mathrm{C}$ for 40 cycles. The dynamic range of reverse transcription and the amplification efficiency was determined for each primer pair and cell culture condition. Thus, 
$\mathrm{Cq}$ values within these ranges were reliably used to calculate the fold change in gene expression compared to an internal standard using the ${ }^{\Delta \Delta} \mathrm{Cq}$ method.

\section{Immunoblotting}

Cells were lysed on ice in 20 mM Tris, pH 7.4, 150 mM NaCl, 40 mM GlcNAc, 2 mM EDTA, 1 mM DTT, 1\% Nonidet P-40 lysis buffer with protease inhibitors (1 mM $\beta$-glycerophosphate, 1 $\mathrm{mM}$ NaF, $2 \mathrm{mM}$ PMSF, $1 \mathrm{X}$ inhibitor cocktail composed of $1 \mu \mathrm{g} / \mathrm{ml}$ leupeptin, $1 \mu \mathrm{g} / \mathrm{ml}$ antipain, $10 \mu \mathrm{g} / \mathrm{ml}$ benzamidine, and $0.1 \%$ aprotinin (Sigma)) added immediately before lysis. Lysates were incubated on ice for 20 minutes and vortexed every 5 minutes. Lysates were then centrifuged for 20 minutes, $4^{\circ} \mathrm{C}$ and the supernatant was removed to another tube. Protein concentration of the lysate was determined using protein assay dye reagent (Biorad), using known concentrations of bovine serum albumin (Biorad) as the standard. Lysates were then denatured by addition of 4X protein solubility mixture (100 mM Tris, pH 6.8, 10 mM EDTA, 8\% SDS, 50\% sucrose, 5\% beta-mercaptoethanol, $0.08 \%$ Pyronin Y) and boiling for 2 minutes. Equal amounts of lysates were loaded onto 4-15\% Criterion precast TGX gels (Biorad). Electrophoresis occurred at $125 \mathrm{~V}$, and then the gel proteins were transferred to PVDF membranes at 0.4A. Membranes were blocked with 3\% BSA, 0.01\% sodium azide in TBST (25 $\mathrm{mM}$ Tris,pH 7.6, $150 \mathrm{mM} \mathrm{NaCl}, 0.05 \%$ Tween-20) for at least 20 minutes. Blots were then probed overnight at $4^{\circ} \mathrm{C}$ with primary antibody to protein of interest at 1:1,000 dilution. The next day blots were washed 5 times in TBST for 5 minutes each. HRP-conjugated secondary antibody at 1:10,000 dilution was added for an hour at room temperature, followed by washing 5 times for 5 minutes each. Blots were then developed using the chemiluminescence HRP (horseradish peroxidase) antibody detection method (HyGlo Spray, Denville Scientific). Commonly, blots were stripped with $200 \mathrm{mM}$ glycine, $\mathrm{pH} 2.5$ for one hour at room temperature, 
blocked, and re-probed with antibodies to other proteins of interest. Where shown, Image J (48) was used to quantify the density of protein bands compared to an internal standard protein band such as actin. Antibodies used in these studies: pACC1 (Ser79), ACC1, pSTAT3 (Tyr705), STAT3 (Cell Signaling Technologies); O-GlcNAc (clone: RL2), ROR $\gamma \mathrm{t}$ (Abcam); actin (Sigma); OGT (clone: AL-34) and OGA (clone: 345) antibodies were a generous gift from the laboratory of Dr. Gerald Hart in the Department of Biological Chemistry at The Johns Hopkins University.

\section{Immunoprecipitation (IP)}

CD4+ T cells were lysed with lysis buffer (50 mM Tris, $\mathrm{pH} 7.4,150 \mathrm{mM} \mathrm{NaCl}, 1 \mathrm{mM}$ DTT, $1 \%$ NP-40, $40 \mathrm{mM} \mathrm{N}$-acetylglucosamine) and protein concentration was quantified using Protein Assay Dye Reagent (Biorad). One $\mu \mathrm{g}$ of antibody for the protein of interest or one $\mu \mathrm{g}$ of isotype matched IgG was added to equal amounts of whole cell lysate diluted to an equal volume in Nonidet P-40 lysis buffer and rotated overnight at $4{ }^{\circ} \mathrm{C}$. As an additional control, $1 \mu \mathrm{g}$ antibody to the protein of interest was added to lysis buffer only and rotated overnight at $4^{\circ} \mathrm{C}$. Protein GSepharose beads (Millipore) were added and rotated at $4^{\circ} \mathrm{C}$ for 2 hours. The protein $\mathrm{G}$ beads were then washed three times with NP-40 lysis buffer containing $600 \mathrm{mM} \mathrm{NaCl}$ followed by two PBS washes, briefly vortexing beads in between washes. Washed beads were re-suspended in Laemlli buffer, boiled for 2 minutes, and run on 4-15\% gradient Criterion TGX gels (Biorad). Gel proteins were transferred to PVDF membranes and blocked with 3\% BSA, $0.01 \%$ sodium azide in TBST (25 mM Tris,pH 7.6, $150 \mathrm{mM} \mathrm{NaCl}, 1 \%$ Tween-20). Blots were then probed overnight at $4{ }^{\circ} \mathrm{C}$ with antibodies to O-GlcNAc (RL2, Abcam), followed by immunoprecipitated protein (ACC1, pSTAT3 (Tyr705), STAT3 (CST), ROR $\gamma \mathrm{t}$ (Abcam)) and developed using the chemiluminescence HRP (horseradish peroxidase) antibody detection method (HyGlo Spray, 
Denville Scientific). For ROR $\gamma$ t immunoprecipitation, samples were treated with 5 units of IdeZ protease (Promega) in PBS for 30 minutes at $37^{\circ} \mathrm{C}$ after washing the beads.

\section{Chromatin Immunoprecipitation (ChIP)}

Mouse naïve CD4+ T cells were isolated as previously described from mice fed standard chow. TMG was added to naïve CD4+ T cells for 6 hours before activation and differentiated towards the Th17 lineage as previously described. After 4 days of culture, cells were harvested and fixed with $2 \mathrm{mM}$ ethylene glycol bis(succinimidyl succinate) (EGS; Thermo Scientific) in PBS for 30 minutes followed by $1 \%$ formaldehyde (Thermo Scientific) for 10 minutes. Nuclei were extracted by re-suspending fixed cells in hypotonic cell lysis buffer (10 mM Tris, pH 8.0, $10 \mathrm{mM}$ $\mathrm{NaCl}, 3 \mathrm{mM} \mathrm{MgCl} 2,40 \mathrm{mM}$ GlcNAc, $0.5 \% \mathrm{NP}-40)$ with freshly added protease inhibitors (1 $\mathrm{mM} \beta$-glycerophoshate, $1 \mathrm{mM} \mathrm{NaF}, 1 \mathrm{X}$ protease inhibitor cocktail (containing aprotinin, leupeptin, antipain, benzamidine), and $2 \mathrm{mM}$ PMSF) for 20 minutes on ice. Nuclear lysis buffer (50 mM Tris, pH 8.0, $10 \mathrm{mM}$ EDTA, 1\% SDS, 25\% glycerol) with freshly added protease inhibitors as previously described and the chromatin was sonicated using the QSonica sonicator and cooling system (Model \#:Q800R and Oasis 180 respectively) for 200 cycles of 15 seconds on at $75 \%$ amplitude and 45 seconds off. Sonication efficiency was checked by treating sheared chromatin diluted in ChIP buffer (50 mM Tris, pH 7.5, $150 \mathrm{mM} \mathrm{NaCl}, 5 \mathrm{mM}$ EDTA, $0.5 \%$ NP40, $1 \%$ Triton X-100) with $1 \mu \mathrm{g}$ RNase A (Invitrogen) overnight at $65^{\circ} \mathrm{C}$, followed by $2 \mathrm{ug}$ Proteinase K (Sigma) for 6 hours at $65^{\circ} \mathrm{C}$, before addition of phenol:chloroform:isoamyl alcohol (Acros Organics). The top aqueous layer was taken and $20 \mu \mathrm{g}$ of glycogen (Invitrogen) followed by $1 \mathrm{~mL}$ of cold $100 \%$ ethanol (Sigma) was added and incubated overnight at $-20^{\circ} \mathrm{C}$ to precipitate the DNA. The DNA was pelleted by centrifuging for 30 minutes at $4{ }^{\circ} \mathrm{C}$, then washed with $75 \%$ ethanol, and centrifuged for an additional 10 minutes at $4{ }^{\circ} \mathrm{C}$. The supernatant was 
aspirated and the DNA pellet was allowed to dry for at least 6 hours. DNA was re-suspended in DEPC-treated, DNase free water (Ambion) and run on a 1.5\% agarose gel. Bands of 100-300 base pairs in length indicated a successful sonication cycle. After ensuring adequate shearing of the chromatin, $2 \mu \mathrm{g}$ of antibody to the protein of interest or $2 \mathrm{ug}$ of isotype control was then added to equal amounts of sheared chromatin diluted four-fold with ChIP buffer and rotated overnight at $4{ }^{\circ} \mathrm{C}$. The next day $20 \mu \mathrm{L}$ of isotype matched Dynabeads (Life Technologies) were added and rotated for another 2 hours. Beads were then washed with $1 \mathrm{~mL}$ cold ChIP buffer five times using the DynaMag-2 Magnet (12321D, Invitrogen), rotating for 5 minutes at $4^{\circ} \mathrm{C}$ between washes. $100 \mu \mathrm{L}$ of $10 \%$ Chelex 100 slurry was added to the beads and boiled for 10 minutes. 1 $\mu \mathrm{g}$ of RNase A was added and incubated at $65^{\circ} \mathrm{C}$ for 15 minutes minimum followed by addition of $2 \mu \mathrm{g}$ Proteinase $\mathrm{K}$ for 30 minutes at $65^{\circ} \mathrm{C}$. The samples were boiled again for 10 minutes to inactivate Proteinase $\mathrm{K}$, and then centrifuged at $12,000 \mathrm{x} \mathrm{g}$ for one minute, $4^{\circ} \mathrm{C}$. The supernatant $(70 \mu \mathrm{L})$ was transferred to a new tube and the remaining Chelex resin was washed with $130 \mu \mathrm{L}$ water, re-spun, and resulting supernatant added to the first one. $10 \%$ of the chromatin used for the IP was reserved as input for the qPCR reaction. DNA from inputs was extracted using the same method to determine sonication efficiency. $10 \mu \mathrm{L}$ of the immunoprecipitated DNA or DNA purified from inputs was used per reaction for quantitative PCR and run on the CFX96 Real Time PCR Detection System as previously described. The Cq values were normalized to percentage of input. Antibodies used in these studies: rabbit control IgG and ROR $\gamma \mathrm{t}$ (Abcam)

\section{Lipidomics}

Mouse naïve CD4+ T cells were isolated, activated, and differentiated towards the Th17 lineage as previously described from mice fed standard chow with and without TMG treatment. After 
four days of culture, cells were re-stimulated with plate-bound anti-CD3 and anti-CD28 for 8 hours before harvesting, washing with PBS, and snap-freezing the cell pellet.

Lipid extraction. Frozen cell pellets were subjected to monophasic lipid extraction in methanol : chloroform : water (2: $1: 0.74, \mathrm{v}: \mathrm{v}: \mathrm{v})$ as previously described (49). During lipid extraction, each sample was spiked with synthetic di-myristoyl phosphatidylcholine obtained from Avanti Polar Lipids (Alabaster, AL), and D7-cholesterol obtained from Steraloids (Newport, RI) at 1 nmole/mg protein as an internal standard for relative quantitation of lipids and sterols. Dried lipid extracts were washed three times with $10 \mathrm{mM}$ ammonium bicarbonate, dried under vacuum, and resuspended in methanol containing $0.01 \%$ butylated hydroxytoluene. Samples were stored under a blanket of nitrogen at -80 degrees Celsius until further analysis.

Global Lipidomics Analysis. For each analysis, lipid extracts were transferred to an Eppendorf twin-tec 96-well plate (Sigma Aldrich, St. Louis, MO), and evaporated under nitrogen. The dried lipid film was then resuspended in isopropanol:methanol:chloroform (4:2:1 v:v:v) containing 20 $\mathrm{mM}$ ammonium formate and sealed with Teflon Ultra Thin Sealing Tape (Analytical Sales and Services, Pompton Plains, NJ). Appropriate sample dilution to minimize ion suppression effects was determined as previously described (49). Global lipidomics analysis was performed by direct infusion high resolution/accurate mass spectrometry and tandem mass spectrometry. Samples were introduced to the mass spectrometer by nanoelectrospray ionization (nESI) using an Advion Triversa Nanomate nESI source (Advion, Ithaca, NY) with a spray voltage of $1.4 \mathrm{kV}$ and a gas pressure of 0.3 psi. A Thermo Scientific LTQ-Orbitrap Velos (San Jose, CA) mass spectrometer was used for lipid detection. High resolution MS and MS/MS spectra were acquired for each sample in positive and negative ionization modes using the Orbitrap FT analyzer operating at 100,000 mass resolving power (defined at $\mathrm{m} / \mathrm{z} 400$ ). 
Analysis of Free and Total Sterol Content. Sterols and oxysterols were analyzed by high resolution/accurate mass LC-MS using a Shimadzu Prominence HPLC equipped with an in-line solvent degassing unit, autosampler, column oven, and two LC-20AD pumps, coupled to a Thermo Scientific LTQ-Orbitrap Velos mass spectrometer. Lipid extracts were used directly for analysis of 'free' sterols, or subjected to alkaline hydrolysis of sterol esters for analysis of total cellular sterols as previously described (50). Ten microliter injections of each total or hydrolyzed lipid extract were separated using a Phenomenex (Torrance, CA) Synergi Hydro-RP C18 column, $2 \mathrm{~mm} \times 150 \mathrm{~mm}$, with 3 micron particles and 80 micron pore size, at 50 degrees Celsius. The gradient elution method was modified from (50) and utilized A: water containing $0.1 \%$ formic acid and B: methanol containing $0.1 \%$ formic acid, with a 13 minute gradient from $85 \%$ $\mathrm{B}$ to $100 \% \mathrm{~B}$ at a flow rate of 250 microliters/minute. The column eluent was introduced to the LTQ-Orbitrap Velos by a heated electrospray ionization source, using a spray voltage of $4.5 \mathrm{kV}$, sheath gas pressure of $30 \mathrm{psi}$, and auxillary gas pressure of $10 \mathrm{psi}$. The source heater and MS capillary inlet tube were held at 350 degrees Celsius. Sterols and oxysterols were analyzed by full scan positive ion mode MS using the Orbitrap detector at a resolution of 60,000 (defined at $\mathrm{m} / \mathrm{z} 400)$, to detect sterol in-source fragmentation derived $\left[\mathrm{M}-\mathrm{H}_{2} \mathrm{O}+\mathrm{H}\right]^{+}$and $\left[\mathrm{M}-2 \mathrm{H}_{2} \mathrm{O}+\mathrm{H}\right]^{+}$ions, which were the most abundant sterol ions formed under the conditions utilized. Targeted high resolution HCD-MS/MS at 45\% normalized collision energy was employed on known sterolrelated ions and their product ions (50) to verify the identity of each sterol peak.

Peak finding, analyte identification, and quantification. For global lipidomics analysis, lipids were identified using the Lipid Mass Spectrum Analysis (LIMSA) v.1.0 software linear fit algorithm, in conjunction with a user-defined database of hypothetical lipid compounds for automated peak finding and correction of ${ }^{13} \mathrm{C}$ isotope effects. Relative quantification of lipid 
abundance between samples was performed by normalization of target lipid ion peak areas to the di-myristoyl phosphatidylcholine internal standard as previously described (51). For free and total sterol analysis, chromatographic peak alignment, compound identification, and relative quantitation against the D7-cholesterol internal standard was performed using MAVEN software (52).

\section{Mass spectrometry}

Mouse naïve CD4+ T cells were isolated, activated, and differentiated towards the Th17 lineage as previously described from mice fed standard chow. After 4 days of culture, cells were harvested, lysed, and ACC1 was immunoprecipitated as previously described. Immune-purified complexes bound to agarose beads were trypsin-digested as previously described (53).

LC-MS analysis. Following enzymatic digestion, the resulting peptides were concentrated on a centrivac concentrator (Labconco) to a final volume of $20 \mu \mathrm{L}$. The peptide extracts were analyzed using an Orbitrap Fusion Lumos mass spectrometer (Thermo Fisher Scientific) coupled to an uHPLC (nLC 1200, Thermo Fisher Scientific). In each run, the sample was injected directly into the reversed phase column (Acclaim PepMap RSLC, $50 \mu \mathrm{m}$ x $15 \mathrm{~cm}, \mathrm{C} 18$ reversed phase $2 \mu \mathrm{m}, 100 \AA$ ), and washed with $0.1 \%$ formic acid for 5 minutes at $500 \mathrm{nl} / \mathrm{min}$. The column was mounted on the electrospray stage of the mass spectrometer, and the peptides were eluted with a gradient of acetonitrile (solvent B: $90 \%$ acetonitrile, $0.1 \%$ formic acid) in $0.1 \%$ formic acid in water (solvent A). The gradient profile was as follows: $0-5 \mathrm{~min}, 5-15 \% \mathrm{~B} ; 5-60 \mathrm{~min}, 15-$ $40 \% \mathrm{~B} ; 60-70 \mathrm{~min}, 40 \% \mathrm{~B} ; 70-75 \mathrm{~min}, 40-75 \% \mathrm{~B} ; 75-83 \min 75 \% \mathrm{~B}$. At the end of each chromatographic run, the column was washed with $100 \% \mathrm{~B}$. The flow rate was maintained at $300 \mathrm{nl} / \mathrm{min}$. 
MS Acquisition. The mass spectrometer was operated in positive ionization mode with a nanospray flex ionization source operated at $2.6 \mathrm{Kv}$ and source temperature at 250. Multiple runs were performed using different fragmentation methods as described below. The instrument was operated in data-dependent acquisition mode, with full MS scans over a mass range of $\mathrm{m} / \mathrm{z} 350-1900$ with detection in the Orbitrap (120 K resolution) and with auto gain control (AGC) set to 100,000. In each cycle of data-dependent acquisition analysis, following each survey scan, the most intense ions above a threshold ion count of 30,000 were selected for fragmentation at normalized collision energy of $28 \%$ (HCD) or $35 \%$ (CID). The number of selected precursor ions for fragmentation was determined by the "Top Speed" acquisition algorithm and a dynamic exclusion of $60 \mathrm{~s}$. Fragment ion spectra were acquired in the linear IT, with an AGC of 4,000 and a maximum injection time of $300 \mathrm{~ms}$ for IT MS2 detection. For ETD fragmentation, calibrated charge dependent ETD parameters were enabled to determine ETD reagent ion AGC and ETD reaction times, and all MS/MS were mass analyzed in the Orbitrap with a resolution of $15,000 \mathrm{~K}$ at $200 \mathrm{~m} / \mathrm{z}$. All data were acquired with Xcalibur software v3.0.63 (Tune v2.0 1258).

Data analysis. For data analysis all MS/MS scans were searched using Proteome Discoverer (version 2.2, Thermo Fisher Scientific) running the Sequest HT algorithm. A database search was conducted against a human protein database derived from the NIBInr repository as in January 9,2017 . The refined data were subjected to database search using trypsin cleavage specificity, with a maximum of 2 missed cleavages. The following variable modifications were selected: pyroglutamination from $\mathrm{Q}$ and $\mathrm{E}$ (N-terminal), oxidation of $\mathrm{M}$, and deamidation of $\mathrm{N}$, Q. Carboxymethylation of $\mathrm{C}$ was selected as a fixed modification. HexNac was selected as variable modification. A maximum of 3 modifications/peptide was allowed. Estimation of false 
positive rate (FDR) was conducted by searching all spectra against a decoy database consisting of the inverted sequences of all proteins in the original (direct) database. For peptide identification a FDR $£ 1$ was defined and a minimum of two unique peptides per protein was required for protein identification. Amino acid sequence assignment of all peptides of interest was subsequently inspected manually.

\section{Human $\mathbf{T}$ cell isolation, activation, and differentiation}

Human whole blood samples were obtained with consent from patient volunteers by the Biospecimen Repository Core Facility (BRCF) at the University of Kansas Medical Center. Inclusion criteria for volunteers was a body mass index (BMI, calculated as weight in kilograms/height in meters squared) between 18-30 and no prior type 1 or type 2 diabetes diagnoses. Exclusion criteria for samples included patient history of or current immunotherapy for cancer, autoimmune disorder, or current use of steroids or immune-modifying drugs (i.e. methotrexate). Whole blood was diluted 1:1 with PBS and gently layered on top of Lymphocyte Separation Medium (Corning) and then centrifuged at 2,000 x $\mathrm{g}$ for 15 minutes at room temperature with the lowest level of brake. Samples of plasma were collected and snap frozen, and the remaining plasma was aspirated. The white blood cell layer was collected and washed twice with PBS. CD4+ T cells were isolated from the washed white blood cell layer using antihuman CD4 particles (BD Biosciences). Naïve CD4+ T cells were obtained by staining CD4+ cells with mouse anti-human CD45RA and mouse anti-human CD197 (CCR7) (BD Biosciences) for 30 minutes on ice, washing with PBS $+2 \% \mathrm{FBS}$, and then sorting for the double-positive population of cells. Unsorted CD4+ T cells and naïve cells were treated with TMG or vehicle for 6 hours before activation with anti-CD3 and anti-CD28 conjugated beads from the Human T Cell Activation/Expansion Kit (Miltenyi). Cells were cultured in RPMI-1640 media (Sigma) 
containing 10\% FBS (Gemini), 1\% penicillin-streptomycin (Life Technologies), $2 \mathrm{mM}$ GlutaMAX (Life Technologies), $10 \mathrm{mM}$ HEPES, $1 \mathrm{mM}$ sodium pyruvate, and $1 \mathrm{mM}$ MEM nonessential amino acids (Sigma). Unsorted CD4+ T cells and naïve CD4+ T cells were cultured under both Th0 (no polarizing cytokines added) or Th17 conditions (human IL-6 (50 ng/mL), human IL-1 $\beta(10 \mathrm{ng} / \mathrm{mL})$, human IL-23 (10 ng/mL), human TGF $\beta 1$ (3 ng/mL) (all Miltenyi), and neutralizing antibodies to IFN $\gamma$ (clone: XMG1.2) and IL-4 (clone: 11B11) at $10 \mu \mathrm{g} / \mathrm{ml}$ (Bio X Cell)). All cells were incubated at $37^{\circ} \mathrm{C}$ in $5 \% \mathrm{CO} 2$ in a $95 \%$ humidified incubator. On day 3 of culture, $20 \mathrm{ng} / \mathrm{mL}$ of human IL-2 (Miltenyi) was added to cells per the expansion kit protocol. On day 7 of culture, cells and supernatants were harvested. IL-17A levels in supernatants were quantified using a human IL-17A ELISA (Invitrogen) and normalized to number of cells present at day 7. Protein and RNA was harvested from cells and used for western blotting or qPCR analyses respectively as previously described.

\section{Statistics}

Student's T test was performed to compare means between two groups. A p value less than 0.05 was considered statistically significant $(*)$, less than $0.01(* *)$, and less than $0.001(* * *)$. Standard deviation or standard error of the mean is used for error bars as indicated in figure legends.

\section{Primer Tables}

Mouse primers

\begin{tabular}{|l|l|l|}
\hline & Forward $\left(5^{\prime} \rightarrow 3^{\prime}\right)$ & Reverse $\left(5^{\prime} \rightarrow 3^{\prime}\right)$ \\
\hline HPRT & GGCCAGACTTTGTTGGATTTG & CGCTCATCTTAGGCTTTGTATTTG \\
\hline
\end{tabular}




\begin{tabular}{|l|l|l|}
\hline IL-17A & CGCAATGAAGACCCTGATAGAT & CTCTTGCTGGATGAGAACAGAA \\
\hline IL-23R & GAGCCAGACAGCAAGTATGT & CAGTTTCTTGGGAAGTTTGGTG \\
\hline IFN $\gamma$ & GGCCATCAGCAACAACATAAG & GTTGACCTCAAACTTGGCAATAC \\
\hline IL-4 & GAAGAACACCACAGAGAGTGAG & TGCAGCTCCATGAGAACAC \\
\hline IL-5 & CCCAACCTTAGCATCCTTTCT & AGGGAGTTGAGGAGAGATTGA \\
\hline IL-10 & TGCACTACCAAAGCCACAA & GATCCTCATGCCAGTCAGTAAG \\
\hline RORC & ATCTGGAGGAAGGACAACTTTC & CCTAGGGATACCACCCTTCATA \\
\hline IL-17 & CAGCTCCCAAGAAGTCATGC & GCAACATCTGTCTCGAAGGTAG \\
promoter & & \\
\hline CNS2 & CACATGGACAATGTAATGGATC & CAACTCTAAGAAGCAAACCTAACAC \\
& A & A \\
\hline
\end{tabular}

Human Primers

\begin{tabular}{|l|l|l|}
\hline & Forward $\left(5^{\prime} \rightarrow 3^{\prime}\right)$ & Reverse $\left(5^{\prime} \rightarrow 3^{\prime}\right)$ \\
\hline HPRT & CTTTCCTTGGTCAGGCAGTATAA & AGTCTGGCTTATATCCAACACTTC \\
\hline IL-17A & ACCGGAATACCAATACCAATCC & GGATATCTCTCAGGGTCCTCAT \\
\hline IL-23R & GCTGGTGTCATGGAGGAATTA & TTCCTTGGTTGGCAGTTCTTA \\
\hline IFN $\gamma$ & ATGTCCAACGCAAAGCAATAC & ACCTCGAAACAGCATCTGAC \\
\hline
\end{tabular}




\section{CHAPTER 3: RESULTS}

\section{In murine CD4+ $\mathrm{T}$ cells, pharmacological elevation of O-GIcNAc increases pro- inflammatory IL-17A and IFN $\gamma$ cytokines, while having no effect on anti-inflammatory IL- 10 and IL-4 cytokines.}

To determine if O-GlcNAc plays a role in the function of $\mathrm{T}$ cell effectors, we treated murine splenic CD4+ T cells with Thiamet-G (TMG), a highly specific OGA inhibitor (54), for 6 hours before activation under non-polarizing conditions (termed Th0). Six hours allows for total cellular level of O-GlcNAc to become prominently increased, and thus will provide information on how $\mathrm{T}$ cell effector function is altered under abnormally elevated O-GlcNAc levels. TMG treatment led to elevated O-GlcNAc levels over the four days of cell culture (Figure 1A). As has been previously observed $(55,56)$, levels of OGT decrease and levels of OGA increase in response to elevated O-GlcNAcylation in an attempt to restore steady state levels of O-GlcNAc. This is a well-described compensatory phenomenon, suggesting cells have a particular level of O-GlcNAcylation that is ideal for their function. Interestingly, re-stimulation of CD4+ T cells after 4 days of culture appears to "reset" or promote a restoration of the homeostatic level of OGlcNAc, OGT, and OGA. Although the TMG treated cells still had elevated O-GlcNAc levels on day 5, the level decreased dramatically, while activation in the untreated cells increased OGlcNAc levels - a phenomenon which confirms previous reports $(2,57)$. These results suggest a critical level of O-GlcNAc is essential for T cell activation and demonstrate the effect of TMG 
on O-GlcNAc, OGT, and OGA over the course of CD4+ T cell differentiation and proliferation.
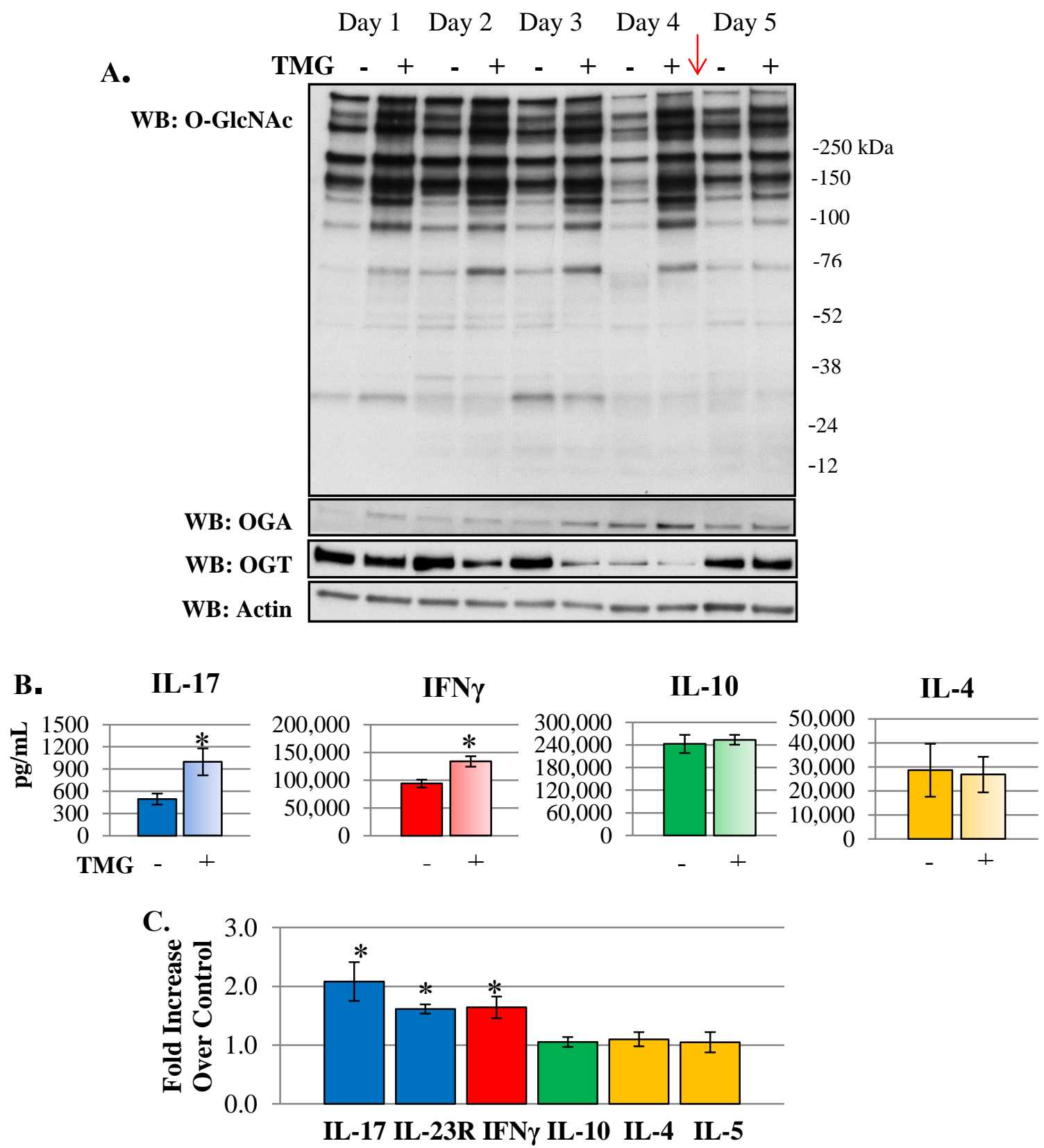

D.

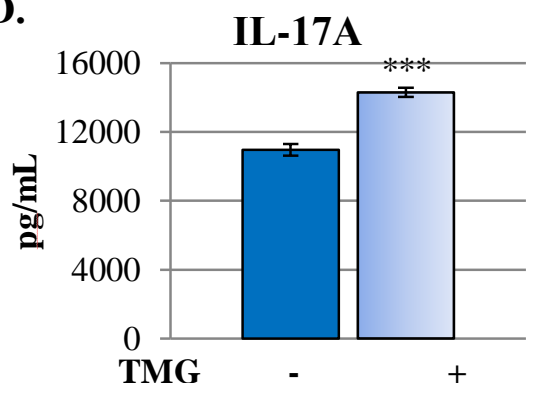

E.

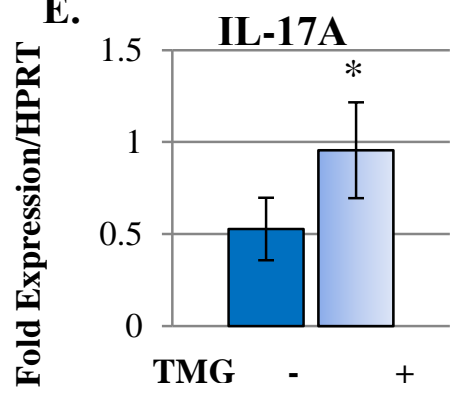




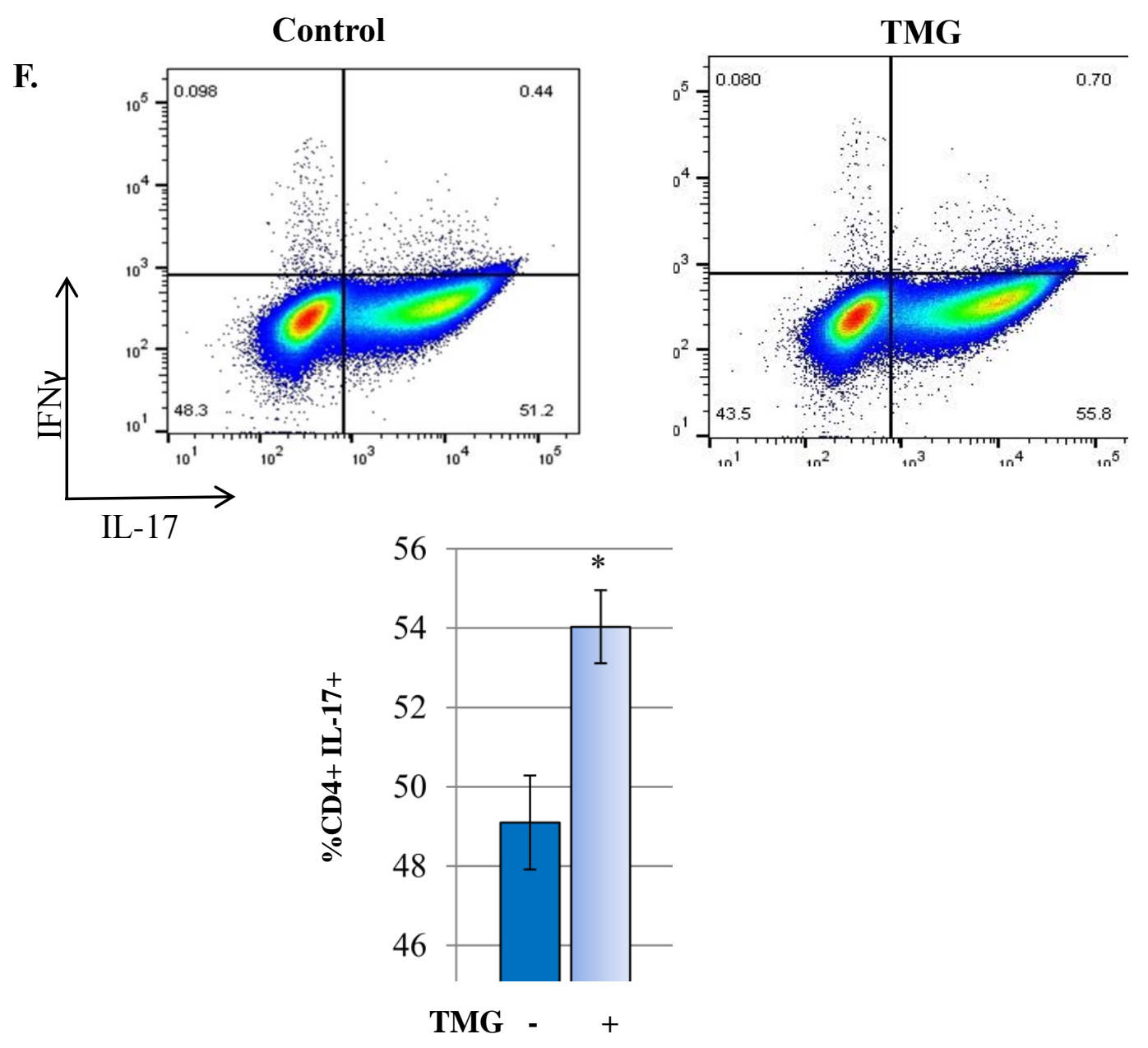

Figure 1. In murine CD4+ $T$ cells, pharmacological elevation of O-GlcNAc increases pro-inflammatory IL-17A and IFN $\gamma$ cytokines, while having no effect on antiinflammatory IL-10 and IL-4 cytokines. A. TMG treatment increases O-GlcNAc levels over the course of $\mathrm{CD} 4+\mathrm{T}$ cell differentiation and proliferation with corresponding decreases in O-GlcNAc transferase (OGT) and increases in O-GlcNAcase (OGA). The red arrow indicates the time of re-stimulation. B. Protein levels of cytokines secreted from CD4+ T cells with and without TMG treatment. C. Transcript levels of cytokines secreted from CD4+ T cells with and without TMG treatment. D. Protein level of IL-17A in naïve cells treated with and without TMG and polarized to the Th17 lineage. E. Transcript level of IL-17A in naïve cells treated with and without TMG and polarized to the Th17 lineage. F. Representative histogram showing CD4+ IL-17+ cells are significantly increased with TMG treatment. $25 \mathrm{~K}$ cells plotted per condition. Dead cells were excluded. Bars represent mean $+/-$ SEM of 5 biological replicates in B. and C. and 3 different biological replicates in D.-F.; $* \mathrm{p}<0.05, * * * \mathrm{p}<0.001$

After activated CD4+ T cells differentiated and proliferated over the course of four days and cells were re-stimulated, supernatants were harvested 24 hours later. The levels of key cytokines 
produced by the four main effector types (Th1, Th2, Th17, and iTreg) were analyzed by ELISA. Strikingly, IL-17A, the major cytokine secreted by Th17 cells, doubled (Figure 1B). Additionally, IFN $\gamma$, the major cytokine secreted by Th1 cells was also significantly increased. However, IL-4 and IL-10, cytokines predominantly produced by the Th2 and iTreg lineages respectively, showed no significant changes. Since both IL-17A and IFN $\gamma$ are pro-inflammatory cytokines and IL-4 and IL-10 have immunomodulatory functions, this suggests that elevated OGlcNAcylation promotes increased inflammatory function of CD4+ T cells, while having no significant effect on the anti-inflammatory function. Transcript levels of IL-17A, IFN $\gamma$, IL-4, and IL-10 followed similar trends to protein levels (Figure 1C). Additionally, another critical Th17 marker, IL-23 receptor (IL-23R), was also significantly increased. IL-23 binding and signaling through IL-23R stabilizes the Th17 phenotype $(58,59)$ and is also a marker of pathogenic Th17 function (60). Overall, markers of Th17 function are increased with elevated O-GlcNAcylation.

Th17 cells compose less than $1 \%$ of $\mathrm{CD} 4+\mathrm{T}$ cells in the peripheral blood (61). To investigate the mechanism of O-GlcNAc's regulation of Th17 function, we sought to obtain a more homogenous population of Th17 cells. Thus, we isolated murine splenic naïve CD4+ T cells $\left(\mathrm{CD} 62 \mathrm{~L}^{\mathrm{hi}} \mathrm{CD} 44^{\mathrm{lo}}\right)$ and then treated with and without TMG before activation and polarization towards the Th17 lineage. Potentially, polarization would overcome the effect of TMG we previously observed with a mixed population of CD4+ T cells. However, even with polarization towards a Th17 lineage, TMG treatment still significantly increased both protein and transcript IL-17A levels (Figure 1D and 1E). Intracellular cytokine staining showed a significant but modest increase in CD4+IL-17+ cells, suggesting there may be some effect on differentiation as well as functional cytokine output (Figure 1F). 


\section{In human CD4+ T cells, pharmacological elevation of O-GIcNAc increases pro- inflammatory IL-17A cytokine levels in addition to transcript levels of genes under ROR $\gamma t$ transcriptional control.}

Th17 cells infiltrate adipose tissue to a greater extent in obese humans (62) and secrete more IL17A, contributing to adipose insulin resistance (63). Thus, we wanted to determine if TMG treatment increased IL-17A from human CD4+ T cells. We obtained fresh venous whole blood from human volunteers through the Biospecimen Repository Core Facility (BRCF) at the University of Kansas Medical Center. Healthy volunteers were defined by a non-obese BMI (between 18 and $30 \mathrm{~kg} / \mathrm{m}^{\wedge} 2$ ) and no previous type 1 or type 2 diabetes diagnoses. Volunteers were excluded if they had a history of autoimmunity or past or current treatment with immunemodifying agents (i.e. immunotherapy for cancer treatment). Further characteristics of volunteers, including gender, age, and ethnicity, are detailed in Table $\mathbf{1 .}$

\begin{tabular}{ll}
\hline Table 1. Human Volunteer Characteristics \\
\hline Female (\%) & $8 / 9(88.9)$ \\
\hline White, Non-Hispanic (\%) & $8 / 9(88.9)$ \\
\hline Mean age (range) & $53(34-80)$ \\
\hline Mean BMI (range) & $22.6(18.9-26.4)$
\end{tabular}

CD4+ T cells were isolated from blood and treated with and without TMG before activation under Th0 and Th17 conditions. IL-17A significantly increased with elevated O-GlcNAc levels under both Th0 and Th17 polarizing conditions, recapitulating the results seen in mice (Figure 2A). Since Th17 function in human CD4+ T cells was also sensitive to changes in O-GlcNAc, we isolated naïve CD4+ T cells $\left(C D 45 R A^{\text {hi }} C C R 7^{\text {hi }}\right)$ from the blood, treated with and without TMG before activation, and polarized towards the Th17 lineage. Again, increasing O-GlcNAc trended towards increased IL-17A secretion from naïve CD4+ T cells polarized to the Th17 
lineage (Figure 2B). Next we compared transcript levels of IL-17A and other pro-inflammatory cytokine markers, such as IL-23R and IFN $\gamma$, with and without TMG treatment in the CD4+ T cell population polarized to Th17 lineage. IL-17A and IL-23R, both transcriptional targets of ROR $\gamma \mathrm{t}$, and IFN $\gamma$, the main pro-inflammatory cytokine from Th1 cells, were significantly increased with elevated O-GlcNAcylation (Figure 2C). Thus, we have demonstrated a clear effect of elevated O-GlcNAc levels on regulating pro-inflammatory cytokine signalingparticularly IL-17- the major cytokine that mediates the function of Th17 cells. 

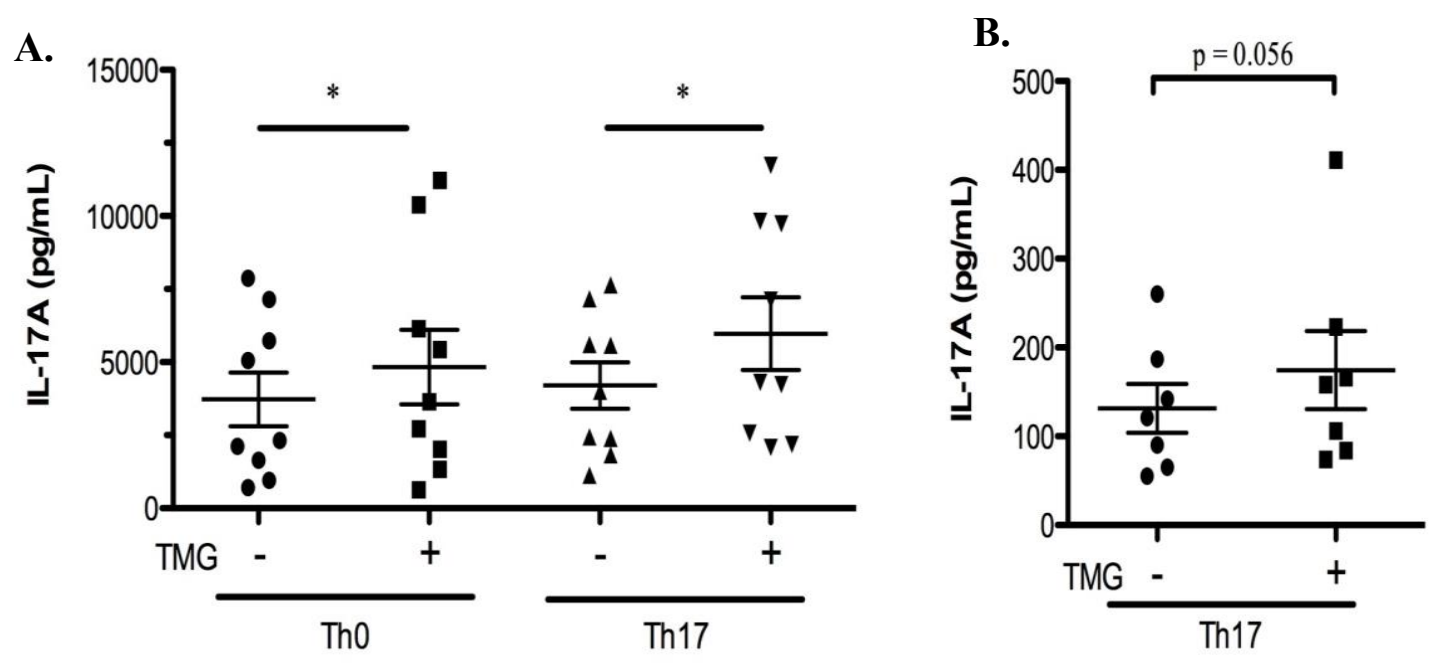

C.

IL-17

IL-23R

IFNY
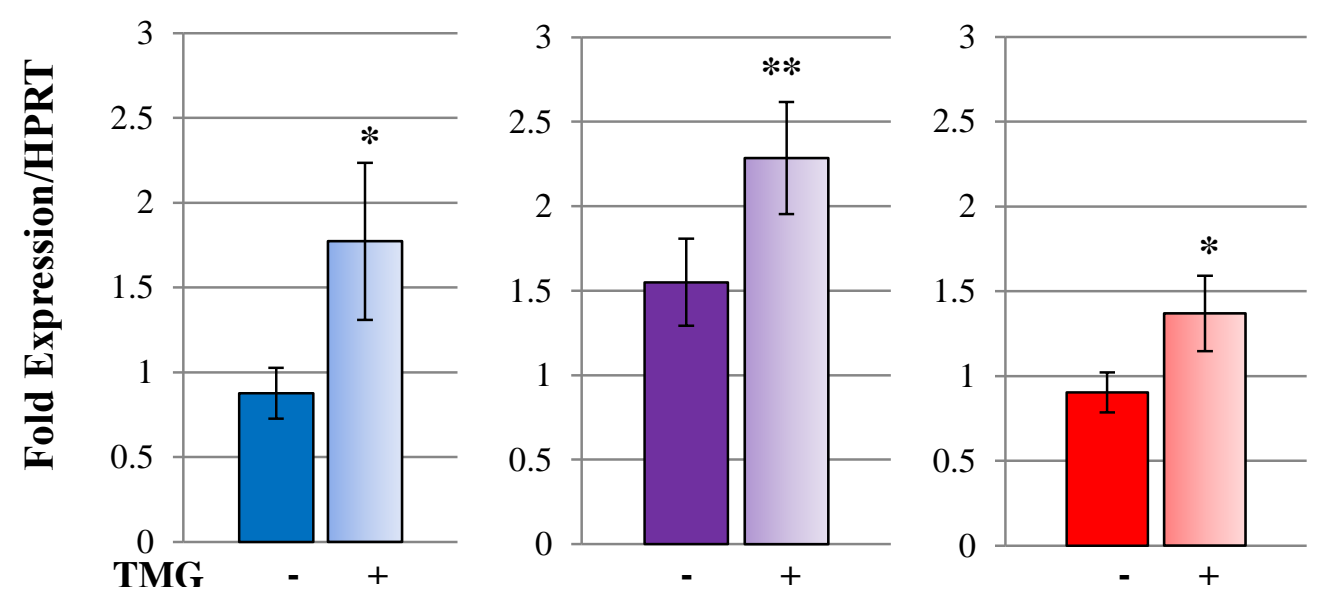

Figure 2. In human CD4+ $T$ cells, pharmacological elevation of O-GIcNAc increases pro-inflammatory IL-17A cytokine levels in addition to transcript levels of genes under RORyt transcriptional control. A. TMG treatment increases IL-17A secretion from human CD4+ cells polarized under Th0 and Th17 conditions. B. TMG treatment trends toward increased IL-17A secretion from human naïve (CD45RA ${ }^{\text {hi }}$ CCR7 ${ }^{\text {hi }}$ ) CD4+ cells polarized under Th17 conditions. C. IL-17, IL-23R, and IFN $\gamma$ transcript levels all significantly increase with TMG treatment. Bars represent mean $+/$ - SEM of 9 and 7 human donors in A. and B. respectively and mean $+/$ SEM of 7 human donors in $\mathrm{C} . ; * \mathrm{p}<0.05,{ }^{* *} \mathrm{p}<0.01$ 


\section{Western diet feeding in mice results in elevated O-GIcNAc levels in naïve CD4+ T cells and increases IL-17A secretion from naïve CD4+ T cells, which is exacerbated by TMG treatment.}

The previous data provide evidence that elevated O-GlcNAc increases pro-inflammatory cytokine production from CD4+ T cells. To investigate the physiological relevance of this effect in a disease model, we utilized a diet-induced obese mouse model (DIO). A DIO model was chosen because 1.) IL-17A is increased in the serum of obese mice and humans (64) and contributes to chronic low-grade inflammation that drives downstream pathology $(65,66)$, and 2.) O-GlcNAc levels are sensitive to the nutritional state of the host and thus we would expect them to be elevated in a DIO model, phenocopying the effects of TMG in our in vitro studies. To test this hypothesis, we fed C57BL/6 male mice a high fat and cholesterol "Western" diet (WD) chow for 16 weeks. As expected, WD fed mice gained significantly more weight and their blood glucose was significantly elevated 15 weeks after initiation of the diet compared to mice fed standard chow (SC) (Figure 3A and 3B). Naïve CD4+ T cells (CD62L ${ }^{\text {hi }}$ CD44 $4^{\text {lo }}$ ) isolated from WD fed mice had significantly elevated O-GlcNAc levels compared to SC fed mice (Figure 3C). Interestingly, OGT and OGA levels were not different between WD and SC fed mice, suggesting that elevated O-GlcNAc levels in the WD fed mice reach a new, albeit elevated "set point," where levels of OGT and OGA are not down- or up-regulated respectively to try to maintain typically lower homeostatic O-GlcNAc levels. When naïve CD4+ T cells from WD and SC fed mice were activated and polarized towards a Th17 lineage, cells from WD fed mice secreted more IL-17A as would be expected from previous studies $(64,67)$. Strikingly, when the same naïve CD4+ T cells from WD and SC fed mice were treated with TMG before activation and polarization, cells from SC fed mice secreted levels of IL-17A comparable to cells from WD fed mice and IL-17A secretion from cells from WD fed mice was even further exacerbated 
(Figure 3D). The trends seen with IL-17A transcript levels were similar to the trends seen in protein levels (Figure 3E). Taken together, these results demonstrate that in a type 2 diabetes model, elevated O-GlcNAc levels in $\mathrm{CD} 4+\mathrm{T}$ cells lead to a phenotype similar to
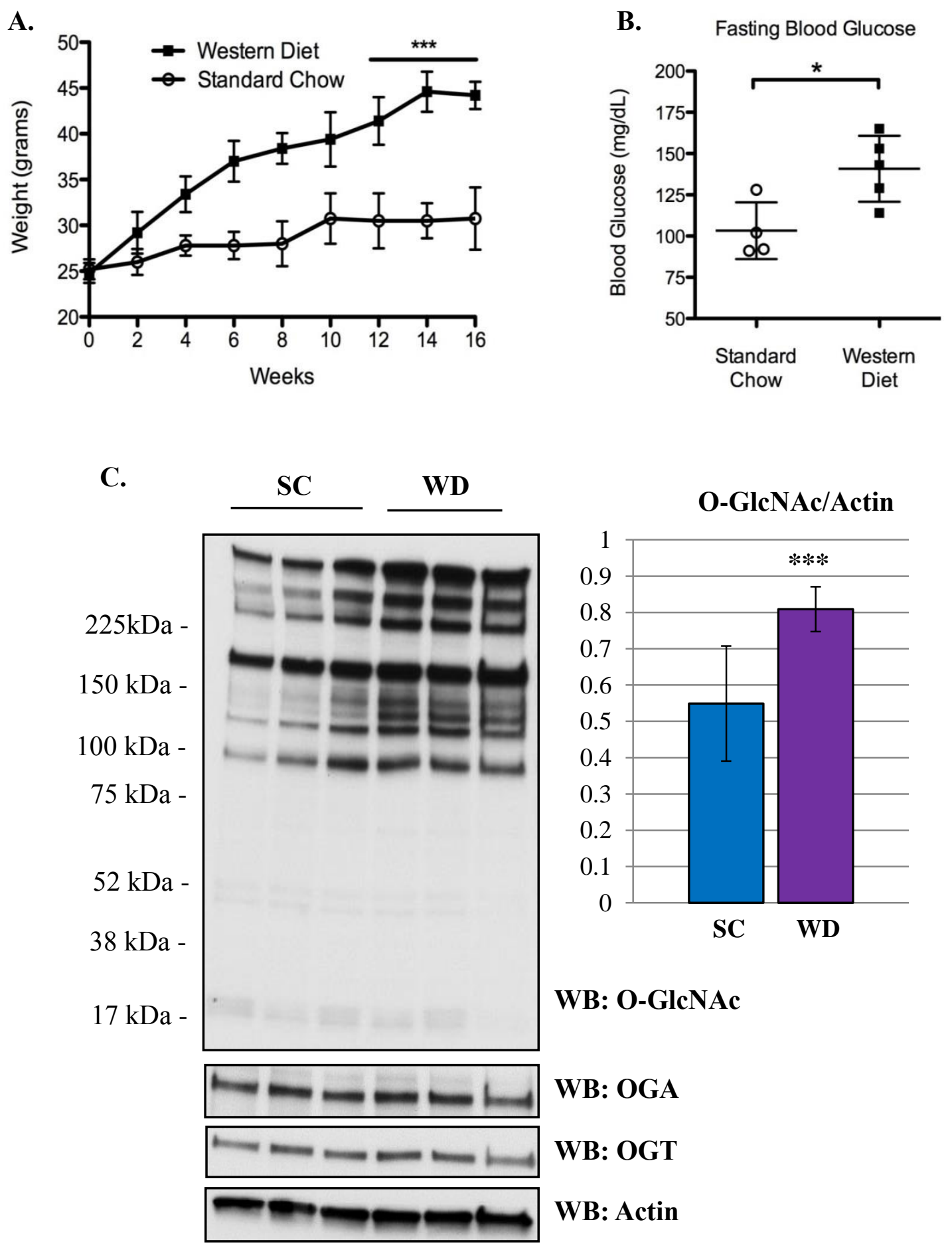

WB: O-GIcNAc

WB: OGA

WB: OGT

WB: Actin 
pharmacological OGA inhibition by TMG. This suggests that O-GlcNAc is a critical regulator of Th17 functional activity and when aberrantly elevated — as in obesity—could contribute to the inflammatory milieu that drives the devastating pathology subsequent to type 2 diabetes.

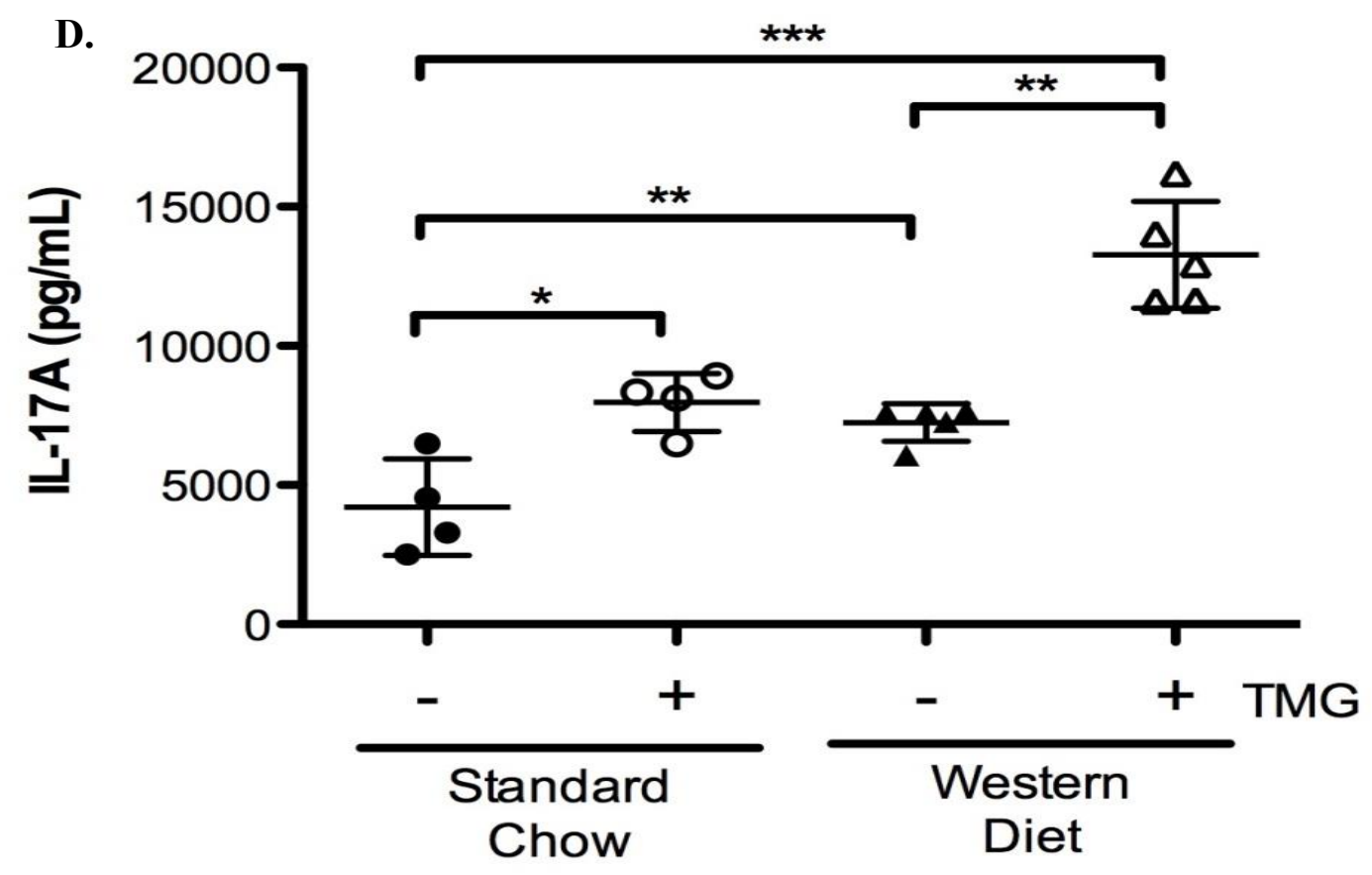

E.

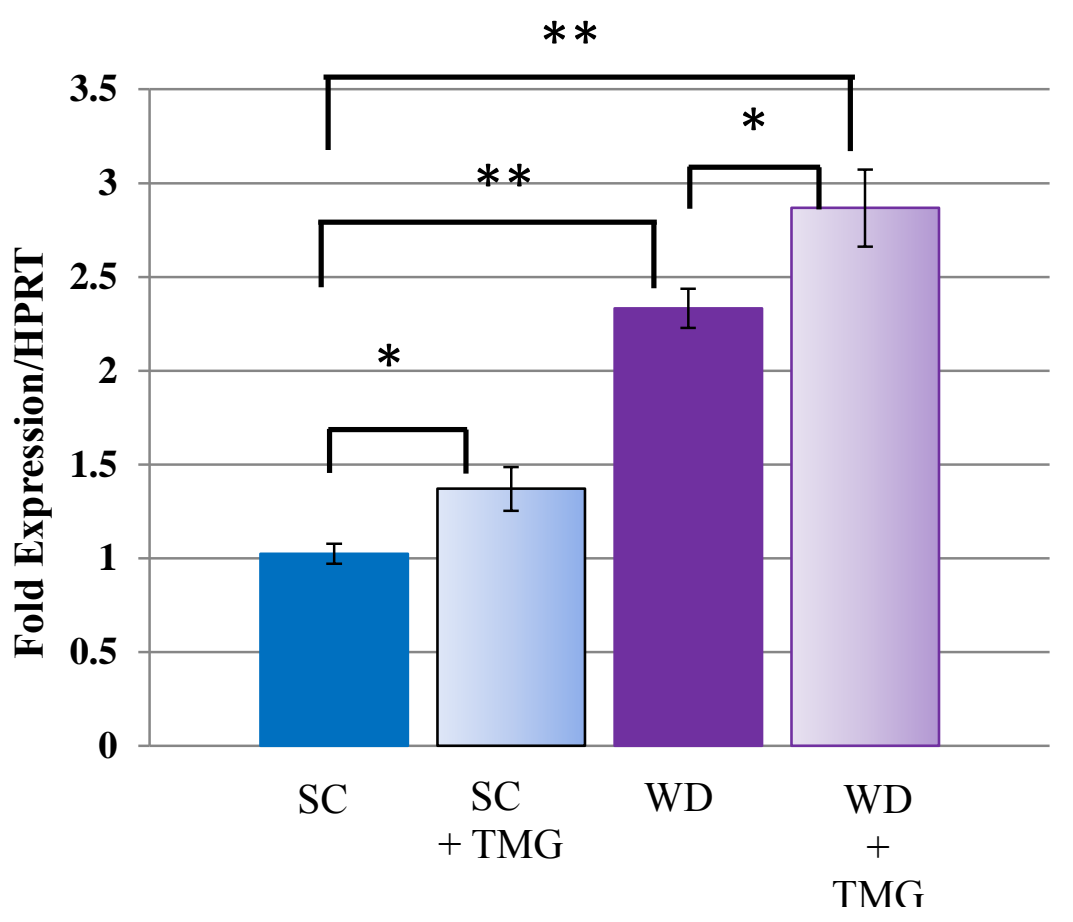


Figure 3. Western diet feeding in mice results in elevated O-GIcNAc levels in naïve CD4+ $T$ cells and increases IL-17A secretion from naïve CD4+ $T$ cells, which is exacerbated by TMG treatment. A. WD feeding results in significantly increased weight gain. B. WD feeding results in significantly elevated fasting blood glucose levels. C. WD fed mice have significantly elevated O-GlcNAc levels. D. Naïve CD4+ $\mathrm{T}$ cells polarized to the Th17 lineage from WD fed mice secrete significantly more IL17A than cells from SC mice. Cells from SC fed mice treated with TMG secrete levels similar to cells from WD mice, and TMG treatment of cells from WD fed mice significantly exacerbates IL-17A secretion. E. IL-17A transcript levels mimic the trends seen with IL-17A protein secretion. In A. and B., points represent average -/+ SD and are calculated from 4 and 5 biological replicates (SC and WD respectively). In C., inset of densitometry is from 8 biological replicates and bars represent mean $-/+$ SD. Each lane in blot represents cell lysate from one mouse. In D. and E. bars represent mean -/+ SEM of 4 and 5 biological replicates (SC and WD respectively). HPRT is used an internal reference for gene expression.

\section{Elevated O-GIcNAcylation has no effect on RORyt protein or transcript levels over the 24 hour period after re-stimulation when increased IL-17 secretion occurs.}

To investigate a mechanism for increased IL-17A secretion under OGA inhibition, we hypothesized that ROR $\gamma \mathrm{t}$ (retinoic acid related orphan receptor, $\mathrm{t}$ splice variant) would be increased with elevated O-GlcNAc levels. ROR $\gamma$ t is the master transcription factor that directs the Th17 lineage and is essential for IL-17A gene transcription. Interestingly, in naïve cells isolated from wild type mice and polarized to the Th17 lineage, we found no differences in ROR $\gamma \mathrm{t}$ by either protein or transcript level in the presence of TMG on the fourth day of cell culture (indicated as " 0 " time point) or over a 24 hour span after re-stimulation (Figure 4A and 4B). Furthermore, we saw no significant differences in $\mathrm{ROR} \gamma \mathrm{t}$ protein or transcript levels at 24 hours after re-stimulation in Th17 differentiated cells from mice fed SC or WD (Figure 4C and 4D). These results suggest that O-GlcNAc neither regulates the stability of ROR $\gamma \mathrm{t}$ or its transcripts nor does O-GlcNAc affect transcription factors required for ROR $\gamma \mathrm{t}$ transcription. 
A.

\begin{tabular}{|c|c|c|c|c|c|c|c|c|c|c|c|c|}
\hline \multicolumn{6}{|c|}{ Th17 - TMG } & \multicolumn{6}{|c|}{ Th17 + TMG } & \multirow[b]{2}{*}{ hours } \\
\hline 0 & 2 & 4 & 8 & 16 & 24 & 0 & 2 & 4 & 8 & 16 & 24 & \\
\hline
\end{tabular}

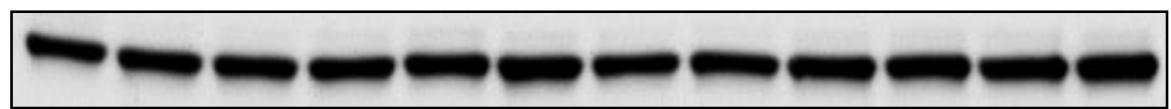

WB: Actin
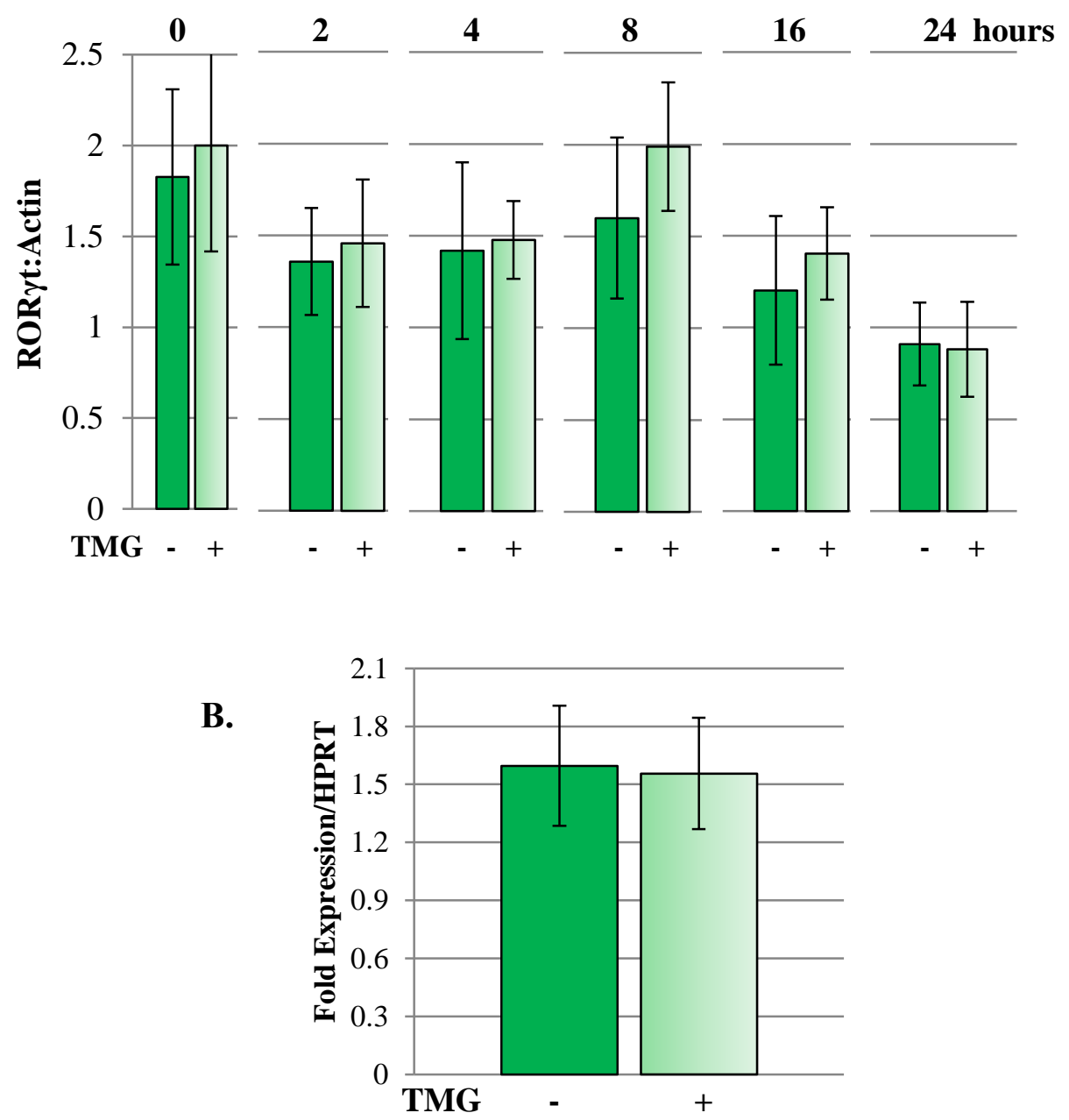

Elevated O-GIcNAcylation does not increase STAT3 levels or alter activating phosphorylation of STAT3. 
Another critical transcription factor involved in the initial differentiation of Th17 cells is STAT3

(signal transducer and activator of transcription 3). Interleukin-6 (IL-6), an essential cytokine for

Th17 differentiation, signals through IL-6 receptor, which activates STAT3 through

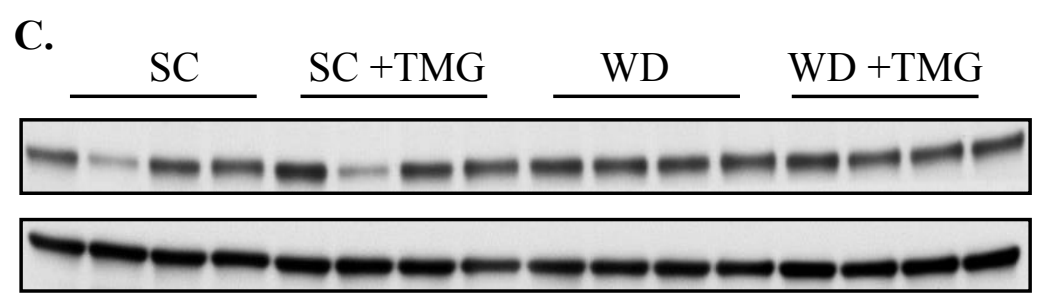

WB: ROR $\gamma \mathrm{t}$

WB: Actin

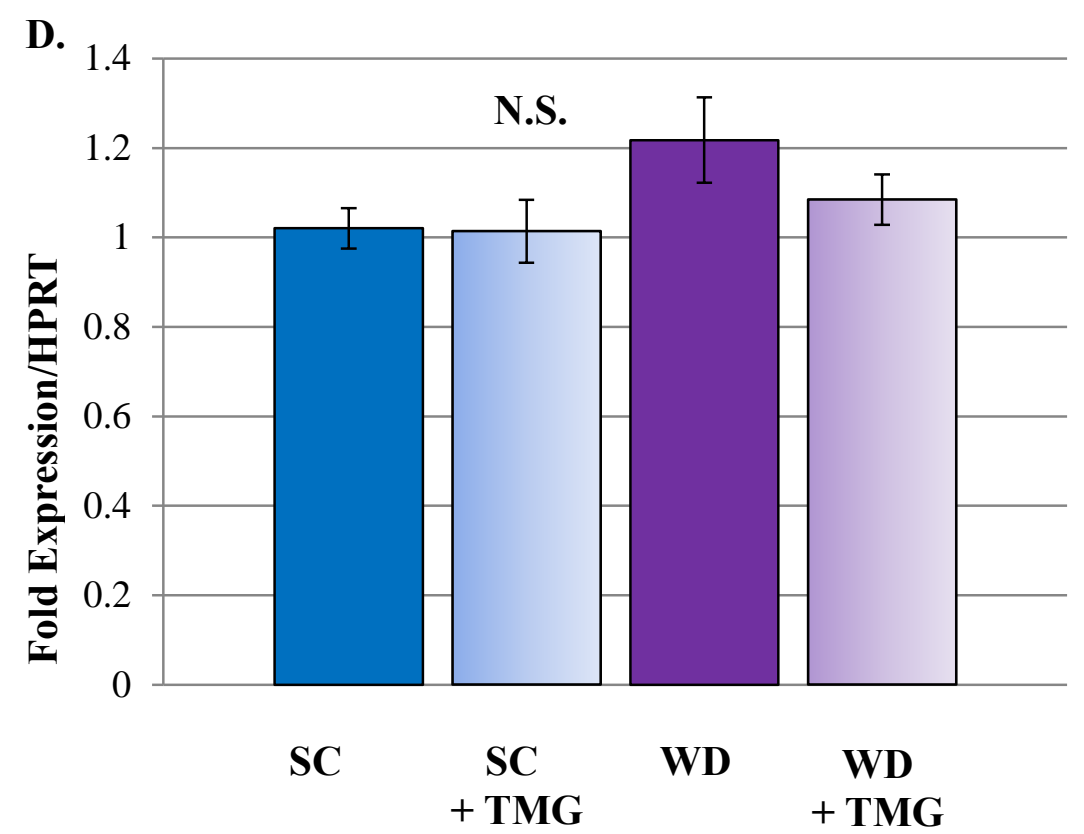

Figure 4. In murine differentiated Th17 CD4+ T cells, pharmacological elevation of O-GlcNAc does not affect ROR $\gamma \mathrm{t}$ protein or transcript levels. A. Prior to restimulation on the fourth day of culture and over 24 hours after re-stimulation, ROR $\gamma \mathrm{t}$ protein levels are unchanged. Densitometry was used to compare ROR $p$ t:actin ratio at specified time points. Blot is representative of 3 biological replicates. Bars represent the mean +/- SEM of 3 biological replicates. B. Transcript levels of ROR $\gamma t$ are unchanged 24 hours after re-stimulation. ROR $\gamma t$ gene expression was normalized to HPRT expression. Bars represent mean $+/$ - SEM of 5 biological replicates. C. ROR $\gamma$ t protein levels are not different between differentiated Th17 cells from SC and WD mice -/+ TMG. Each lane represents cell lysate from one mouse. TMG treated lanes correspond to same mouse as untreated lanes. D. ROR $\gamma \mathrm{t}$ transcript levels are not different between differentiated Th17 cells from SC and WD mice -/+ TMG. Bars represent mean +/-SEM of 4 biological replicates. 
phosphorylation at tyrosine 705 (68). Phospho-STAT3 induces dimerization and translocation to the nucleus and binding of the promoters of various genes essential for the Th17 lineage, including $R O R C$ and $I l 17 a$ genes coding for ROR $\gamma t$ and IL-17A respectively (69). Previously, STAT3 has been identified as being O-GlcNAcylated with the most recent evidence identifying a mono-glycosylated form in human $\mathrm{T}$ cells $(3,70,71)$. Since O-GlcNAc and phosphorylation influence one another (55), we hypothesized that O-GlcNAc regulates STAT3 in our model by enhancing its activating phosphorylation at tyrosine 705 , leading to increased IL-17A transcription. In our hands, we were unable to detect O-GlcNAcylation of STAT3 or phosphoSTAT3 by immunoprecipitation in murine naïve cells polarized to the Th17 lineage ex vivo on the fourth day of cell culture (represented by 0 time point on the Western blot) or 10 minutes after re-stimulation (Figure 5A). It is possible we were unable to detect O-GlcNAcylation that is in fact occurring. However, we also detected no changes in total cellular level of STAT3 or changes in activating phospho-STAT3 with TMG treatment in CD4+ T cells treated with and without TMG over the five days of cell culture (Figure 5B). These results indicate that aberrantly elevated O-GlcNAc is not profoundly affecting STAT3 levels or activity and thus STAT3 is unlikely to be the transcription factor responsible for the increased IL-17 transcription seen with TMG treatment. 


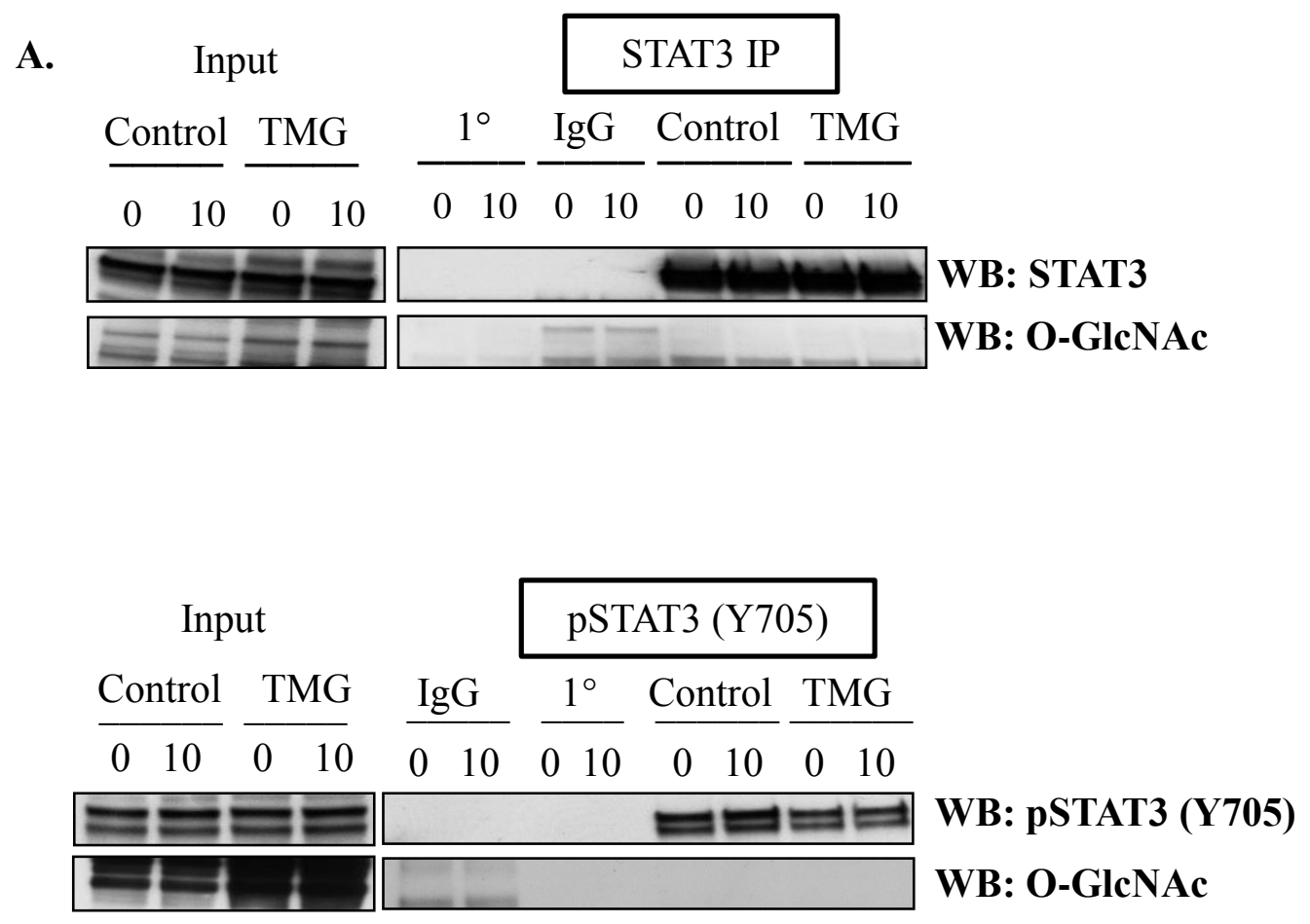

B.

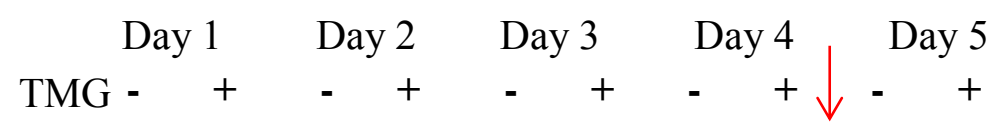
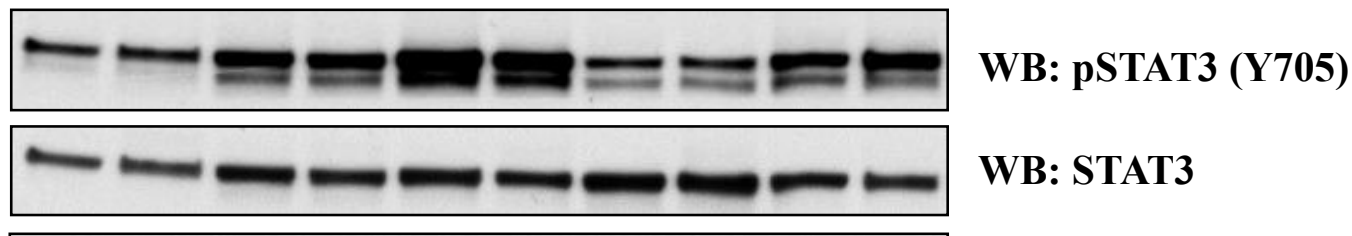

WB: STAT3

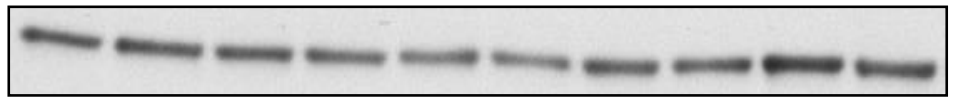

WB: actin

Figure 5. Neither STAT3 nor phospho-STAT3 (Y705) are O-GIcNAcylated and the ratio of pSTAT3:STAT3 does not change with TMG treatment over the course of differentiation. A. STAT3 and pSTAT3 (Y705) are not O-GlcNAcylated. B. pSTAT3:STAT3 ratio does not change with TMG treatment. Blots represent at least 3 replicates.

Elevated O-GIcNAcylation promotes retention of RORyt at the IL-17 locus.

With no apparent effect of elevated O-GlcNAcylation on the levels of two transcription factors arguably most essential for IL-17A transcription, we speculated that ROR $\gamma t$ is being retained at the IL-17A locus - a phenomenon which has been previously observed (23). We performed 
chromatin immunoprecipitation (ChIP) of ROR $\gamma \mathrm{t}$ at the IL-17 promoter and an enhancer, conserved non-coding sequence 2 (CNS-2), which is required for IL-17A transcription (72). TMG treatment resulted in significantly increased ROR $\gamma$ t binding at promoter and enhancer regions in Th17 cells differentiated ex vivo and fixed on the fourth day of cell culture (Figure 6A). O-GlcNAc transferase (OGT) and O-GlcNAcase (OGA) are frequently part of transcriptional complexes and O-GlcNAc cycling is known to be essential for modulation of the activity of many transcription factors (73-77). Potentially, OGT could be O-GlcNAcylating ROR $\gamma \mathrm{t}$ and directly affecting its activity or stability at the IL-17A locus. However, we were unable to detect O-GlcNAcylation of ROR $\gamma$ t by immunoprecipitation (Figure 6B). Thus, TMG treatment appears to promote "locking in" of ROR $\gamma \mathrm{t}$ at the IL-17A promoter and enhancer regions. 

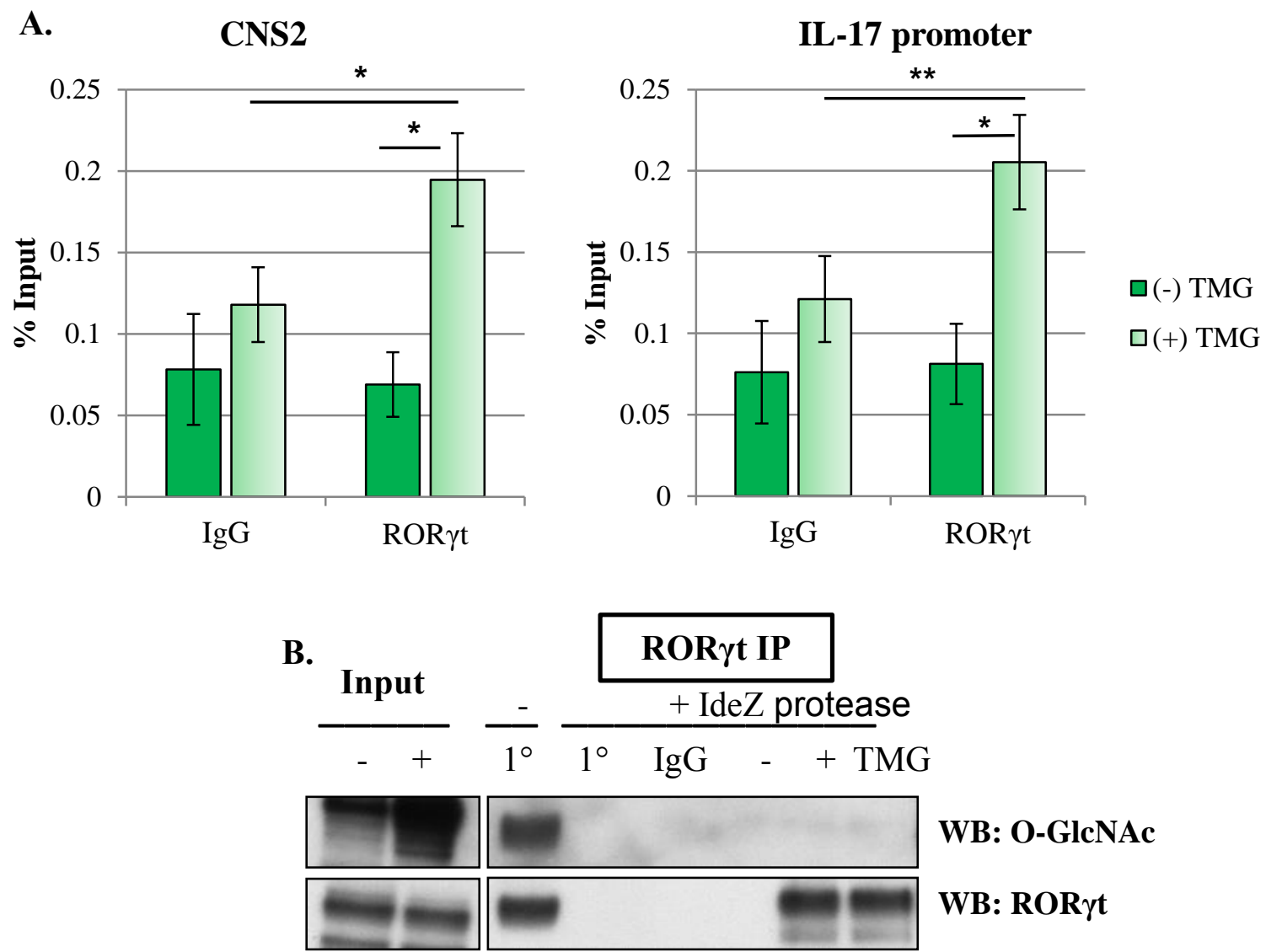

WB: O-GIcNAc

WB: ROR $\gamma \mathbf{t}$

Figure 6. Elevated O-GlcNAcylation promotes retention of ROR $\gamma$ t at the IL-17 locus. A. ROR $\gamma \mathrm{t}$ is significantly increased at the IL-17 promoter and CNS2 enhancer region with TMG treatment on day 4 of cell culture. Bars represent mean + - SEM of 4 biological replicates. ${ }^{*} p<0.05,{ }^{* *} p<0.01 \quad$ B. ROR $\gamma \mathrm{t}$ is not OGlcNAcylated in Th17 cells differentiated ex vivo. IdeZ protease was used to cleave antibody at the hinge region and allow visualization of proteins that migrate with heavy chain (as seen in IdeZ untreated lane).

In murine differentiated Th17 cells, pharmacological elevation of $O$-GIcNAc increases lipid ligands capable of increasing ROR $\gamma \mathrm{t}$ transcriptional activity.

Among the lineage defining transcription factors for CD4+ T cells, ROR $\gamma$ t activity is uniquely regulated by the binding of lipid ligands. We thus investigated alterations in the lipidome that might increase ROR $\gamma \mathrm{t}$ transcriptional activity at the IL-17 gene. Cholesterol biosynthetic intermediates, such as 7, 27 -dihydroxycholesterol $(7 \beta, 27-\mathrm{OHC})$ and $7 \alpha, 27-$ dihydroxycholesterol $(7 \alpha, 27-\mathrm{OHC})$, are known endogenous ligands capable of binding the 
A.

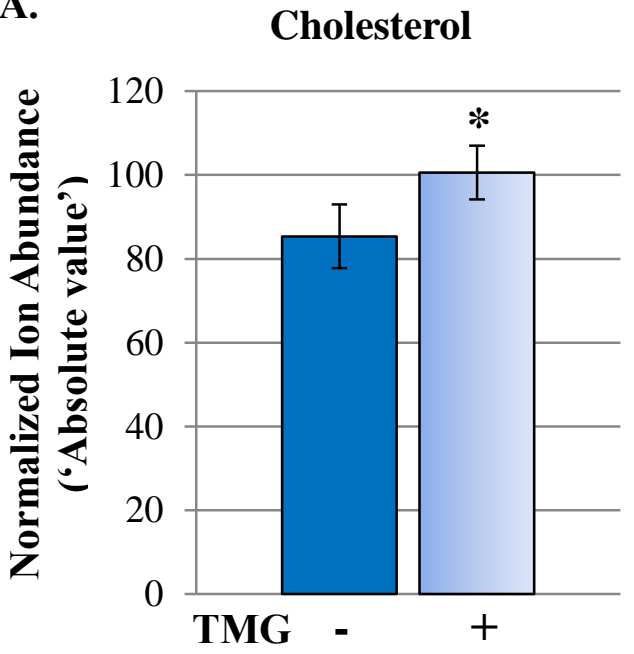

Total All Sterols

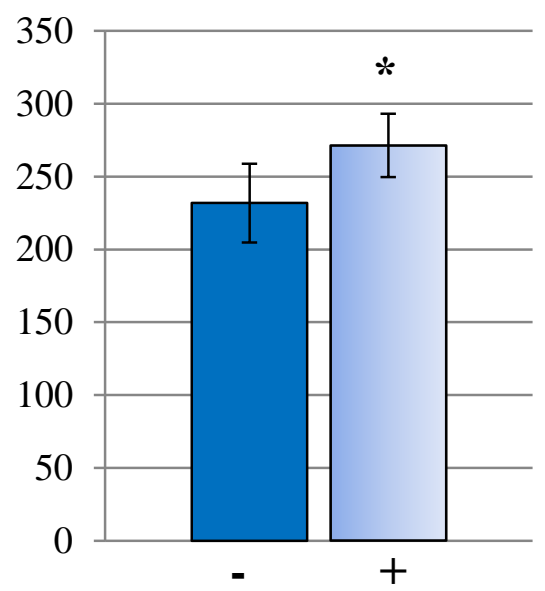

\section{B. Saturated Fatty Acids (SFA)}

\section{Stearic Acid (18:0)}

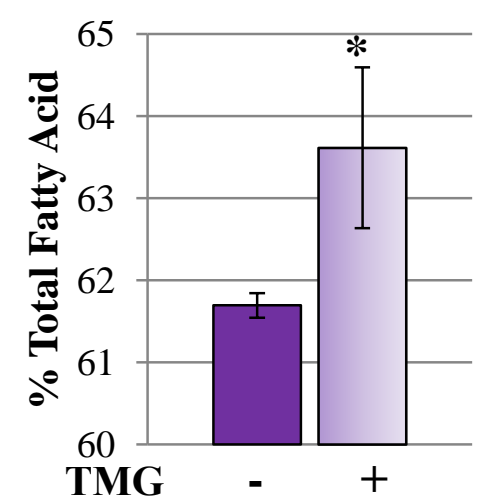

Myristic Acid

(14:0)

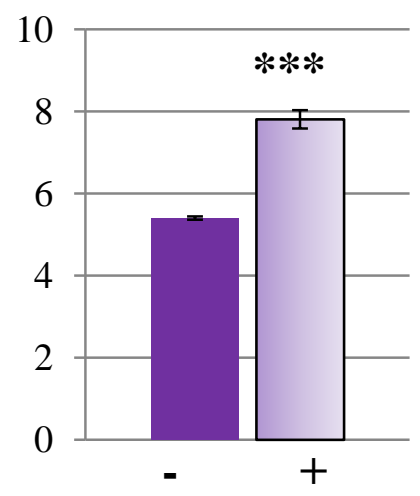

Behenic Acid (22:0)

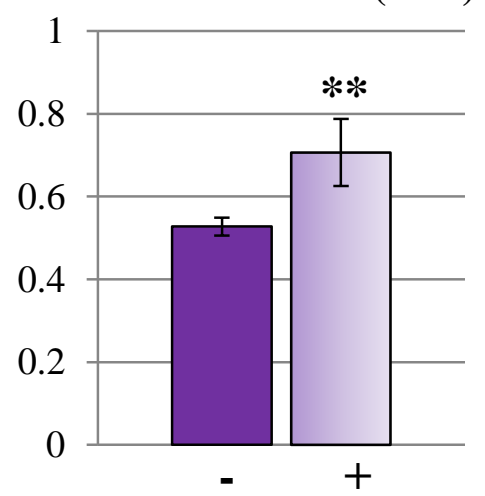

ligand binding domain of ROR $\gamma \mathrm{t}$, strongly activating its transcriptional activity $(24,25)$. Additionally, fatty acids are critical for optimal ROR $\gamma$ t activity as evidenced by a lack of Th17 differentiation under conditions of pharmacological inhibition or genetic deletion of the ratelimiting enzyme in fatty acid biosynthesis, acetyl CoA carboxylase 1 (ACC1) (22,23). The type of fatty acid ligand is also important for ROR $\gamma t$ activity. An increased ratio of saturated fatty acids (SFA) to polyunsaturated fatty acids (PUFA) increases ROR $\gamma t$ transcriptional activity at the pro-inflammatory IL-17A promoter, while decreasing activity at the anti-inflammatory IL-10 promoter, thus promoting pathogenic Th17 differentiation (78). To investigate how O-GlcNAc 
alters the lipidome of $\mathrm{T}$ cells, we treated murine splenic naïve $\mathrm{CD} 4+\mathrm{T}$ cells with and without TMG before activation, polarized towards a Th17 lineage, and then performed an untargeted broad analysis of the lipidome by mass spectrometry. Of note, cholesterol and total sterol populations were significantly elevated with TMG treatment (Figure 7A). One possibility for these results is increased cholesterol synthesis and thus increased cholesterol biosynthetic intermediates capable of activating ROR $\gamma$ t. Additionally, of the top twenty fatty acids detected in the cells, most SFA, such as stearic acid (C18:0), were significantly increased and all PUFA, such as arachidonic acid (C20:4), were significantly decreased with TMG treatment (Figure 7B and 7C). Together, these results demonstrate that elevated O-GlcNAcylation alters the lipid microenvironment such that cholesterol intermediates and fatty acids capable of acting as activating ligands of ROR $\gamma \mathrm{t}$ at the IL-17A locus were significantly increased. Furthermore, an increase in these lipid ligands is a possible explanation for why ROR $\gamma$ t is retained longer at the IL-17 locus. 


\section{Polyunsaturated Fatty Acids (PUFA)}

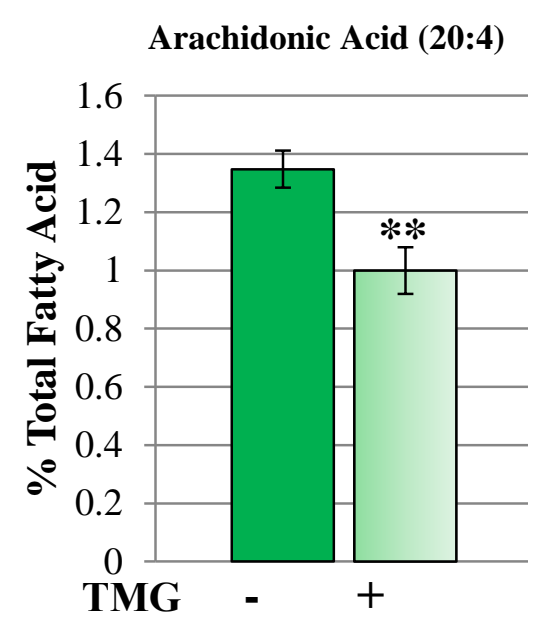

Docosahexaenoic Acid

(22:6)

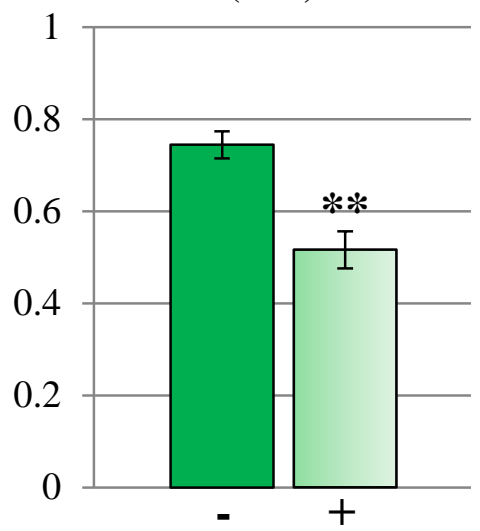

Docosapentaenoic Acid

(22:5)

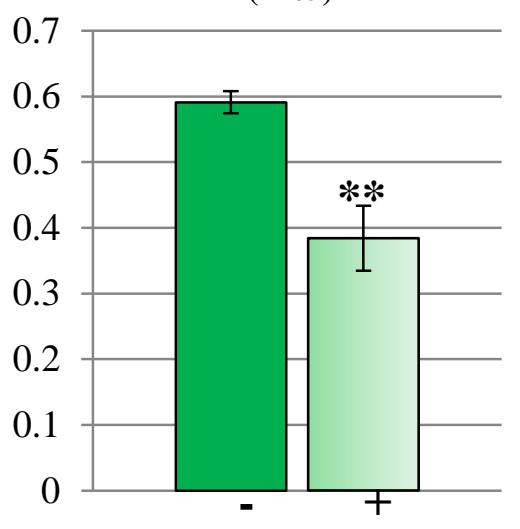

Docosatetraenoic Acid

(22:4)

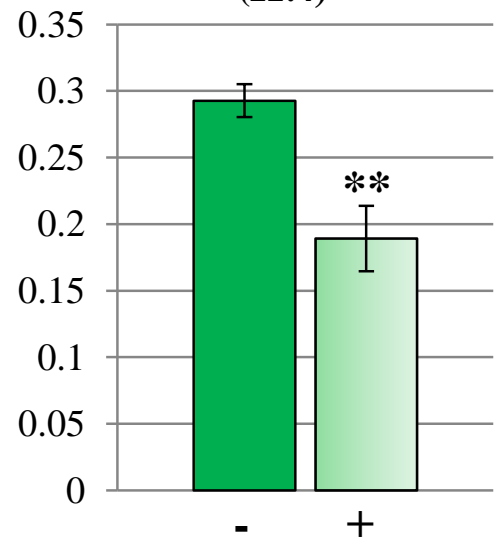

Dihomo- $\gamma$-linolenic acid (20:3)

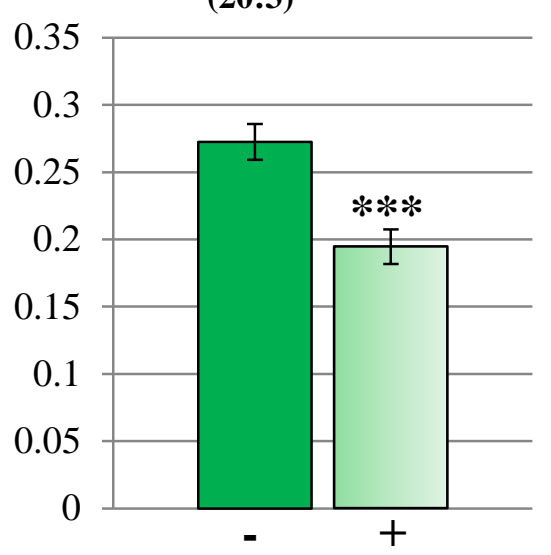

Figure 7. In murine differentiated Th17 cells, pharmacological elevation of $\mathrm{O}$ GlcNAc increases lipid ligands capable of increasing ROR $\gamma \mathrm{t}$ transcriptional activity. A. The absolute value or normalized ion abundance of total sterols and particularly cholesterol are increased with TMG treatment. B. Of the top 20 fatty acids present in cells, the percentage of saturated fatty acids increased with TMG treatment. C. Of the top 20 fatty acids present in cells, the percentage of all polyunsaturated fatty acids decreased with TMG treatment. Bars represent mean $+/$ - SD of 5 biological replicates; ${ }^{*} \mathrm{p}<0.05,{ }^{* *} \mathrm{p}<$ $0.01,{ }^{* * *} \mathrm{p}<0.001$

TMG treatment changes flux through the interrelated ceramide, sphingomyelin, and choline metabolic pathways.

Another striking finding from the lipidomics analysis is a significant increase in ceramide with concomitant significant decrease in sphingomyelin levels with TMG treatment (Figure 8A). 
A.

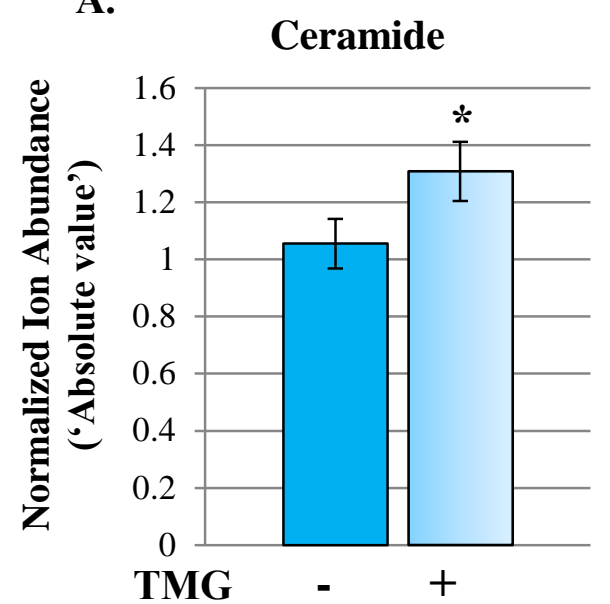

C.

- TMG

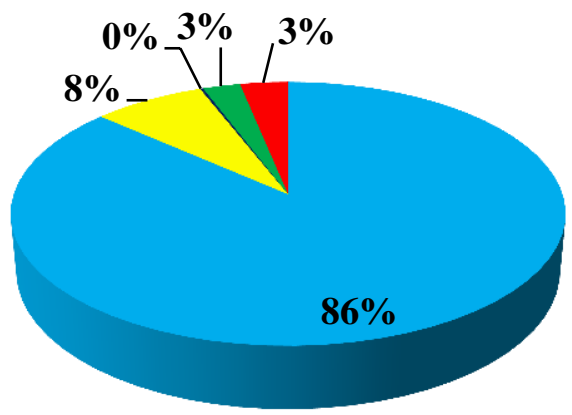

Sphingomyelin

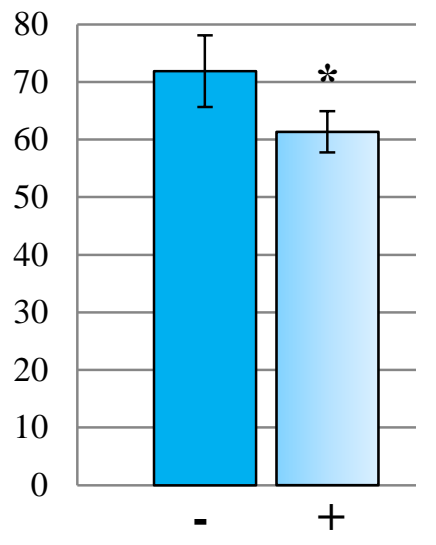

B. Palmitic Acid

(16:0)

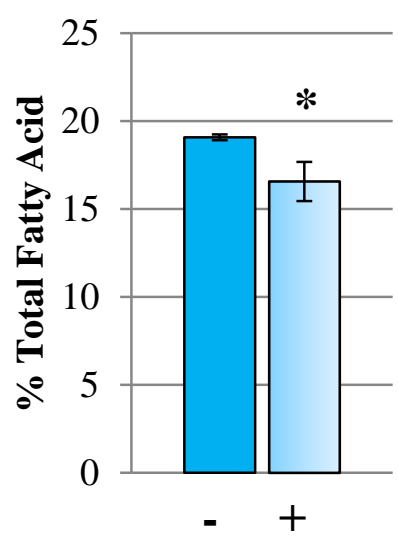

+ TMG

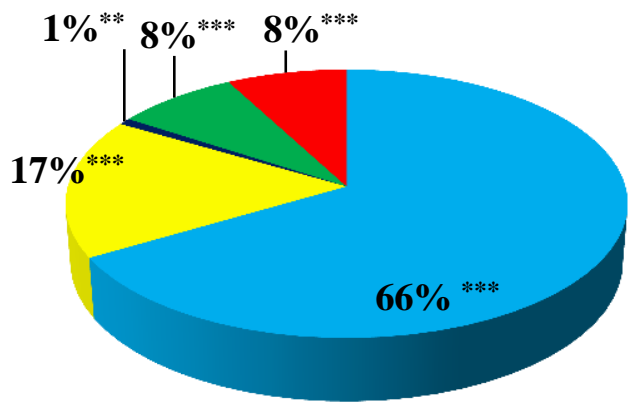

$\square \mathrm{PC} \backsim \mathrm{PE} \square \mathrm{PG} \square \mathrm{PI} \square \mathrm{PS}$

Figure 8. TMG treatment changes flux through the interrelated choline, sphingomyelin, and ceramide metabolic pathways. A. PC is significantly decreased with TMG treatment, while all other phospholipids significantly increase. Percentages are means of 5 biological replicates (all S.D. less than $0.35 \%$ ) in A. PC = phosphatidylcholine, $\mathrm{PE}=$ phosphatidylethanolamine, $\mathrm{PG}=$ phosphatidylglycerol, $\mathrm{PI}$ $=$ phosphatidylinositol, $\mathrm{PS}=$ phosphoserine. $\mathrm{B}$. The absolute value of ceramide significantly increases, while sphingomyelin significantly decreases with TMG treatment. C. Total fatty acid percentage of palmitic acid significantly decreases with TMG treatment. In B. and C., bars represent mean $+/-$ S.D. *p $<0.05$, **p $<0.01$, $* * * \mathrm{p}<0.001$

Ceramide and sphingomyelin are interchangeable through the actions of membrane bound sphingomyelinase and sphingomyelin synthase. An increase in ceramide levels is notable because ceramide is known to promote insulin resistance in adipose, muscle, and liver and is a general cellular metabolite that accumulates in obesity (79). Ceramide synthase 6 is the 
ceramide synthase isoform highly expressed in immune cells and preferentially generates ceramide with fatty acyl chains composed of palmitic acid (C16:0) (80). Intriguingly, we found that of the saturated fatty acids present in the top twenty fatty acids present overall, only palmitic acid (C16:0) was significantly decreased (Figure 8B). Potentially, elevated O-GlcNAcylation alters the metabolism of the $\mathrm{T}$ cells such that free palmitic acid is being more rapidly diverted into acylation of proteins or formation of other metabolites such as C16-ceramide. The choline metabolic pathway also feeds into pathways that generate sphingomyelin and ceramide. Phosphatidylcholine (PC) plus ceramide can be enzymatically converted to sphingomyelin with the release of diacylglycerol $(\mathrm{PC}+$ ceramide $\rightarrow$ sphingomyelin $+\mathrm{DAG})(81)$. Interestingly, we found a significant decrease in the percentage of phosphatidylcholine with compensatory increases in the other 4 phospholipid classes (Figure 8C). In addition to choline being shunted towards PC and sphingomyelin formation, it may also have implications for the methylation status of the cell, since choline can also be converted to betaine, which is a metabolite involved in the regeneration of methionine from homocysteine (81). Overall, these results suggest aberrant O-GlcNAcylation is promoting an "obese," inflammatory lipid signature in T cells with potential cross-talk with methylation via disruptions in choline metabolism.

\section{Acetyl CoA carboxylase 1 (ACC1), the rate limiting enzyme of fatty acid biosynthesis, is modified by O-GIcNAc.}

The substrates needed for both long chain fatty acids and cholesterol synthesis originate from the actions of acetyl CoA carboxylase (ACC1), the rate-limiting enzyme in fatty acid catabolism. ACC1 catalyzes the carboxylation of acetyl CoA to form malonyl CoA. Importantly, de novo fatty acid synthesis is essential for Th17 differentiation (22), and specifically ACC1 activity is essential for Th17 differentiation (23). UDP-GlcNAc, OGT's substrate, is made through the 
hexosamine biosynthetic pathway and requires input from all four major biomolecules: carbohydrate, amino acid, fatty acid, and nucleic acid (82). As nutrient flux changes through the

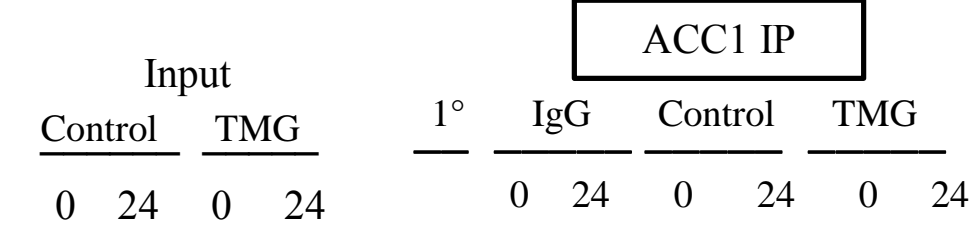
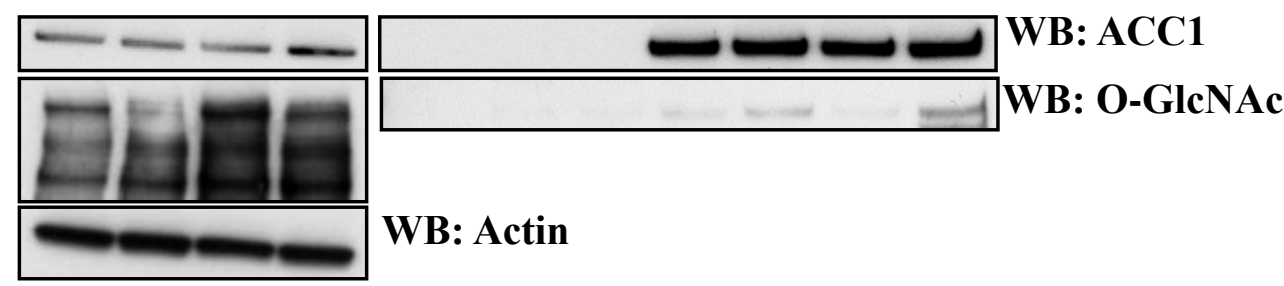

WB: Actin

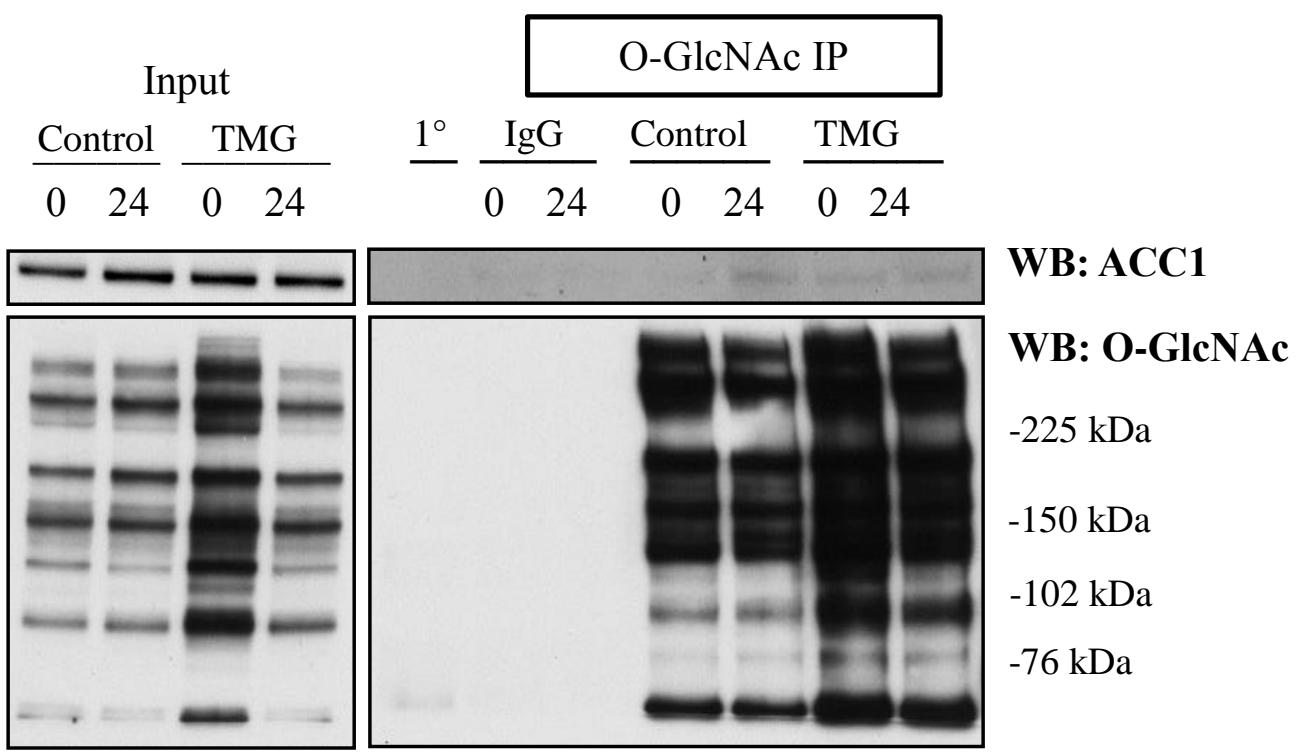

WB: Actin

cell, UDP-GlcNAc concentrations and O-GlcNAcylation by OGT change accordingly (38).

Thus, we hypothesized that as a cellular nutrient sensor, O-GlcNAc modifies ACC1 and regulates its activity. We first immunoprecipitated ACC1 from CD4+ T cells and observed that it was O-GlcNAcylated, and the reverse procedure of pulling proteins down with an O-GlcNAc antibody also yielded ACC1 (Figure 7A). We then confirmed this finding by performing 
electron transfer dissociation mass spectrometry (ETD-MS) on immunoprecipitated ACC1 from

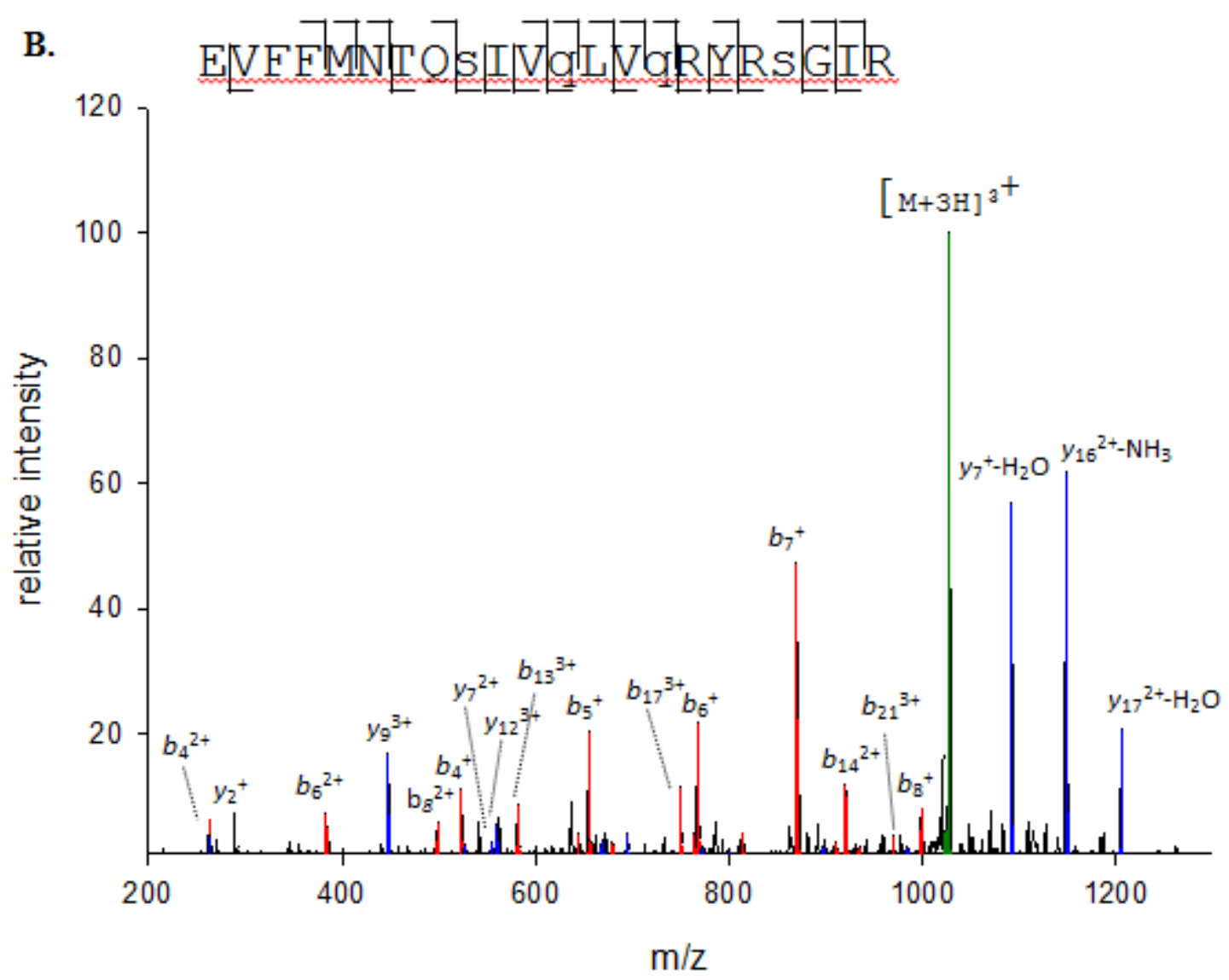

TMG treated murine naïve $\mathrm{T}$ cells polarized ex vivo to the Th17 lineage. Mass spectrometry analysis uncovered 4 high confidence O-GlcNAc sites on murine ACC1 (Figure 7B, Table 2). Two of these sites had homologous sites in a reported human partial C-terminal domain ACC1 crystal structure (PDB ID: 4ASI, RCSB Protein Data Bank) (Figure 7C, Table 2). In the human crystal structure and analogous mouse domains, O-GlcNAc sites were found in the central region (S966 and S976) and carboxyl transferase domain (S2091), implying that O-GlcNAc may regulate binding of protein partners in the central region (83) and/or the final step in the formation of malonyl $\mathrm{CoA}$ respectively, potentially altering ACC1 binding partner function or ACC1 catalytic activity directly. To investigate whether O-GlcNAc might regulate ACC1 activity, we looked at levels of phosphorylation of ACC1 at serine 79. AMP kinase (5' 
adenosine monophosphate-activated protein kinase) senses low ATP levels in a cell and inhibits ACC1's energy intensive, biosynthetic activity by phosphorylating it at S79 (84). We thus checked phospho-ACC1 levels over $0,2,4,8,16$, and 24 hours after re-stimulation of naïve CD4+ $\mathrm{T}$ cells differentiated towards the Th17 lineage and found no significant changes in phospho-ACC1 levels (Figure 7D). Thus, elevated O-GlcNAc does not increase the phosphorylation of ACC1 or alter AMPK inhibitory activity towards ACC1 in any appreciable way.

Table 2. Murine ACC1 high confidence O-GIcNAc modified sites (analogous amino acid in human ACC1 crystal structure)

\begin{tabular}{lc}
\hline S2091 (S2129) & S966 \\
S2285 (S2323) & S976 \\
\hline
\end{tabular}




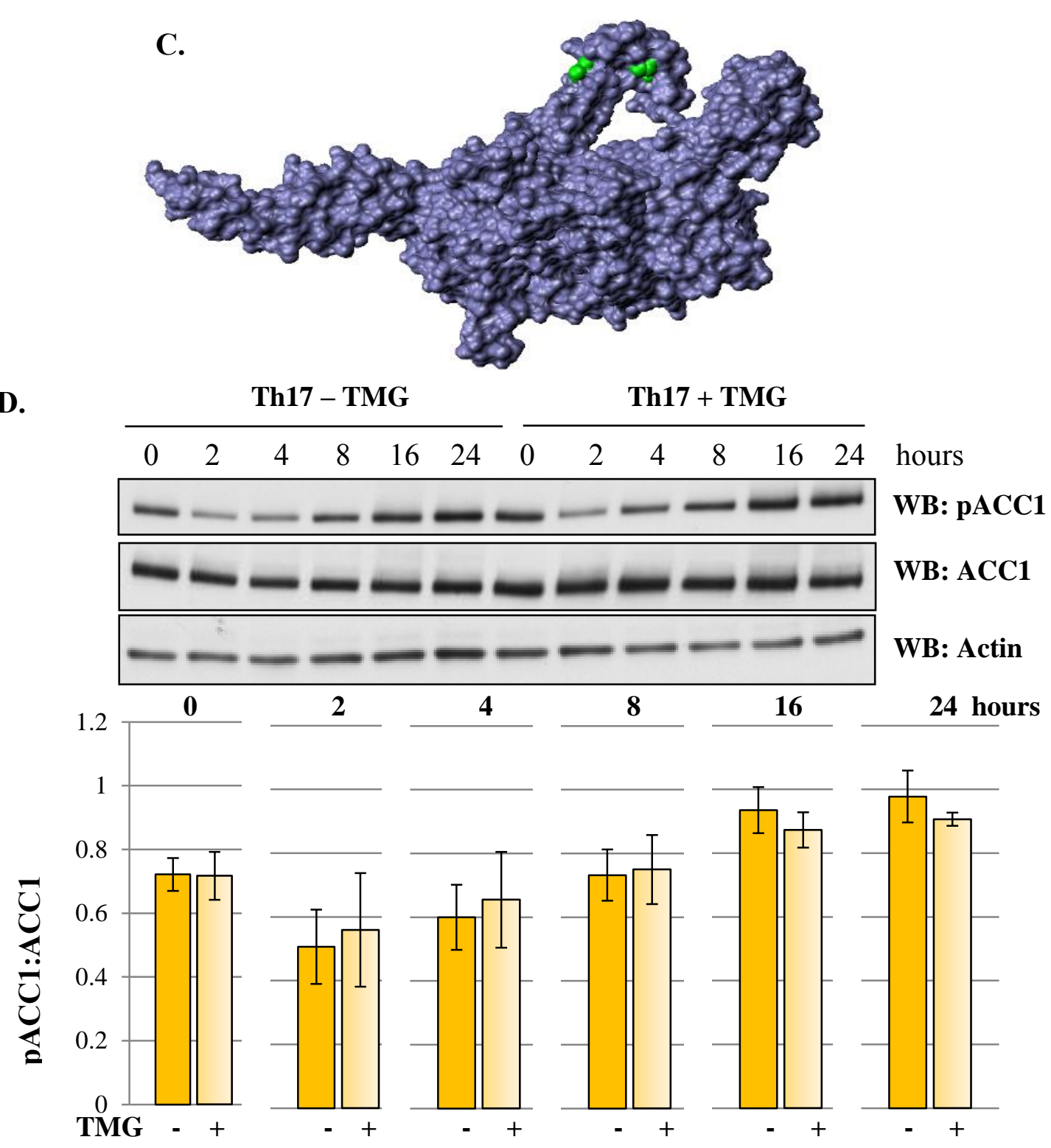

D.

Figure 9. Acetyl CoA carboxylase 1 (ACC1), the rate limiting enzyme of fatty acid biosynthesis, is modified by $\mathrm{O}$-GIcNAc and TMG treatment does affect inhibitory phosphorylation by AMPK. A. ACC1 or O-GlcNAc modified proteins were immunoprecipitated from $\mathrm{CD} 4+\mathrm{T}$ cells and show $\mathrm{ACC} 1$ is modified by O-GlcNAc. B. Representative mass spectra plot of high confidence O-GlcNAc modified sites S966 and S976 on ACC1. C. Location of analogous O-GlcNAc modified residues S2129 and S2323 in the carboxyl transferase domain on a purified human partial C-terminal crystal structure of ACC1. D. Inhibitory phosphorylation of ACC1 at S79 is unchanged with TMG treatment over the 24 hours of re-stimulation. pACC1 and ACC1 levels were normalized to actin. Blot is representative of 3 biological replicates. Densitometry bars represent mean +/- SEM of 3 replicates. 
Over-nutrition elevates CD4+ T cell O-GIcNAc levels, leading to increased proinflammatory IL-17 cytokine production and enhanced risk for obesity-related pathology. In summary, we propose that over-nutrition elevates O-GlcNAc levels in naïve CD4+ T cells.

ACC1 is O-GlcNAcylated and may be an initial mechanism driving the increased synthesis of saturated fatty acids and cholesterol biosynthetic intermediates which bind ROR $\gamma$ t and increase its activity at the IL-17 promoter and enhancer regions. Increased IL-17 secretion is a cytokine

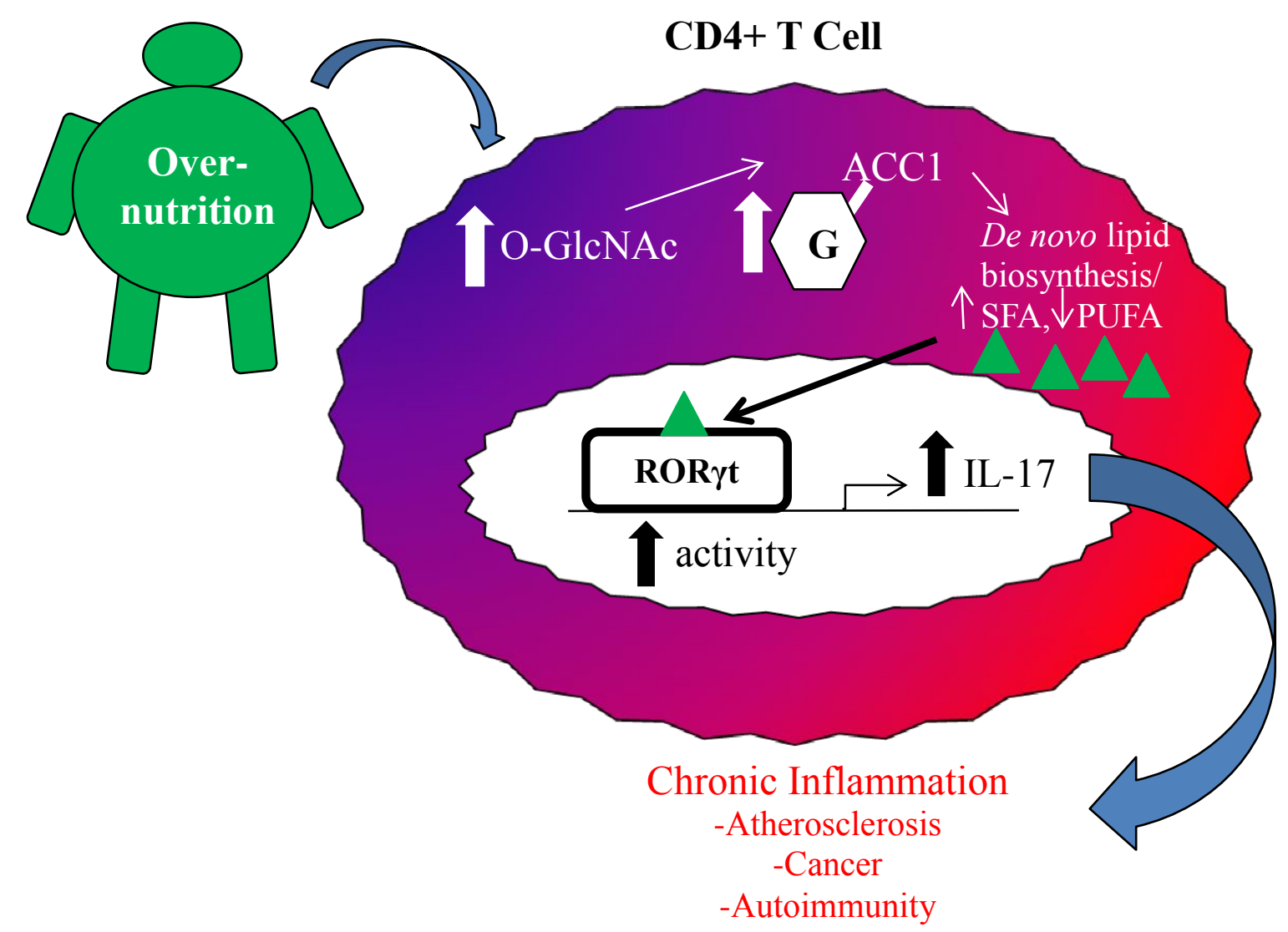

Figure 10. Over-nutrition elevates CD4+ $T$ cell $O$-GlcNAc levels, leading to increased pro-inflammatory IL-17 cytokine production and enhanced risk for obesity-associated pathology. Diseases of over-nutrition, such as obesity and diabetes, result in aberrantly increased O-GlcNAc levels in CD4+ T cells. Elevated O-GlcNAc levels alter lipid metabolism in Th17 cells and favor formation of lipid ligands which increase RORyt activity at the IL-17 promoter. Increased IL-17 levels raise the risk of pathological obesity-related sequelae, such as atherosclerotic plaque formation, cancer, and autoimmune diseases. 
that drives insulin resistance, atherosclerotic plaque formation, and increases the risk for autoimmunity and cancer. 


\section{CHAPTER 4: DISCUSSION}

Portions reprinted with permission from Machacek, M., Slawson, C., and Fields, P. E. (2018) OGlcNAc: a novel regulator of immunometabolism. Journal of Bioenergetics and Biomembranes.

Obesity has reached epidemic proportions in the developed world and is increasingly becoming a problem in less developed nations (85). Patients with diseases of over-nutrition, such as obesity and type 2 diabetes, have a well-defined chronic, low-grade inflammation. This inflammation has been implicated in much of the downstream pathology associated with increased adiposity, such as atherosclerosis, insulin resistance, and increased risk of autoimmunity and cancer $(65,67)$. Thus, to lessen the morbidity, mortality, and financial burden consequent to obesity, it is imperative we better understand mechanisms that drive pathology related to excess adiposity. Among this chronic inflammatory milieu, $\mathrm{CD} 4^{+} \mathrm{T}$ cell effectors, particularly Th1 and Th17 cells, are critical players in the development of atherosclerotic plaques and infiltrate adipose tissue to mediate insulin resistance $(64,67)$. Unfortunately, mechanisms driving increased Th1 and Th17 $\mathrm{CD} 4+\mathrm{T}$ cells and their respective cytokines in the presence of excess nutrients are poorly understood. In this study, we hypothesized that a homeostatic level of O-GlcNAcylation is necessary for the proper regulation of CD4+ T cell function and differentiation. Since O-GlcNAc levels are sensitive to environmental and nutritional changes, we further postulated that OGlcNAc would increase under conditions of over-nutrition and enhance pro-inflammatory function of $\mathrm{CD} 4+\mathrm{T}$ cells, providing a mechanistic explanation for increased inflammation in diseases of over-nutrition.

\section{Major Findings}

To answer the question of how O-GlcNAc regulates CD4+ T cell function, we cultured murine CD4+ T cells with Thiamet-G (TMG), a highly specific O-GlcNAcase inhibitor, to disrupt 
homeostatic O-GlcNAc levels. We observed a significant increase in pro-inflammatory cytokines, IL-17A and IFN $\gamma$, major cytokines secreted by the Th17 and Th1 lineages respectively. The most pronounced and significant effect by ELISA, intracellular cytokine staining, and analysis of RNA transcript levels was an effect on IL-17A. Importantly, this effect on IL-17 was also observed with human CD4+ T cells, suggesting a similar mechanism is operational in humans. Additionally, IL-23 receptor, another protein under transcriptional control of ROR $\gamma \mathrm{t}$, had significantly elevated transcript levels. IL-23R stabilizes the Th17 phenotype and is one marker that defines a strongly pro-inflammatory, pathogenic Th17 cell phenotype (60). Because of the strong effect of TMG on Th17 functional markers, we then isolated naïve CD4+ T cells and treated with TMG to elevate O-GlcNAc levels before activation and polarization towards the Th17 lineage. Th17 cells differentiated ex vivo secreted significantly more IL-17 with TMG treatment and had a significantly increased albeit low percentage of cells secreting both IL-17 and IFN $\gamma$, another marker of increased pathogenicity $(60,86)$. A key characteristic of non-pathogenic Th17 cells is the production of both IL-17 and the immunosuppressive cytokine, IL-10, which is expressed abundantly by immunosuppressive regulatory T cells (Tregs) (60). We observed no change in IL-10 protein or transcript levels in CD4+ T cells treated with TMG, suggesting no significant decrease in Tregs or non-pathogenic Th17 cells. Additionally, we observed only a modest, though significant, $4 \%$ increase in the number of cells producing IL-17 with TMG treatment. Overall, our data suggests a stronger effect of abnormally elevated O-GlcNAc resulting in more IL-17 being secreted per cell versus skewing differentiation towards Th17s at the expense of Tregs.

With evidence of excess O-GlcNAcylation resulting in increased Th17 and Th1 inflammatory cytokines which are abnormally elevated in obesity, we wanted to determine O-GlcNAc's role in 
a Western diet (WD) fed mouse model. In agreement with O-GlcNAc acting as a nutritional sensor, O-GlcNAc levels were significantly increased in the naïve CD4+ T cells of WD fed mice. Interestingly, the levels of OGT and OGA were not different between mice fed standard chow (SC) and mice on the Western diet. Normally, O-GlcNAc levels are vigorously maintained at a level particular for the needs of a cell (56). For example, when O-GlcNAcylation is increased with TMG treatment, OGA levels will increase and OGT levels will decrease to return O-GlcNAc levels to baseline. However, these results suggest that long-term nutritional excess causes O-GlcNAc levels to "reset" to an abnormally high level. When this atypically high new set-point was pushed even further TMG treatment, both cells from SC and WD fed mice produced significantly more IL-17. These results are in agreement with a known effect of a single nucleotide polymorphisms (SNPs) in the MGEA gene which encodes OGA. In a Mexican American population with these SNPs, OGA expression is decreased and there is increased incidence and earlier age of onset of type 2 diabetes (6). Thus, O-GlcNAcylation is a mechanism contributing to increased pro-inflammatory IL-17 secretion, particularly relevant in the context of diseases of over-nutrition, where O-GlcNAc levels attain a higher homeostatic level.

How does TMG treatment lead to increased IL-17A? After observing no changes in the protein and transcript levels of STAT3 and ROR $\gamma \mathrm{t}$, two transcription factors critical in the differentiation of Th17 cells, we discovered that the lipid microenvironment was significantly altered. Lipid ligands, such as sterols and saturated fatty acids, capable of binding and activating ROR $\gamma \mathrm{t}$ at the IL-17 locus were increased with TMG treatment. Furthermore, we identified sites of OGlcNAcylation on acetyl CoA carboxylase 1 (ACC1), which provides the building blocks for both long chain fatty acid and cholesterol synthesis (87). In addition to increased fatty acid and sterol products that result from ACC1 activity, two other lines of evidence suggest increased 
ACC1 activity with TMG treatment. First, palmitic acid (C16:0) is the first fatty acid produced as a result of ACC1 initiating fatty acid biosynthesis, and as such, negatively feedbacks to inhibit ACC1. The significant decrease in palmitate with TMG treatment but significant increase in longer chain saturated fatty acids suggests palmitate is being rapidly diverted into elongation pathways or acylation of proteins and is thus less available to inhibit ACC1 activity. Additionally, we were unable to detect a change in inhibitory phosphorylation of ACC1 by AMPK at serine 79, so there is not increased inhibition of ACC1 with TMG treatment. Of note, lipidomics analysis of endothelial cells treated with soraphen A, a potent inhibitor of ACC1, resulted in opposite effects of what we observed (88). With inhibition of ACC1, polyunsaturated fatty acids (PUFA) increased and phosphatidylglycerol (PG) decreased in endothelial cells, whereas we observed a significant decrease in PUFAs and increase in PG in our T cell model. In addition to an O-GlcNAc site (S2091) being present in the carboxyl transferase (CT) domain of ACC1, which catalyzes the final step of malonyl CoA formation, sites were found in the central region of ACC1 (S966 and S976). In a crystal structure of yeast ACC1, the central region was found to be composed of 5 unique domains and was responsible for bringing the biotin carboxylase (BC) and CT domains together (89), which is an important step in catalysis. Importantly, deletion of residues $940-972$ in the first domain of the central region abolished catalytic activity. Overall, multiple lines of evidence suggest TMG treatment favors increased ACC1 activity and production of ligands which enhance ROR $\gamma \mathrm{t}$ activity.

One final finding of interest from the lipidomics analysis, which provides further insight into how TMG treatment is broadly altering cellular metabolism, was a significant increase in ceramide and decrease in sphingomyelin. Of particular relevance to our study, ceramide is well known to accumulate in obesity, specifically in liver, muscle, and adipose tissues (79) where it 
suppresses insulin signaling pathways and promotes insulin resistance. Thus, it is notable that we also observed an increase in ceramide in Th17 cells treated with TMG. Multiple metabolic pathways feed into the production of ceramide, and of those, three are most relevant to our results. First, the de novo synthesis pathway begins with the transfer of serine to palmitoyl-CoA (79). Since we observed a significant decrease in palmitate, this is potentially one pathway palmitate is being shunted towards. Second, in the catabolic pathway, ceramide synthases convert sphingosine plus a fatty acid into ceramide. Fatty acids of various chain lengths can be used to acylate ceramide. Ceramide synthase 6 (CerS6) is the synthase responsible for specifically using palmitate in the synthesis of ceramide. Importantly, CerS6 knock-out mice are resistant to weight gain and insulin resistance when fed a high fat diet (90). Myeloid cell specific knock-out mice were not protected from weight gain or insulin resistance, but effects on lymphoid cells were not examined. Interestingly, knock-out of CerS6 in splenocytes that were then adoptively transferred into a mouse colitis model led to maintenance of body weight and better pathology scores in the intestine (91). However, the authors concluded it was most likely due to a decreased proliferative or migratory ability of the transferred $\mathrm{T}$ cells, since transferred $\mathrm{T}$ cells isolated from the lamina propria did not show a difference in Th17 and Treg percentage or IL-17 production. Thus, the potential effects of CerS6 activity in T cells treated with TMG will require further study. Finally, sphingomyelin found in the plasma membrane can be converted to ceramide by acid sphingomyelinase (ASM). Knockdown or pharmacological inhibition of ASM reduced IL-17 production from Th17 cells acquired from human patients with Crohn's disease, an inflammatory bowel disease with increased Th7 function (92). ASM increases IL-17 production by associating with two human Th17 cell surface markers in the membrane, CD39 and CD161, and increases their activation of mTOR and STAT3 pathways necessary for Th17 
function. In agreement with an important role for ASM in Th17 function, ASM-deficient mice have increased systemic Tregs $(93,94)$. Although we did not observe changes in STAT3 signaling in murine $\mathrm{CD} 4+\mathrm{T}$ cells, it is possible O-GlcNAc might play a clearer role in ASM function in human cells, which have better defined expression of CD161 and association with ASM. Also of note, the conversion of ceramide to sphingomyelin requires phosphotidylcholine (79). We observed a significant decrease in PC, which would suppress conversion of ceramide back to sphingomyelin. Taken together, ceramide increases with TMG treatment are another indication of an inflammatory, obese phenotype and will require further investigation to fully understand the role it plays in our $\mathrm{T}$ cell model.

\section{Study Limitations}

Several limitations were present in this study. First, our studies rely on use of pharmacological inhibition of OGA. Thiamet-G (TMG) is highly specific for OGA, demonstrating 37,000 fold specificity for O-GlcNAcase compared to lysosomal hexosaminidase present in cells (95). However, off-target effects remain a possibility. Genetic knock-out of OGT and OGA enzymes are embryonic lethal (96) and when conditionally knocked-out lead to cell death in proliferating cells $(97,98)$. This requirement of O-GlcNAcylation for cell proliferation makes it particularly difficult in studying $\mathrm{T}$ cell differentiation and function, since activation induces massive proliferation of $\mathrm{T}$ cells. Thus, genetic manipulations to understand the role of O-GlcNAc often require identification of O-GlcNAc sites and then site-specific mutagenesis in a mouse model. We would like to perform such an experiment with ACC1 to determine the effects of O-GlcNAc on $\mathrm{ACC} 1$ and subsequent alterations to T cell function. Second, our work relied on in vitro assays of $\mathrm{T}$ cell phenotype and function. We have yet to determine if the enhanced IL-17 secretion exacerbates or leads to inflammatory disease in vivo. Furthermore, it would be 
interesting to isolate Th17 cells infiltrating adipose or atherosclerotic plaques and compare to peripheral Th17s to see how O-GlcNAc/OGT/OGA levels change. Finally, there is inherent difficulty in therapeutically targeting a post-translational modification that modifies thousands of proteins and is involved in many critical cellular processes, including transcription, translation, and cell cycle progression. As the O-GlcNAc field progresses it is likely more site specific tools will be developed and there may be technologies developed for site-specific O-GlcNAc modulation, allowing us to therapeutically fine-tune O-GlcNAc.

\section{Future Directions}

As a post-translational protein modification exquisitely sensitive to changes in metabolic state and environmental factors, O-GlcNAc is poised as a major regulator of T cell function. Based on our data demonstrating that elevated O-GlcNAcylation causes metabolic shifts that enhance Th17 function, what other functions might O-GlcNAc have in $\mathrm{CD}^{+} \mathrm{T}$ cell biology and in other cell types sensitive to similar metabolic changes? We propose three areas worth further investigation.

First, a fascinating feature of $\mathrm{CD}^{+} \mathrm{T}$ cell subsets is their substantial plasticity. For example, Th17 cells have two distinct functional states - a non-pathogenic state in which cells secrete both IL-17 and IL-10, an anti-inflammatory cytokine typical of iTregs, and a pathogenic state, in which cells secrete both IL-17 and IFN $\gamma$, the classical Th1 cytokine $(99,100)$. This dual Th17/Th1-like phenotype is linked to the pathogenesis of many autoimmune diseases, including multiple sclerosis, inflammatory bowel disease, and type 1 diabetes $(60,86,100)$. Non-pathogenic Th17 cells convert to a pathogenic state when injected into a non-obese diabetic mouse model of type 1 diabetes, suggesting that abnormal metabolism may be involved in this conversion (86). 
Further supporting a role for metabolic factors, the saturated to unsaturated fatty acid ratio in Th17 cells is critical for pathogenicity. Increased saturated fatty acids due to a decreased expression of CD5L, a protein whose only previously known function was in macrophages, drove pathogenicity by creating ligands that specifically enhanced ROR $\gamma t$ transcriptional activity at the IL-17 locus, while decreasing IL-10 transcriptional activity. In future studies, it would be interesting to examine how O-GlcNAc might regulate critical nodes that shift plasticity, such as CD5L, and ways this could be altered therapeutically as a molecular switch of cellular states.

Second, pro-inflammatory Th1 and Th17 cells critically drive many autoimmune diseases. As mentioned previously, aberrant OGT levels have been implicated in promoting inflammatory $\mathrm{T}$ cells in multiple sclerosis and systemic lupus erythematosus (SLE) (4,5). Additionally, disruptions in metabolic pathways of $\mathrm{T}$ cells have been implicated in autoimmune inflammation, which could lead to increased shunting of metabolites into the hexosamine biosynthetic pathway, fueling O-GlcNAcylation. For example, inappropriate, chronic stimulation of the PI3K-AKTmTOR signaling pathway leads to the accumulation of inflammatory Th17 cells in SLE (101). Synovial infiltrating inflammatory $\mathrm{T}$ cells in rheumatoid arthritis have decreased glycolytic flux at the rate-limiting step, shunting substrates towards the pentose phosphate pathway (PPP) (102). Increased PPP flux increases production of NADPH, an essential reductant for fatty acid synthesis, thought to drive abnormal fatty acid metabolism and formation of intracellular lipid droplets. In addition to increased shunting to the PPP, it seems likely that impaired glycolysis might also increase flux through the HBP and abnormally elevate O-GlcNAcylation. Thus, determining the exact role of O-GlcNAc regulation in autoimmune T cells could lead to fruitful insight into pathogenic mechanisms driving autoimmune $\mathrm{CD}^{+} \mathrm{T}$ cell inflammation. 
Finally, an effect of elevated O-GlcNAcylation on increasing cellular ceramide levels could have broad implications for tissues involved in insulin resistance and atherosclerosis. Insulin signaling activates protein kinase B (also known as Akt), which then phosphorylates multiple substrates with the effect of increasing glucose uptake and metabolic programs involved in cell growth and survival (103). Critically, ceramide blocks protein PKB activation by promoting phosphorylation events that prevent its localization to the membrane and removal of inhibitory phosphorylation $(104,105)$. Interestingly, $\mathrm{PKB}$ is O-GlcNAcylated and elevated OGlcNAcylation also contributes to insulin resistance by blocking PKB phosphorylation (106). In future studies, it would be interesting to more clearly tease out the interplay between O-GlcNAc, ceramide, and insulin signaling proteins. Increased ceramide levels are also pathogenic in heart disease. For example, increased ceramide promotes retention of oxidized low-density lipoprotein (ox-LDL) in the atherosclerotic plaque (107), a critical step in recruiting macrophages and inflammatory $\mathrm{T}$ cells. In individuals with unstable angina or acute myocardial infarction, blood levels of ceramide and activity of acid sphingomyelinase are increased, but then fall after restoration of blood flow (108). Thus beyond exploring the effects of increased ceramide in $\mathrm{T}$ cells, it would be of value to better understand if and how O-GlcNAc promotes ceramide production in the vasculature and insulin responsive organs, such as skeletal muscle, adipose, and liver.

\section{Conclusion}

Obesity and diabetes are major public health concerns and the immune system is a critical driver of pathogenesis in these diseases. Intervening at the level of inflammation is of critical importance in preventing pathological complications. Unfortunately, the mechanisms driving chronic inflammation have been difficult to elucidate. The results of this study represent the first 
investigation of how the O-GlcNAc post-translational modification regulates CD4+ T cell function and differentiation and support a role for aberrant O-GlcNAcylation in mediating a proinflammatory Th17 response in a type 2 diabetic mouse model. Human CD4+ T cells showed a similar significant increase in IL-17 production when treated with TMG. Thus, mechanistic insights derived from murine CD4+ $\mathrm{T}$ cells may be applicable to humans. Importantly, we discovered that the rate-limiting enzyme in fatty acid biosynthesis, ACC1, is O-GlcNAcylated and the lipid profile of cells treated with TMG shifts towards an inflammatory phenotype and produces ligands driving ROR $\gamma \mathrm{t}$ transcriptional activity at the IL-17 locus. This works thus fills in a piece of the mechanistic puzzle for why inflammatory cytokine production increases in CD4+ T cells in disease of over-nutrition. 


\section{BIBLIOGRAPHY}

1. Geginat, J., Paroni, M., Facciotti, F., Gruarin, P., Kastirr, I., Caprioli, F., Pagani, M., and Abrignani, S. (2013) The CD4-centered universe of human T cell subsets. Seminars in Immunology 25, 252-262

2. Golks, A., Thi-Thanh Thao Tran, Jean Francois Goetschy, and Danilo Guerini. (2007) Requirement for O-linked $\mathrm{N}$-acetylglucosaminyltransferase in lymphocytes activation. European Molecular Biology Organization 26, 4368-4379

3. Lund, P. J., Elias, J. E., and Davis, M. M. (2016) Global Analysis of O-GlcNAc Glycoproteins in Activated Human T Cells. The Journal of Immunology 197, 3086-3098

4. Hewagama, A., Gorelik, G., Patel, D., Liyanarachchi, P., Joseph McCune, W., Somers, E., Gonzalez-Rivera, T., The Michigan Lupus, C., Strickland, F., and Richardson, B. (2013) Overexpression of X-Linked genes in T cells from women with lupus. Journal of Autoimmunity 41, 60-71

5. Liu, R., Ma, X., Chen, L., Yang, Y., Zeng, Y., Gao, J., Jiang, W., Zhang, F., Li, D., Han, B., Han, R., Qiu, R., Huang, W., Wang, Y., and Hao, J. (2017) MicroRNA-15b Suppresses Th17 Differentiation and Is Associated with Pathogenesis of Multiple Sclerosis by Targeting O-GlcNAc Transferase. The Journal of Immunology

6. Lehman, D. M., Fu, D.-J., Freeman, A. B., Hunt, K. J., Leach, R. J., Johnson-Pais, T., Hamlington, J., Dyer, T. D., Arya, R., Abboud, H., Göring, H. H. H., Duggirala, R., Blangero, J., Konrad, R. J., and Stern, M. P. (2005) A Single Nucleotide Polymorphism in MGEA5 Encoding O-GlcNAc-selective N-Acetyl- $\beta$-D-Glucosaminidase Is Associated With Type 2 Diabetes in Mexican Americans. Diabetes 54, 1214-1221

7. Loos, J., Roos D. (1973) Changes in the carbohydrate metabolism of mitogenically stimulated human peripheral lymphocytes. 3. Stimulation by tuberculin and allogenic cells. Experimental Cell Research 79, 136-142

8. $\quad$ Frauwirth, K. A., Riley, J. L., Harris, M. H., Parry, R. V., Rathmell, J. C., Plas, D. R., Elstrom, R. L., June, C. H., and Thompson, C. B. (2002) The CD28 Signaling Pathway Regulates Glucose Metabolism. Immunity 16, 769-777

9. Rathmell, J. C., Elstrom, R. L., Cinalli, R. M., and Thompson, C. B. (2003) Activated Akt promotes increased resting $\mathrm{T}$ cell size, CD28-independent $\mathrm{T}$ cell growth, and development of autoimmunity and lymphoma. European Journal of Immunology 33, 2223-2232

10. Wang, R., Dillon, Christopher P., Shi, Lewis Z., Milasta, S., Carter, R., Finkelstein, D., McCormick, Laura L., Fitzgerald, P., Chi, H., Munger, J., and Green, Douglas R. (2011) The Transcription Factor Myc Controls Metabolic Reprogramming upon T Lymphocyte Activation. Immunity 35, 871-882

11. Sinclair, L. V., Rolf, J., Emslie, E., Shi, Y.-B., Taylor, P. M., and Cantrell, D. A. (2013) Control of amino-acid transport by antigen receptors coordinates the metabolic reprogramming essential for T cell differentiation. Nat Immunol 14, 500-508

12. Nakaya, M., Xiao, Y., Zhou, X., Chang, J.-H., Chang, M., Cheng, X., Blonska, M., Lin, X., and Sun, S.-C. (2014) Inflammatory T Cell Responses Rely on Amino Acid Transporter ASCT2 Facilitation of Glutamine Uptake and mTORC1 Kinase Activation. Immunity 40, 692-705

13. Griffiths, M., and Keast, D. (1990) The effect of glutamine on murine splenic leukocyte responses to T and B cell mitogens. Immunol Cell Biol 68, 405-408 
14. Jones, R. G., and Thompson, C. B. (2007) Revving the Engine: Signal Transduction Fuels T Cell Activation. Immunity 27, 173-178

15. Hensley, C. T., Wasti, A. T., and DeBerardinis, R. J. (2013) Glutamine and cancer: cell biology, physiology, and clinical opportunities. The Journal of Clinical Investigation 123, 3678-3684

16. Michalek, R. D., Gerriets, V. A., Jacobs, S. R., Macintyre, A. N., MacIver, N. J., Mason, E. F., Sullivan, S. A., Nichols, A. G., and Rathmell, J. C. (2011) Cutting Edge: Distinct Glycolytic and Lipid Oxidative Metabolic Programs Are Essential for Effector and Regulatory CD4+ T Cell Subsets. The Journal of Immunology 186, 3299-3303

17. Macintyre, A. N., Valerie A. Gerriets, Amanda G. Nichols, Ryan D. Michalek, Michael C. Rudolph, , and Divino Deoliveira, S. M. A., E. Dale Abel, Benny J. Chen, Laura P. Hale, and Jeffrey C. Rathmell. (2014) The Glucose Transporter Glut1 is Selectively Essential for CD4 T Cell Activation and Effector Function. Cell Metabolism 20, 61-72

18. Gerriets, V. A., Kishton, R. J., Nichols, A. G., Macintyre, A. N., Inoue, M., Ilkayeva, O., Winter, P. S., Liu, X., Priyadharshini, B., Slawinska, M. E., Haeberli, L., Huck, C., Turka, L. A., Wood, K. C., Hale, L. P., Smith, P. A., Schneider, M. A., MacIver, N. J., Locasale, J. W., Newgard, C. B., Shinohara, M. L., and Rathmell, J. C. (2015) Metabolic programming and PDHK1 control CD4+ T cell subsets and inflammation. The Journal of Clinical Investigation 125, 194-207

19. Delgoffe, G. M., Kole, T. P., Zheng, Y., Zarek, P. E., Matthews, K. L., Xiao, B., Worley, P. F., Kozma, S. C., and Powell, J. D. (2009) The mTOR Kinase Differentially Regulates Effector and Regulatory T Cell Lineage Commitment. Immunity 30, 832-844

20. Wullschleger, S., Loewith, R., and Hall, M. N. (2006) TOR Signaling in Growth and Metabolism. Cell 124, 471-484

21. Delgoffe, G. M., Pollizzi, K. N., Waickman, A. T., Heikamp, E., Meyers, D. J., Horton, M. R., Xiao, B., Worley, P. F., and Powell, J. D. (2011) The kinase mTOR regulates the differentiation of helper $\mathrm{T}$ cells through the selective activation of signaling by mTORC1 and mTORC2. Nat Immunol 12, 295-303

22. Berod, L., Friedrich, C., Nandan, A., Freitag, J., Hagemann, S., Harmrolfs, K., Sandouk, A., Hesse, C., Castro, C. N., Bahre, H., Tschirner, S. K., Gorinski, N., Gohmert, M., Mayer, C. T., Huehn, J., Ponimaskin, E., Abraham, W.-R., Muller, R., Lochner, M., and Sparwasser, T. (2014) De novo fatty acid synthesis controls the fate between regulatory $\mathrm{T}$ and T helper 17 cells. Nat Med 20, 1327-1333

23. Endo, Y., Asou, Hikari K., Matsugae, N., Hirahara, K., Shinoda, K., Tumes, Damon J., Tokuyama, H., Yokote, K., and Nakayama, T. (2015) Obesity Drives Th17 Cell Differentiation by Inducing the Lipid Metabolic Kinase, ACC1. Cell Reports 12, 10421055

24. Soroosh, P., Wu, J., Xue, X., Song, J., Sutton, S. W., Sablad, M., Yu, J., Nelen, M. I., Liu, X., Castro, G., Luna, R., Crawford, S., Banie, H., Dandridge, R. A., Deng, X., Bittner, A., Kuei, C., Tootoonchi, M., Rozenkrants, N., Herman, K., Gao, J., Yang, X. V., Sachen, K., Ngo, K., Fung-Leung, W.-P., Nguyen, S., de Leon-Tabaldo, A., Blevitt, J., Zhang, Y., Cummings, M. D., Rao, T., Mani, N. S., Liu, C., McKinnon, M., Milla, M. E., Fourie, A. M., and Sun, S. (2014) Oxysterols are agonist ligands of ROR $\gamma \mathrm{t}$ and drive Th17 cell differentiation. Proceedings of the National Academy of Sciences 111, 1216312168 
25. Santori, Fabio R., Huang, P., van de Pavert, Serge A., Douglass Jr, Eugene F., Leaver, David J., Haubrich, Brad A., Keber, R., Lorbek, G., Konijn, T., Rosales, Brittany N., Rozman, D., Horvat, S., Rahier, A., Mebius, Reina E., Rastinejad, F., Nes, W. D., and Littman, Dan R. (2015) Identification of Natural ROR $\gamma$ Ligands that Regulate the Development of Lymphoid Cells. Cell Metabolism 21, 286-297

26. Shi, L. Z., Wang, R., Huang, G., Vogel, P., Neale, G., Green, D. R., and Chi, H. (2011) HIF1 $\alpha$-dependent glycolytic pathway orchestrates a metabolic checkpoint for the differentiation of $\mathrm{T}<\mathrm{sub}>\mathrm{H}</ \mathrm{sub}>17$ and $\mathrm{T}<\mathrm{sub}>\mathrm{reg}</ \mathrm{sub}>$ cells. The Journal of Experimental Medicine 208, 1367-1376

27. Dang, Eric V., Barbi, J., Yang, H.-Y., Jinasena, D., Yu, H., Zheng, Y., Bordman, Z., Fu, J., Kim, Y., Yen, H.-R., Luo, W., Zeller, K., Shimoda, L., Topalian, Suzanne L., Semenza, Gregg L., Dang, Chi V., Pardoll, Drew M., and Pan, F. (2011) Control of TH17/Treg Balance by Hypoxia-Inducible Factor 1. Cell 146, 772-784

28. Zhang, M. A., Rego, D., Moshkova, M., Kebir, H., Chruscinski, A., Nguyen, H., Akkermann, R., Stanczyk, F. Z., Prat, A., Steinman, L., and Dunn, S. E. (2012) Peroxisome proliferator-activated receptor (PPAR) $\alpha$ and $-\gamma$ regulate IFN $\gamma$ and IL-17A production by human T cells in a sex-specific way. Proceedings of the National Academy of Sciences 109, 9505-9510

29. Reis, B. S., Lee, K., Fanok, M. H., Mascaraque, C., Amoury, M., Cohn, L. B., Rogoz, A., Dallner, O. S., Moraes-Vieira, P. M., Domingos, A. I., and Mucida, D. (2015) Leptin Receptor Signaling in T Cells Is Required for Th17 Differentiation. The Journal of Immunology 194, 5253-5260

30. Gerriets, V. A., Danzaki, K., Kishton, R. J., Eisner, W., Nichols, A. G., Saucillo, D. C., Shinohara, M. L., and MacIver, N. J. (2016) Leptin directly promotes T-cell glycolytic metabolism to drive effector T-cell differentiation in a mouse model of autoimmunity. European Journal of Immunology 46, 1970-1983

31. Yu, X., Rollins, D., Ruhn, K. A., Stubblefield, J. J., Green, C. B., Kashiwada, M., Rothman, P. B., Takahashi, J. S., and Hooper, L. V. (2013) TH17 Cell Differentiation Is Regulated by the Circadian Clock. Science 342, 727-730

32. Wu, C., Yosef, N., Thalhamer, T., Zhu, C., Xiao, S., Kishi, Y., Regev, A., and Kuchroo, V. K. (2013) Induction of pathogenic TH17 cells by inducible salt-sensing kinase SGK1. Nature 496, 513-517

33. Kleinewietfeld, M., Manzel, A., Titze, J., Kvakan, H., Yosef, N., Linker, R. A., Muller, D. N., and Hafler, D. A. (2013) Sodium chloride drives autoimmune disease by the induction of pathogenic TH17 cells. Nature 496, 518-522

34. Heikamp, E. B., Patel, C. H., Collins, S., Waickman, A., Oh, M.-H., Sun, I.-H., Illei, P., Sharma, A., Naray-Fejes-Toth, A., Fejes-Toth, G., Misra-Sen, J., Horton, M. R., and Powell, J. D. (2014) The AGC kinase SGK1 regulates TH1 and TH2 differentiation downstream of the mTORC2 complex. Nat Immunol 15, 457-464

35. Ivanov, I. I., Atarashi, K., Manel, N., Brodie, E. L., Shima, T., Karaoz, U., Wei, D., Goldfarb, K. C., Santee, C. A., Lynch, S. V., Tanoue, T., Imaoka, A., Itoh, K., Takeda, K., Umesaki, Y., Honda, K., and Littman, D. R. (2009) Induction of Intestinal Th17 Cells by Segmented Filamentous Bacteria. Cell 139, 485-498

36. Haghikia, A., Jörg, S., Duscha, A., Berg, J., Manzel, A., Waschbisch, A., Hammer, A., Lee, D.-H., May, C., Wilck, N., Balogh, A., Ostermann, Annika I., Schebb, N. H., Akkad, Denis A., Grohme, Diana A., Kleinewietfeld, M., Kempa, S., Thöne, J., Demir, 
S., Müller, Dominik N., Gold, R., and Linker, Ralf A. (2015) Dietary Fatty Acids Directly Impact Central Nervous System Autoimmunity via the Small Intestine. Immunity 43, 817-829

37. Yan, Y., Zhang, G.-X., Gran, B., Fallarino, F., Yu, S., Li, H., Cullimore, M. L., Rostami, A., and $\mathrm{Xu}, \mathrm{H}$. (2010) IDO Upregulates Regulatory T Cells via Tryptophan Catabolite and Suppresses Encephalitogenic T Cell Responses in Experimental Autoimmune Encephalomyelitis. The Journal of Immunology 185, 5953-5961

38. Kreppel, L. K., and Hart, G. W. (1999) Regulation of a Cytosolic and Nuclear O-GlcNAc Transferase: ROLE OF THE TETRATRICOPEPTIDE REPEATS. Journal of Biological Chemistry 274, 32015-32022

39. Swamy, M., Pathak, S., Grzes, K. M., Damerow, S., Sinclair, L. V., van Aalten, D. M. F., and Cantrell, D. A. (2016) Glucose and glutamine fuel protein O-GlcNAcylation to control T cell self-renewal and malignancy. Nat Immunol 17, 712-720

40. Kearse, K. P. a. G. W. H. (1991) Lymphocyte activation induces rapid changes in nuclear and cytoplasmic glycoproteins. Proceedings of the National Academy of Sciences 88, 1701-1705

41. Ramakrishnan, P., Clark, P. M., Mason, D. E., Peters, E. C., Hsieh-Wilson, L. C., and Baltimore, D. (2013) Activation of the Transcriptional Function of the NF-kB Protein cRel by $<$ em $>\mathrm{O}</ \mathrm{em}>$-GlcNAc Glycosylation. Science Signaling 6, ra75-ra75

42. Juang, Y.-T., Solomou, E. E., Rellahan, B., and Tsokos, G. C. (2002) Phosphorylation and $\langle\mathrm{em}>\mathrm{O}</ \mathrm{em}>$-Linked Glycosylation of Elf-1 Leads to Its Translocation to the Nucleus and Binding to the Promoter of the TCR $\zeta$-Chain. The Journal of Immunology 168, 2865-2871

43. Tsokos, G. C., Nambiar, M. P., and Juang, Y.-T. (2003) Activation of the Ets Transcription Factor Elf-1 Requires Phosphorylation and Glycosylation. Annals of the New York Academy of Sciences 987, 240-245

44. Nambiar, M. P., Fisher, C. U., Warke, V. G., Krishnan, S., Mitchell, J. P., Delaney, N., and Tsokos, G. C. (2003) Reconstitution of deficient T cell receptor $\zeta$ chain restores $\mathrm{T}$ cell signaling and augments $\mathrm{T}$ cell receptor/CD3-induced interleukin-2 production in patients with systemic lupus erythematosus. Arthritis \& Rheumatism 48, 1948-1955

45. Tan, E. P., Sarah Caro, Anish Potnis, Christopher Lanza, and Chad Slawson. (2013) OLinked N-Acetylglucosamine Cycling Regulates Mitotic Spindle Organization. Journal of Biological Chemistry 288, 27085-27099

46. Slawson, C., Zachara, N. E., Vosseller, K., Cheung, W. D., Lane, M. D., and Hart, G. W. (2005) Perturbations in O-linked $\beta$-N-Acetylglucosamine Protein Modification Cause Severe Defects in Mitotic Progression and Cytokinesis. Journal of Biological Chemistry 280, 32944-32956

47. Lanza, C., Tan, E. P., Zhang, Z., Machacek, M., Brinker, A. E., Azuma, M., and Slawson, C. (2016) Reduced O-GlcNAcase expression promotes mitotic errors and spindle defects. Cell Cycle 15, 1363-1375

48. Schneider, C. A., Rasband, W. S., and Eliceiri, K. W. (2012) NIH Image to ImageJ: 25 years of Image Analysis. Nature methods 9, 671-675

49. Lydic, T. A., Busik, J. V., and Reid, G. E. (2014) A monophasic extraction strategy for the simultaneous lipidome analysis of polar and nonpolar retina lipids. Journal of Lipid Research 55, 1797-1809 
50. McDonald, J. G., Thompson, B. M., McCrum, E. C., and Russell, D. W. (2007) Extraction and Analysis of Sterols in Biological Matrices by High Performance Liquid Chromatography Electrospray Ionization Mass Spectrometry. in Methods in Enzymology, Academic Press. pp 145-170

51. Lydic, T. A., Townsend, S., Adda, C. G., Collins, C., Mathivanan, S., and Reid, G. E. (2015) Rapid and comprehensive 'shotgun' lipidome profiling of colorectal cancer cell derived exosomes. Methods 87, 83-95

52. Clasquin, M. F., Melamud, E., and Rabinowitz, J. D. (2002) LC-MS Data Processing with MAVEN: A Metabolomic Analysis and Visualization Engine. in Current Protocols in Bioinformatics, John Wiley \& Sons, Inc. pp

53. Mohammed, H., D’Santos, C., Serandour, Aurelien A., Ali, H. R., Brown, Gordon D., Atkins, A., Rueda, Oscar M., Holmes, Kelly A., Theodorou, V., Robinson, Jessica L. L., Zwart, W., Saadi, A., Ross-Innes, Caryn S., Chin, S.-F., Menon, S., Stingl, J., Palmieri, C., Caldas, C., and Carroll, Jason S. (2013) Endogenous Purification Reveals GREB1 as a Key Estrogen Receptor Regulatory Factor. Cell Reports 3, 342-349

54. Yuzwa, S. A., Macauley, M. S., Heinonen, J. E., Shan, X., Dennis, R. J., He, Y., Whitworth, G. E., Stubbs, K. A., McEachern, E. J., Davies, G. J., and Vocadlo, D. J. (2008) A potent mechanism-inspired O-GlcNAcase inhibitor that blocks phosphorylation of tau in vivo. Nat Chem Biol 4, 483-490

55. Hart, G. W., Slawson, C., Ramirez-Correa, G., and Lagerlof, O. (2011) Cross Talk Between O-GlcNAcylation and Phosphorylation: Roles in Signaling, Transcription, and Chronic Disease. Annual Review of Biochemistry 80, 825-858

56. Zhang, Z., Tan, E. P., VandenHull, N. J., Peterson, K. R., and Slawson, C. (2014) OGlcNAcase Expression is Sensitive to Changes in O-GlcNAc Homeostasis. Frontiers in Endocrinology 5

57. Hart, G. W., and Kelly P. Kearse. (1991) Topology of O-linked N-acetylglucosomaine in murine lymphocytes. Archives of Biochemistry and Biophysics 290, 543-548

58. Aggarwal, S., Ghilardi, N., Xie, M.-H., de Sauvage, F. J., and Gurney, A. L. (2003) Interleukin-23 Promotes a Distinct CD4 T Cell Activation State Characterized by the Production of Interleukin-17. Journal of Biological Chemistry 278, 1910-1914

59. Chen, Z., Tato, C. M., Muul, L., Laurence, A., and O'Shea, J. J. (2007) Distinct regulation of interleukin-17 in human T helper lymphocytes. Arthritis \& Rheumatism 56, 2936-2946

60. Ghoreschi, K., Laurence, A., Yang, X.-P., Tato, C. M., McGeachy, M. J., Konkel, J. E., Ramos, H. L., Wei, L., Davidson, T. S., Bouladoux, N., Grainger, J. R., Chen, Q., Kanno, Y., Watford, W. T., Sun, H.-W., Eberl, G., Shevach, E. M., Belkaid, Y., Cua, D. J., Chen, W., and O/'Shea, J. J. (2010) Generation of pathogenic TH17 cells in the absence of TGF-[bgr] signalling. Nature 467, 967-971

61. Shen, H., Goodall, J. C., and Hill Gaston, J. S. (2009) Frequency and phenotype of peripheral blood Th17 cells in ankylosing spondylitis and rheumatoid arthritis. Arthritis \& Rheumatism 60, 1647-1656

62. McLaughlin, T., Liu, L.-F., Lamendola, C., Shen, L., Morton, J., Rivas, H., Winer, D., Tolentino, L., Choi, O., Zhang, H., Hui Yen Chng, M., and Engleman, E. (2014) T-Cell Profile in Adipose Tissue Is Associated With Insulin Resistance and Systemic Inflammation in Humans. Arteriosclerosis, Thrombosis, and Vascular Biology 34, 26372643 
63. Eljaafari, A., Robert, M., Chehimi, M., Chanon, S., Durand, C., Vial, G., Bendridi, N., Madec, A.-M., Disse, E., Laville, M., Rieusset, J., Lefai, E., Vidal, H., and Pirola, L. (2015) Adipose Tissue-Derived Stem Cells From Obese Subjects Contribute to Inflammation and Reduced Insulin Response in Adipocytes Through Differential Regulation of the Th1/Th17 Balance and Monocyte Activation. Diabetes 64, 2477-2488

64. Winer, S., Paltser, G., Chan, Y., Tsui, H., Engleman, E., Winer, D., and Dosch, H. M. (2009) Obesity predisposes to Th17 bias. European Journal of Immunology 39, 26292635

65. Ridker, P. M., Everett, B. M., Thuren, T., MacFadyen, J. G., Chang, W. H., Ballantyne, C., Fonseca, F., Nicolau, J., Koenig, W., Anker, S. D., Kastelein, J. J. P., Cornel, J. H., Pais, P., Pella, D., Genest, J., Cifkova, R., Lorenzatti, A., Forster, T., Kobalava, Z., VidaSimiti, L., Flather, M., Shimokawa, H., Ogawa, H., Dellborg, M., Rossi, P. R. F., Troquay, R. P. T., Libby, P., and Glynn, R. J. (2017) Antiinflammatory Therapy with Canakinumab for Atherosclerotic Disease. New England Journal of Medicine 377, 11191131

66. Kanneganti, T.-D., and Dixit, V. D. (2012) Immunological complications of obesity. Nature Immunology 13, 707

67. Chehimi, M., Vidal, H., and Eljaafari, A. (2017) Pathogenic Role of IL-17-Producing Immune Cells in Obesity, and Related Inflammatory Diseases. Journal of Clinical Medicine 6, 68

68. O'Shea, J. J., and Paul, W. E. (2010) Mechanisms Underlying Lineage Commitment and Plasticity of Helper CD4+ T Cells. Science 327, 1098-1102

69. Ciofani, M., Madar, A., Galan, C., Sellars, M., Mace, K., Pauli, F., Agarwal, A., Huang, W., Parkurst, Christopher N., Muratet, M., Newberry, Kim M., Meadows, S., Greenfield, A., Yang, Y., Jain, P., Kirigin, Francis K., Birchmeier, C., Wagner, Erwin F., Murphy, Kenneth M., Myers, Richard M., Bonneau, R., and Littman, Dan R. (2012) A Validated Regulatory Network for Th17 Cell Specification. Cell 151, 289-303

70. Gewinner, C., Gerald W. Hart, Natasha Zachara, Robert Cole, Christian BeisenherzHuss, and Bernd Groner. (2004) The coactivator of transcription CREB-binding protein interacts preferentially with the glycosylated form of Stat5. Journal of Biological Chemistry 279, 3563-3572

71. Woo, C. M., Lund, P. J., Huang, A. C., Davis, M. M., Bertozzi, C. R., and Pitteri, S. (2018) Mapping and quantification of over 2,000 O-linked glycopeptides in activated human $\mathrm{T}$ cells with isotope-targeted glycoproteomics (IsoTaG). Molecular \& Cellular Proteomics

72. Wang, X., Zhang, Y., Yang, Xuexian O., Nurieva, Roza I., Chang, Seon H., Ojeda, Sandra S., Kang, Hong S., Schluns, Kimberly S., Gui, J., Jetten, Anton M., and Dong, C. (2012) Transcription of $I l 17$ and Ill7f Is Controlled by Conserved Noncoding Sequence 2. Immunity 36, 23-31

73. Zhang, Z., Costa, F. C., Tan, E. P., Bushue, N., DiTacchio, L., Costello, C. E., McComb, M. E., Whelan, S. A., Peterson, K. R., and Slawson, C. (2016) O-Linked NAcetylglucosamine (O-GlcNAc) Transferase and O-GlcNAcase Interact with Mi2 $\beta$ Protein at the A $\gamma$-Globin Promoter. Journal of Biological Chemistry 291, 15628-15640

74. Yang, X., Zhang, F., and Kudlow, J. E. (2002) Recruitment of O-GlcNAc Transferase to Promoters by Corepressor mSin3A: Coupling Protein O-GlcNAcylation to Transcriptional Repression. Cell 110, 69-80 
75. Lewis, B. A., and Hanover, J. A. (2014) O-GlcNAc and the Epigenetic Regulation of Gene Expression. Journal of Biological Chemistry 289, 34440-34448

76. Kelly, W. G., Dahmus, M. E., and Hart, G. W. (1993) RNA polymerase II is a glycoprotein. Modification of the $\mathrm{COOH}$-terminal domain by O-GlcNAc. Journal of Biological Chemistry 268, 10416-10424

77. Yang, X., Su, K., Roos, M. D., Chang, Q., Paterson, A. J., and Kudlow, J. E. (2001) Olinkage of $\mathrm{N}$-acetylglucosamine to Sp1 activation domain inhibits its transcriptional capability. Proceedings of the National Academy of Sciences 98, 6611-6616

78. Wang, C., Yosef, N., Gaublomme, J., Wu, C., Lee, Y., Clish, Clary B., Kaminski, J., Xiao, S., Zu Horste, Gerd M., Pawlak, M., Kishi, Y., Joller, N., Karwacz, K., Zhu, C., Ordovas-Montanes, M., Madi, A., Wortman, I., Miyazaki, T., Sobel, Raymond A., Park, H., Regev, A., and Kuchroo, Vijay K. (2015) CD5L/AIM Regulates Lipid Biosynthesis and Restrains Th17 Cell Pathogenicity. Cell 163, 1413-1427

79. Chavez, Jose A., and Summers, Scott A. A Ceramide-Centric View of Insulin Resistance. Cell Metabolism 15, 585-594

80. Levy, M., and Futerman, A. H. (2010) Mammalian ceramide synthases. IUBMB Life 62, 347-356

81. Corbin, K. D., and Zeisel, S. H. (2012) Choline metabolism provides novel insights into nonalcoholic fatty liver disease and its progression. Current Opinion in Gastroenterology 28, 159-165

82. Slawson, C., Copeland, R. J., and Hart, G. W. (2010) O-GlcNAc signaling: a metabolic link between diabetes and cancer? Trends in Biochemical Sciences 35, 547-555

83. Shen, Y., and Tong, L. (2008) Structural evidence for direct interactions between the BRCT domains of human BRCA1 and a phospho-peptide from human ACC1. Biochemistry 47, 5767-5773

84. Ha, J., Daniel, S., Broyles, S. S., and Kim, K. H. (1994) Critical phosphorylation sites for acetyl-CoA carboxylase activity. Journal of Biological Chemistry 269, 22162-22168

85. Ng, M., Fleming, T., Robinson, M., Thomson, B., Graetz, N., Margono, C., Mullany, E. C., Biryukov, S., Abbafati, C., Abera, S. F., Abraham, J. P., Abu-Rmeileh, N. M. E., Achoki, T., AlBuhairan, F. S., Alemu, Z. A., Alfonso, R., Ali, M. K., Ali, R., Guzman, N. A., Ammar, W., Anwari, P., Banerjee, A., Barquera, S., Basu, S., Bennett, D. A., Bhutta, Z., Blore, J., Cabral, N., Nonato, I. C., Chang, J.-C., Chowdhury, R., Courville, K. J., Criqui, M. H., Cundiff, D. K., Dabhadkar, K. C., Dandona, L., Davis, A., Dayama, A., Dharmaratne, S. D., Ding, E. L., Durrani, A. M., Esteghamati, A., Farzadfar, F., Fay, D. F. J., Feigin, V. L., Flaxman, A., Forouzanfar, M. H., Goto, A., Green, M. A., Gupta, R., Hafezi-Nejad, N., Hankey, G. J., Harewood, H. C., Havmoeller, R., Hay, S., Hernandez, L., Husseini, A., Idrisov, B. T., Ikeda, N., Islami, F., Jahangir, E., Jassal, S. K., Jee, S. H., Jeffreys, M., Jonas, J. B., Kabagambe, E. K., Khalifa, S. E. A. H., Kengne, A. P., Khader, Y. S., Khang, Y.-H., Kim, D., Kimokoti, R. W., Kinge, J. M., Kokubo, Y., Kosen, S., Kwan, G., Lai, T., Leinsalu, M., Li, Y., Liang, X., Liu, S., Logroscino, G., Lotufo, P. A., Lu, Y., Ma, J., Mainoo, N. K., Mensah, G. A., Merriman, T. R., Mokdad, A. H., Moschandreas, J., Naghavi, M., Naheed, A., Nand, D., Narayan, K. M. V., Nelson, E. L., Neuhouser, M. L., Nisar, M. I., Ohkubo, T., Oti, S. O., Pedroza, A., Prabhakaran, D., Roy, N., Sampson, U., Seo, H., Sepanlou, S. G., Shibuya, K., Shiri, R., Shiue, I., Singh, G. M., Singh, J. A., Skirbekk, V., Stapelberg, N. J. C., Sturua, L., Sykes, B. L., Tobias, M., Tran, B. X., Trasande, L., Toyoshima, H., van de Vijver, S., Vasankari, T. J., 
Veerman, J. L., Velasquez-Melendez, G., Vlassov, V. V., Vollset, S. E., Vos, T., Wang, C., Wang, X., Weiderpass, E., Werdecker, A., Wright, J. L., Yang, Y. C., Yatsuya, H., Yoon, J., Yoon, S.-J., Zhao, Y., Zhou, M., Zhu, S., Lopez, A. D., Murray, C. J. L., and Gakidou, E. (2014) Global, regional, and national prevalence of overweight and obesity in children and adults during 1980-2013: a systematic analysis for the Global Burden of Disease Study 2013. The Lancet 384, 766-781

86. Martin-Orozco, N., Chung, Y., Chang, S. H., Wang, Y.-H., and Dong, C. (2009) Th17 cells promote pancreatic inflammation but only induce diabetes efficiently in lymphopenic hosts after conversion into Th1 cells. European Journal of Immunology 39, 216-224

87. Kidani, Y., and Bensinger, S. J. (2017) Reviewing the impact of lipid synthetic flux on Th17 function. Current Opinion in Immunology 46, 121-126

88. Glatzel, D. K., Koeberle, A., Pein, H., Loeser, K., Stark, A., Keksel, N., Werz, O., Mueller, R., Bischoff, I., and Fuerst, R. (2017) Acetyl-CoA carboxylase 1 regulates endothelial cell migration by shifting the phospholipid composition. Journal of Lipid Research

89. Wei, J., and Tong, L. (2015) Crystal structure of the 500-kDa yeast acetyl-CoA carboxylase holoenzyme dimer. Nature 526, 723

90. Turpin, Sarah M., Nicholls, Hayley T., Willmes, Diana M., Mourier, A., Brodesser, S., Wunderlich, Claudia M., Mauer, J., Xu, E., Hammerschmidt, P., Brönneke, Hella S., Trifunovic, A., LoSasso, G., Wunderlich, F. T., Kornfeld, J.-W., Blüher, M., Krönke, M., and Brüning, Jens C. Obesity-Induced CerS6-Dependent $C<s u b>16: 0</ s u b>$ Ceramide Production Promotes Weight Gain and Glucose Intolerance. Cell Metabolism 20, 678-686

91. Scheffel, M. J., Helke, K., Lu, P., Bowers, J. S., Ogretmen, B., Garrett-Mayer, E., Paulos, C. M., and Voelkel-Johnson, C. (2017) Adoptive Transfer of Ceramide Synthase 6 Deficient Splenocytes Reduces the Development of Colitis. Scientific Reports 7, 15552

92. Bai, A., Moss, A., Kokkotou, E., Usheva, A., Sun, X., Cheifetz, A., Zheng, Y., Longhi, M. S., Gao, W., Wu, Y., and Robson, S. C. (2014) CD39 and CD161 Modulate Th17 Responses in Crohn's Disease. The Journal of Immunology 193, 3366-3377

93. Zhou, Y., Salker, M. S., Walker, B., Münzer, P., Borst, O., Gawaz, M., Gulbins, E., Singh, Y., and Lang, F. (2016) Acid Sphingomyelinase (ASM) is a Negative Regulator of Regulatory T Cell (Treg) Development. Cellular Physiology and Biochemistry 39, 985995

94. Hollmann, C., Werner, S., Avota, E., Reuter, D., Japtok, L., Kleuser, B., Gulbins, E., Becker, K. A., Schneider-Schaulies, J., and Beyersdorf, N. (2016) Inhibition of Acid Sphingomyelinase Allows for Selective Targeting of CD4<sup $\rangle+</$ sup $>$ Conventional versus Foxp3<sup $>+</$ sup $>$ Regulatory T Cells. The Journal of Immunology 197, 31303141

95. Yuzwa SA, M. M., Heinonen JE, Shan X, Dennis RJ, He Y, Whitworth GE, Stubbs KA, McEachern EJ, Davies GJ, Vocadlo, DJ. (2008) A potent mechanism-inspired OGlcNAcase inhibitor that blocks phosphorylation of tau in vivo. Nature Chemical Biology 4, 483-490

96. Shafi, R., Iyer, S. P. N., Ellies, L. G., O'Donnell, N., Marek, K. W., Chui, D., Hart, G. W., and Marth, J. D. (2000) The O-GlcNAc transferase gene resides on the X chromosome and is essential for embryonic stem cell viability and mouse ontogeny. Proceedings of the National Academy of Sciences 97, 5735-5739 
97. Keembiyehetty, C., Love, D. C., Harwood, K. R., Gavrilova, O., Comly, M. E., and Hanover, J. A. (2015) Conditional Knock-out Reveals a Requirement for O-Linked NAcetylglucosaminase (O-GlcNAcase) in Metabolic Homeostasis. Journal of Biological Chemistry 290, 7097-7113

98. O'Donnell, N., Zachara, N. E., Hart, G. W., and Marth, J. D. (2004) Ogt-Dependent XChromosome-Linked Protein Glycosylation Is a Requisite Modification in Somatic Cell Function and Embryo Viability. Molecular and Cellular Biology 24, 1680-1690

99. Boniface, K., Blumenschein, W. M., Brovont-Porth, K., McGeachy, M. J., Basham, B., Desai, B., Pierce, R., McClanahan, T. K., Sadekova, S., and de Waal Malefyt, R. (2010) Human Th17 Cells Comprise Heterogeneous Subsets Including IFN- $\gamma$-Producing Cells with Distinct Properties from the Th1 Lineage. The Journal of Immunology 185, 679-687

100. Lee, Y. K., Turner, H., Maynard, C. L., Oliver, J. R., Chen, D., Elson, C. O., and Weaver, C. T. (2009) Late Developmental Plasticity in the T Helper 17 Lineage. Immunity 30, 92107

101. Koga, T., Hedrich, C. M., Mizui, M., Yoshida, N., Otomo, K., Lieberman, L. A., Rauen, T., Crispín, J. C., and Tsokos, G. C. (2014) CaMK4-dependent activation of AKT/mTOR and CREM- $\alpha$ underlies autoimmunity-associated Th17 imbalance. The Journal of Clinical Investigation 124, 2234-2245

102. Shen, Y., Wen, Z., Li, Y., Matteson, E. L., Hong, J., Goronzy, J. J., and Weyand, C. M. (2017) Metabolic control of the scaffold protein TKS5 in tissue-invasive, proinflammatory T cells. Nat Immunol 18, 1025-1034

103. Kandel, E. S., and Hay, N. (1999) The Regulation and Activities of the Multifunctional Serine/Threonine Kinase Akt/PKB. Experimental Cell Research 253, 210-229

104. STRATFORD, S., DEWALD, D. B., and SUMMERS, S. A. (2001) Ceramide dissociates 3'-phosphoinositide production from pleckstrin homology domain translocation. Biochemical Journal 354, 359-368

105. Chavez, J. A., Knotts, T. A., Wang, L.-P., Li, G., Dobrowsky, R. T., Florant, G. L., and Summers, S. A. (2003) A Role for Ceramide, but Not Diacylglycerol, in the Antagonism of Insulin Signal Transduction by Saturated Fatty Acids. Journal of Biological Chemistry 278, 10297-10303

106. Vosseller, K., Wells, L., Lane, M. D., and Hart, G. W. (2002) Elevated nucleocytoplasmic glycosylation by O-GlcNAc results in insulin resistance associated with defects in Akt activation in 3T3-L1 adipocytes. Proceedings of the National Academy of Sciences 99, 5313-5318

107. Li, W., Yang, X., Xing, S., Bian, F., Yao, W., Bai, X., Zheng, T., Wu, G., and Jin, S. (2014) Endogenous Ceramide Contributes to the Transcytosis of oxLDL across Endothelial Cells and Promotes Its Subendothelial Retention in Vascular Wall. Oxidative Medicine and Cellular Longevity 2014, 11

108. Pan, W., Yu, J., Shi, R., Yan, L., Yang, T., Li, Y., Zhang, Z., Yu, G., Bai, Y., Schuchman, E. H., He, X., and Zhang, G. (2014) Elevation of ceramide and activation of secretory acid sphingomyelinase in patients with acute coronary syndromes. Coronary Artery Disease 25, 230-235 